\title{
Development of an Experiment for Measuring Flow Phenomena Occurring in a Lower Plenum for VHTR CFD Assessment
}

Keith G. Condie Glenn E. McCreery Hugh M. Mcllroy, Jr. Donald M. McEligot

September 2005

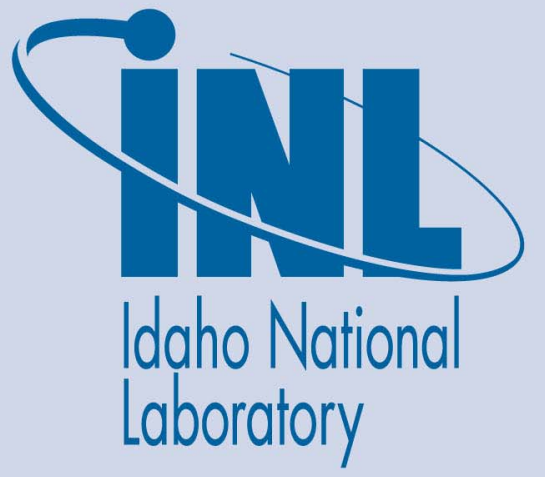

The INL is a U.S. Department of Energy National Laboratory operated by Battelle Energy Alliance 
INL/EXT-05-00603

\title{
Development of an Experiment for Measuring Flow Phenomena Occurring in a Lower Plenum for VHTR CFD Assessment
}

\author{
Keith G. Condie \\ Glenn E. McCreery \\ Hugh M. Mcllroy, Jr. \\ Donald M. McEligot
}

September 2005

\begin{abstract}
Idaho National Laboratory
Idaho Falls, Idaho 83415
\end{abstract}

Prepared for the

U.S. Department of Energy

Office of Nuclear Energy

Under DOE Idaho Operations Office

Contract DE-AC07-05ID14517 


\title{
Development of an experiment for measuring flow phenomena occurring in a lower plenum for VHTR CFD assessment
}

\author{
Keith G. Condie, Glenn E. McCreery, Hugh M. Mcllroy, Jr. and Donald M. McEligot \\ Idaho National Laboratory (INL) \\ Idaho Falls, Idaho 83415 USA
}

The objective of the present report is to document the design of our first experiment to measure generic flow phenomena expected to occur in the lower plenum of a typical prismatic VHTR (Very High Temperature Reactor) concept. In the process, fabrication sketches are provided for the use of CFD (computational fluid dynamics) analysts wishing to employ the data for assessment of their proposed codes. The general approach of the project is to develop new benchmark experiments for assessment in parallel with CFD and coupled CFD/systems code calculations for the same geometry. One aspect of the complex flow in a prismatic VHTR is being addressed: flow and thermal mixing in the lower plenum ("hot streaking" issue). Current prismatic VHTR concepts were examined to identify their proposed flow conditions and geometries over the range from normal operation to decay heat removal in a pressurized cooldown. Approximate analyses were applied to determine key non-dimensional parameters and their magnitudes over this operating range. The flow in the lower plenum can locally be considered to be a situation of multiple jets into a confined crossflow -- with obstructions. Flow is expected to be turbulent with momentum-dominated turbulent jets entering; buoyancy influences are estimated to be negligible in normal full power operation. Experiments are needed for the combined features of the lower plenum flows. Missing from the typical jet experiments available are interactions with nearby circular posts and with vertical posts in the vicinity of vertical walls - with near stagnant surroundings at one extreme and significant crossflow at the other.

Unheated MIR (Matched-Index-of-Refraction) experiments are first steps when the geometry is complicated. One does not want to use a computational technique which will not even handle constant properties properly. The purpose of the fluid dynamics experiments is to develop benchmark databases for the assessment of CFD solutions of the momentum equations, scalar mixing and turbulence models for typical VHTR plenum geometries in the limiting case of negligible buoyancy and constant fluid properties. As indicated by the scaling studies, in normal full power operation of a typical VHTR conceptual design, buoyancy influences should be negligible in the lower plenum. The MIR experiment will simulate flow features of the paths of jets as they mix in flowing through the array of posts in a lower plenum en route to the single exit duct. The conceptual design for such an experiment is described and the development of the final apparatus is presented. Fabrication sketches are provided in Appendix $\boldsymbol{A}$ for the use of CFD analysts wishing to employ the data for assessment of their proposed codes. 


\section{Table of contents}

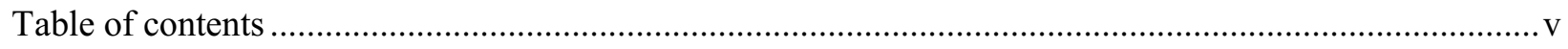

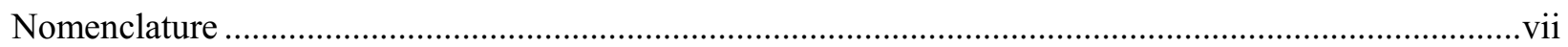

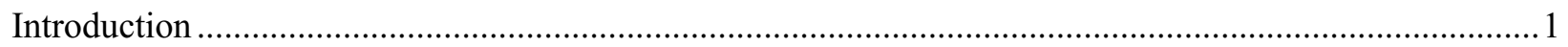

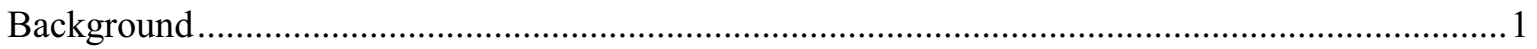

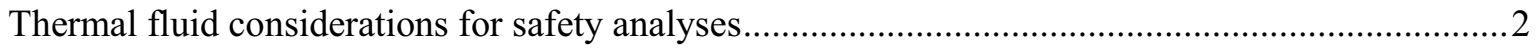

Present R\&D project for improved modeling and benchmark studies ...........................................5

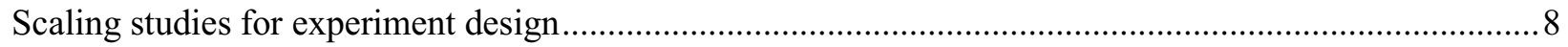

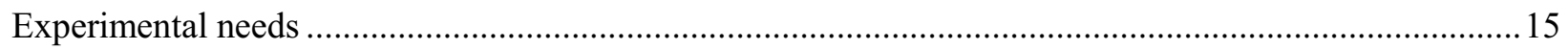

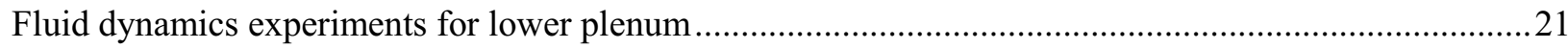

INEEL Matched-Index-of-Refraction flow system .............................................................21

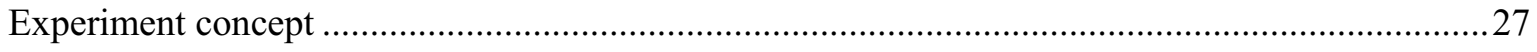

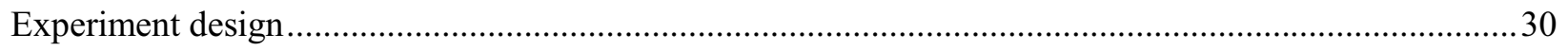

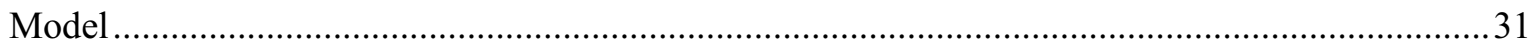

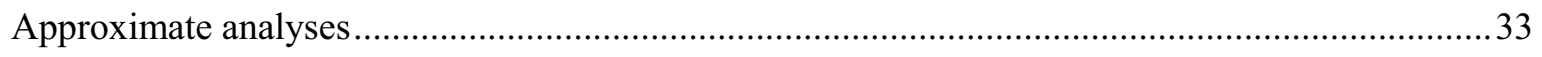

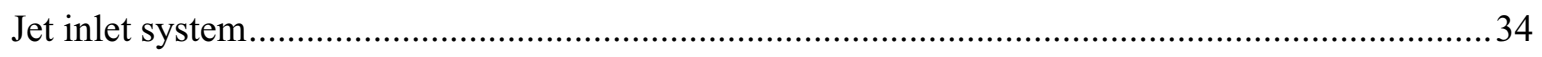

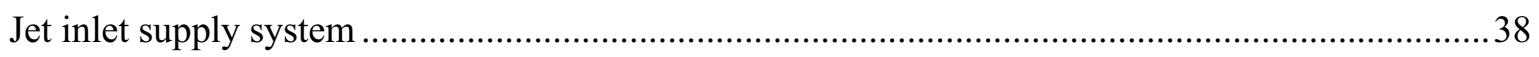

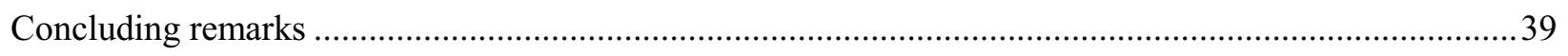

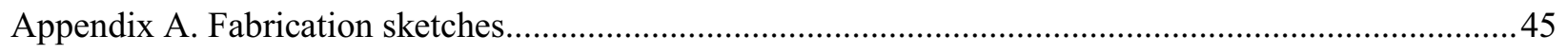

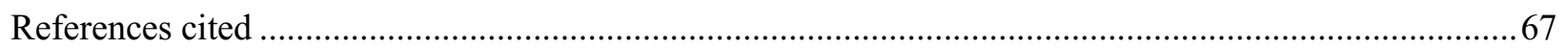




\section{Nomenclature}

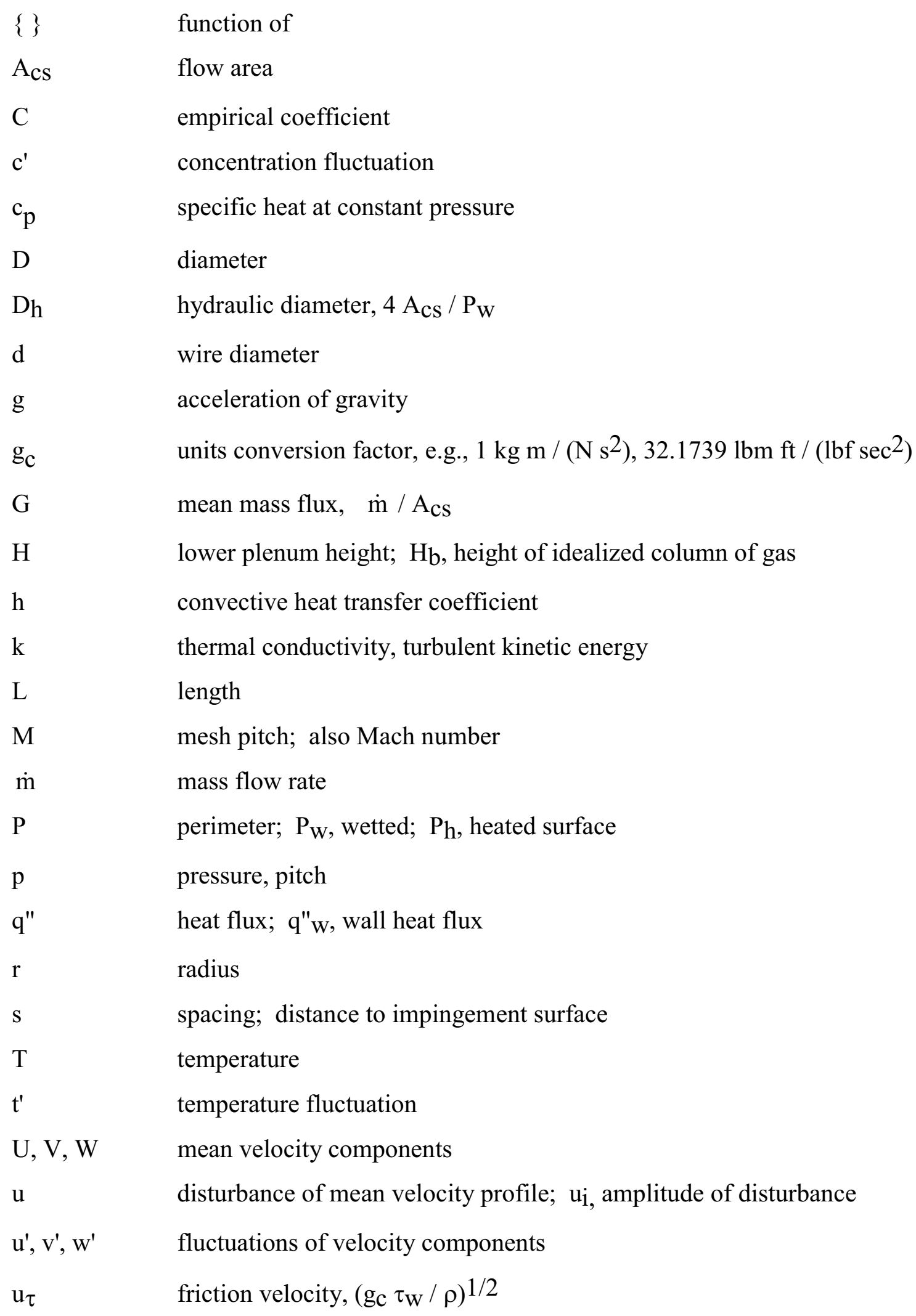




$\begin{array}{ll}\overline{\mathrm{uv}} & \text { Reynolds shear stress } \\ \mathrm{Vb}_{\mathrm{b}} & \text { bulk or mixed-mean streamwise velocity } \\ \mathrm{v} & \text { velocity fluctuation about mean } \\ \mathrm{x} & \text { streamwise coordinate, axial location } \\ \mathrm{y} & \text { distance to wall } \\ \mathrm{z} & \text { spanwise coordinate }\end{array}$

$\underline{\text { Non-dimensional quantities }}$

Bo general buoyancy onset parameter

Bo* Jackson buoyancy parameter, $\mathrm{Gr}^{*} /\left(\mathrm{ReDh}^{3.425} \operatorname{Pr} 0.8\right)$

$\mathrm{f}, \mathrm{f}_{\tau} \quad$ friction factor, $2 \rho \mathrm{b} \mathrm{g}_{\mathrm{c}} \tau_{\mathrm{W}} / \mathrm{G}^{2}$

$\mathrm{Fr}_{j} \quad$ jet Froude number (see text)

Gr* Grashof number based on heat flux, $\mathrm{g} \beta \mathrm{q}$ "wall $\mathrm{Dh}^{4} /\left(\mathrm{k} v^{2}\right)$

$\mathrm{K}$ flow resistance coefficient, $2\left(\mathrm{p}_{1}-\mathrm{p}_{2}\right) /\left(\mathrm{\rho U}^{2}\right)$ where $\mathrm{U}$ is spatially-averaged velocity

$\mathrm{K}_{\mathrm{V}} \quad$ acceleration parameter, $\left(\mathrm{v}_{\mathrm{b}} / \mathrm{V}_{\mathrm{b}}{ }^{2}\right)\left(\mathrm{dV}_{\mathrm{b}} / \mathrm{dx}\right)$

$\mathrm{L}^{+} \quad$ length, $\left(\mathrm{L} / \mathrm{Dh}_{\mathrm{h}}\right) / \mathrm{Re} \mathrm{Dh}$

M Mach number

$\mathrm{Nu} \quad$ Nusselt number, $\mathrm{h} \mathrm{Dh}_{\mathrm{h}} / \mathrm{kb}$

Pr Prandtl number, $c_{p} \mu / k$

$\mathrm{q}^{+} \quad$ heat flux, $\beta \mathrm{q}$ "wall / $\left(\mathrm{G} \mathrm{c}_{\mathrm{p}}\right)$

$\operatorname{Re} \quad$ Reynolds number, $4 \dot{m} / \Pi \mathrm{D} \mu$; ReDh, based on hydraulic diameter, $\mathrm{G} \mathrm{Dh}_{\mathrm{h}} / \mu$;

$\mathrm{Re}_{\mathrm{H}}$, in honeycomb cell; $\mathrm{Re}_{\mathrm{d}}$, based on wire diameter and upstream velocity

Ri overall Richardson number, g $\left(\rho_{1}-\rho_{2}\right) \mathrm{H} /\left(\rho_{1} \mathrm{Vb}^{2}\right)$

$\mathrm{Ri}_{\text {wall }} \quad$ Richardson number defined in terms of wall quantities (see text)

$\mathrm{y}^{+} \quad$ wall-normal coordinate, $\mathrm{y} \mathrm{u}_{\tau} / v$ 


\section{$\underline{\text { Greek symbols }}$}

$\alpha$

$\beta$

$\varepsilon$

$\mu$

$v$

$\rho$

$\tau$

\section{$\underline{\text { Subscripts }}$}

b

c

D

$\mathrm{Dh}$

f, fc

$\mathrm{i}$, in

$\mathrm{j}$

$\max$

$\mathrm{p}$

ref

$\mathrm{S}$

W, wall

$\mathrm{Zu}$

$\infty$ change in flow angle due to screen (see text)

volumetric coefficient of expansion, - $(1 / \rho)(\partial \rho / \partial T) p$

dissipation of turbulence kinetic energy

absolute viscosity

kinematic viscosity, $\mu / \rho$

density

shear stress; $\tau_{\mathrm{W}}$, wall shear stress

evaluated at bulk or mixed-mean temperature (or enthalpy)

coolant channel

based on diameter

evaluated with hydraulic diameter

forced convection

evaluated at inlet, entry

jet

maximum value

support post, plenum

evaluated at reference conditions

support block

wall, evaluated at wall temperature

as defined by Zukauskas [1972]

freestream 


\section{Introduction}

\section{Background}

The ultimate goal of the present study is to provide the data necessary to enable validation of the analysis tools which are planned for use in the analysis of the Very High Temperature Reactor (VHTR) plant. These advanced gas-cooled reactors (AGCRs) for higher efficiency and enhanced safety and for deployable reactors for electrical power generation, process heat utilization and hydrogen generation. While key applications would be VHTRs using the closed Brayton cycle (CBC) for higher efficiency, results of the proposed research should also be valuable in gas-cooled fast-spectrum reactor systems (GFRs) as well as reactors with supercritical-pressure flow. Higher efficiency leads to lower cost/kwh and reduces life-cycle impacts of radioactive waste (by reducing waste/kwh). The outcomes will also be useful for some space power and propulsion concepts and for some fusion reactor concepts as side benefits, but they are not the thrusts of the investigation.

The VHTR is intended to meet four basic requirements: (1) a high coolant outlet temperature, (2) passive safety, (3) a total power output consistent with that expected for commercial high-temperature gas-cooled reactors and (4) economic power production. Both prismatic fuel types and pebble bed fuel types are being considered with helium as the coolant. The present study concentrates on issues for prismatic versions but some aspects are common to pebble bed designs. As an example, the prismatic NGNP Point Design [MacDonald et al., 2003] is an evolutionary version with roots stemming from the Fort Saint Vrain hightemperature gas-cooled reactor; the immediate predecessor is the General Atomics gas turbine modular helium reactor (GTMHR) shown in Figure 1. Currently, modifications of the GT-MHR design are being proposed in order to meet the VHTR design requirements and, thereby, to identify issues and R\&D needs pertinent to typical VHTR designs which are expected to evolve.

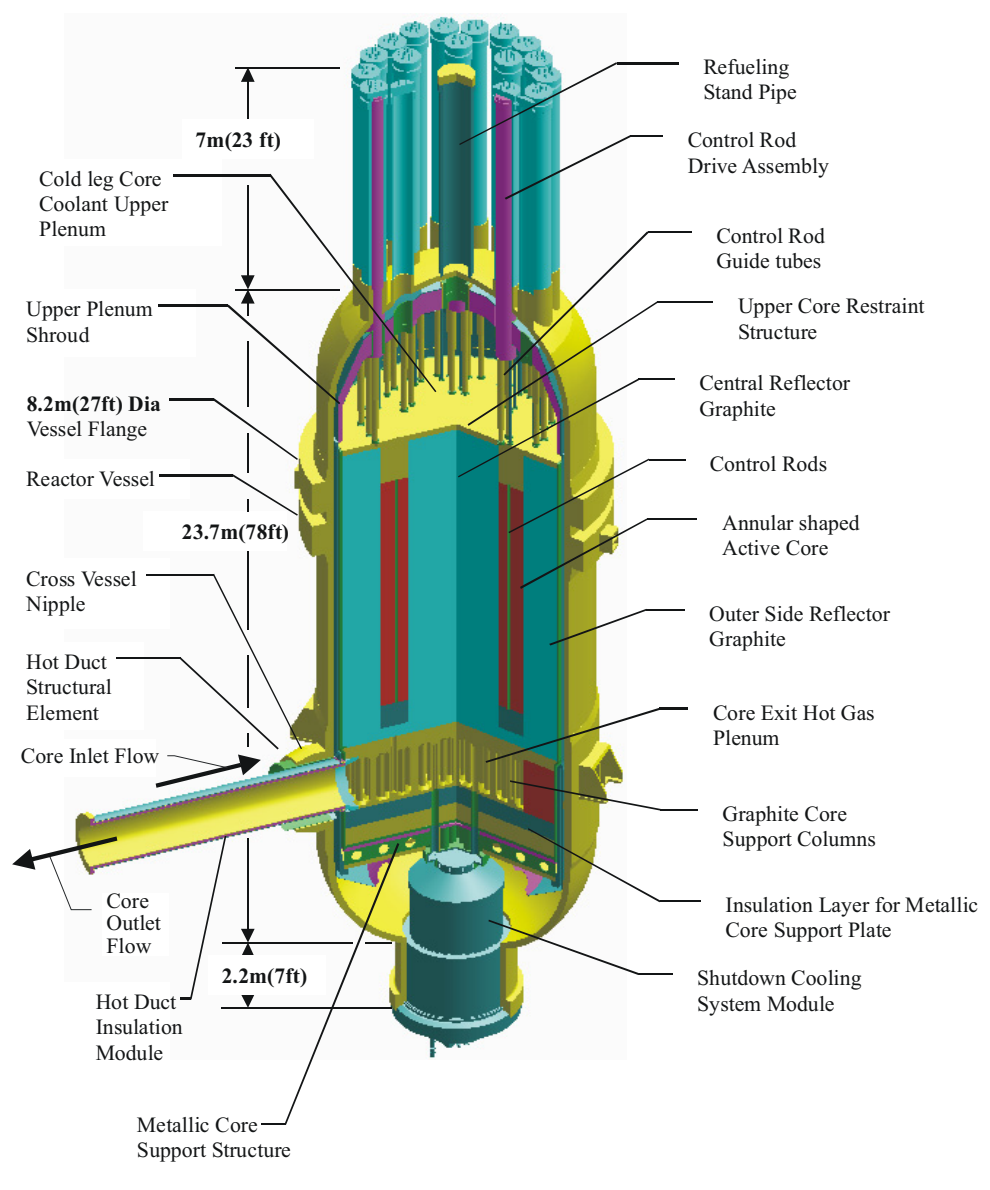

Fig. 1. GT-MHR reactor which serves as an example of a typical prismatic VHTR concept [MacDonald et al., 2003]. 
Advanced gas reactors and combined cycle concepts offer the potential of high thermal efficiency and enhanced safety [Kugeler, 1996]. Gas-cooled reactors are also ideal for use in small deployable systems; historically, one of the first GCRs was an Army reactor for this purpose, the ML-1 at NRTS (now INL). In addition to improving efficiency, AGCR-CBCs enhance system safety by removing steam and water components. Safety is inherently enhanced by avoidance of the steam cycle: no flashing or boiling is possible, there are no neutronic reactions with the coolant, no chemical reactions between coolant and fuel and no corrosive corrosion products. Passive safety features include a negative coefficient of reactivity, core power and power density, passive reactor cavity cooling systems and below-grade containment for protection from aircraft and terrorist actions.

General effects of strong heating of a gas are variation of the transport properties, reduction of density causing acceleration of the flow in the central core, and - in some cases significant buoyancy forces. The ranges of temperatures and, hence, property variation that should be considered for safety analyses in some applications are as follows:

\section{Temperature range}

(K)

$\begin{array}{lcccccc} & \mathrm{T}_{\mathrm{in}} & \mathrm{T}_{\text {wall,max }} & \rho / \rho_{\mathrm{i}} & \mathrm{V} / \mathrm{V}_{\mathrm{i}} & \mathrm{k} / \mathrm{k}_{\mathrm{i}} & \mathrm{c}_{\mathrm{p}} / \mathrm{c}_{\mathrm{pi}} \\ \text { GT-MHR } & 573 & 1873 & 0.31 & 3.3 & 2.6 & 1.1 \\ \text { HTTR } & 673 & 1873 & 0.36 & 2.8 & 2.3 & 1.1 \\ \text { GC-FBR } & 723 & 1323 & 0.55 & 1.8 & 1.6 & 1.06 \\ \text { VHTR/NGNP } & 763 & 1873 & 0.41 & 2.5 & 2.1 & 1.08\end{array}$

Typical reactor thermal hydraulic safety codes use a one-dimensional transient approach, employing correlations such as the Dittus-Boelter relation or equivalent for $\operatorname{Re}>2000$. Their predictions can be optimistic for low-Reynolds-number flow and/or with significant buoyancy forces and/or for gas mixtures. Figure 2a demonstrates that Nusselt numbers (convective heat transfer coefficients) can be factors of two or three lower - and thermal resistances higher - than the correlation suggests for heated gas flow through a circular tube [McEligot, 1986].

Conventional wisdom is that buoyancy forces aid in upflow; this impression can be misleading. Wang, Li and Jackson [2002] show that, in turbulent upflow, the effect of significant buoyancy forces can be to lower the Nusselt number compared to forced flow by fifty per cent in a pipe and 35 per cent in a channel (Figure $2 b$ ). The magnitude of the effect varies with geometry and position. These examples demonstrate the need to assess CFD codes and their turbulence models with experimental measurements.

\section{Thermal fluid considerations for safety analyses}

The high-temperature gas cooled reactors use pressurized helium as coolant to enhance the heat transfer process. Proposed advanced gas-cooled power reactors in the U. S. have design differences from the Japanese HTTR research reactor mentioned in the table above. For power generation higher flow rates are used, giving higher Reynolds numbers in the passages. Annular 
cores are employed with a central reflector region with high thermal capacitance, causing slow, gradual thermal response to disturbances. It is appropriate to consider three of several operating modes. Under extreme accident conditions these reactors can lose their capabilities for forced circulation of their coolant (Loss of Forced Cooling Accident, LOFA - " pressurized cooldown"), and/or lose the capability of containing the coolant (Loss of Coolant Accident, LOCA - "depressurized conduction cooldown"). These accident scenarios are not directly addressed by the present experiment although some aspects of local flow in a lower plenum during a LOFA are treated indirectly.
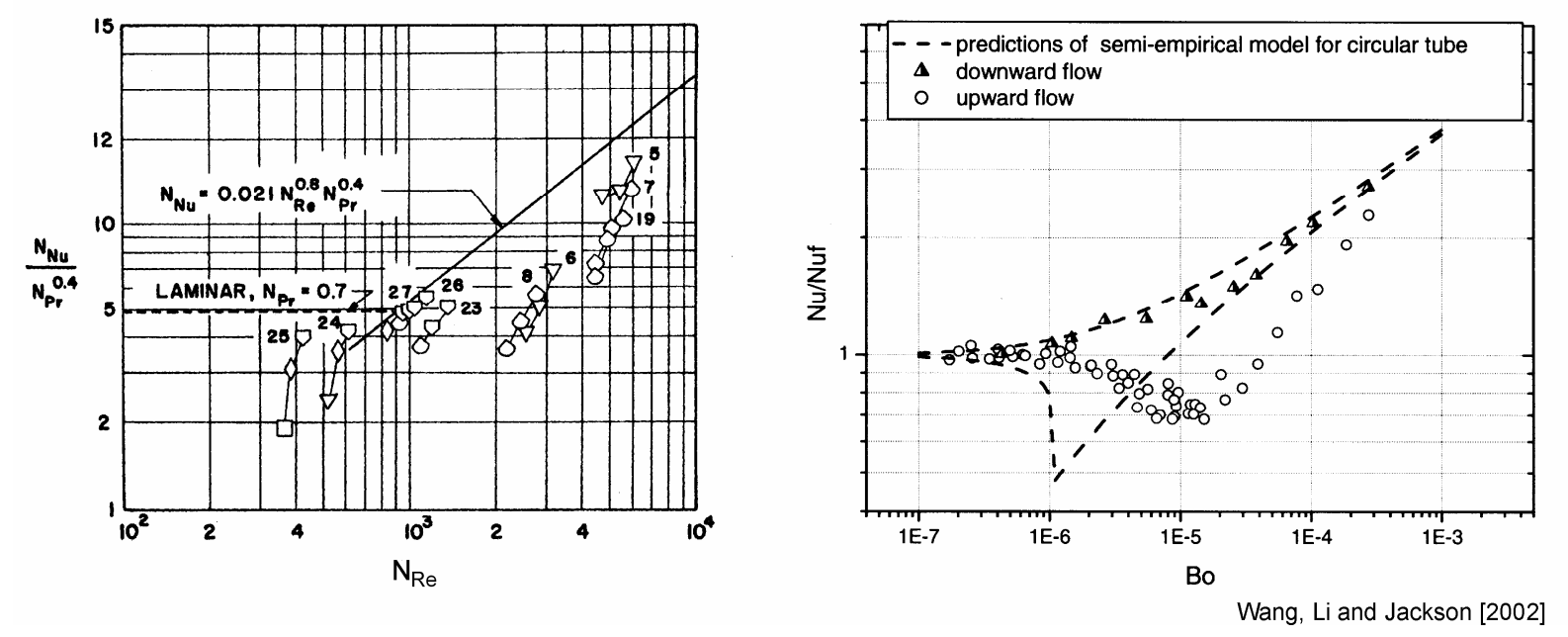

Fig. 2. Typical correlations in reactor thermal hydraulics codes overpredict convective heat transfer parameters for gases in some scenarios: (a) at low Reynolds numbers in a circular tube [McEligot, 1986] and (b) with buoyant effects in turbulent upflow through circular tubes and rectangular channels [Wang, Li and Jackson, 2002].

The design for full power operation is intended to be a steady-state condition. Flow and, therefore, Reynolds numbers in the coolant passages are large so forced convection dominates the heat transfer problem. Typical Reynolds numbers are of the order of 50,000; consequently, buoyancy forces and thermal radiation are not significant and the phenomenon of laminarization is unlikely ("laminarization" is a situation where heat transfer parameters can approach those predicted by laminar analyses -- even though the local Reynolds number can be well above the usual value for a transition Reynolds number [McEligot, 1986]). A concern during this mode of operation is the potential damage to metallic components from local hot "streaks" caused by poor mixing of the high-temperature jets that enter the lower plenum from the hottest coolant channels (Figure 3). The temperature, momentum and turbulence profiles of the gas exiting the channels serve as initial conditions for the passages forming these jets.

During partial load operations (e.g., as low as fifteen per cent of the design power) the helium inventory is reduced to maintain the same volumetric flow rate at the turbine inlet. Under these conditions the typical Reynolds number within the core coolant passages may be reduced to values around 5,000 or lower, at which point a potential transition from turbulent to laminar flow could occur. Computational techniques with supporting test data may be needed to address 
the heat transfer from the fuel to the coolant during this transition from turbulent to laminar flow, including the possibility of an early laminarization of the flow.

\section{Concern: Spatial variations in local fission rate and material behavior will cause "hot channels" which may cause "hot streaking" in the lower plenum - and possible structural problems}

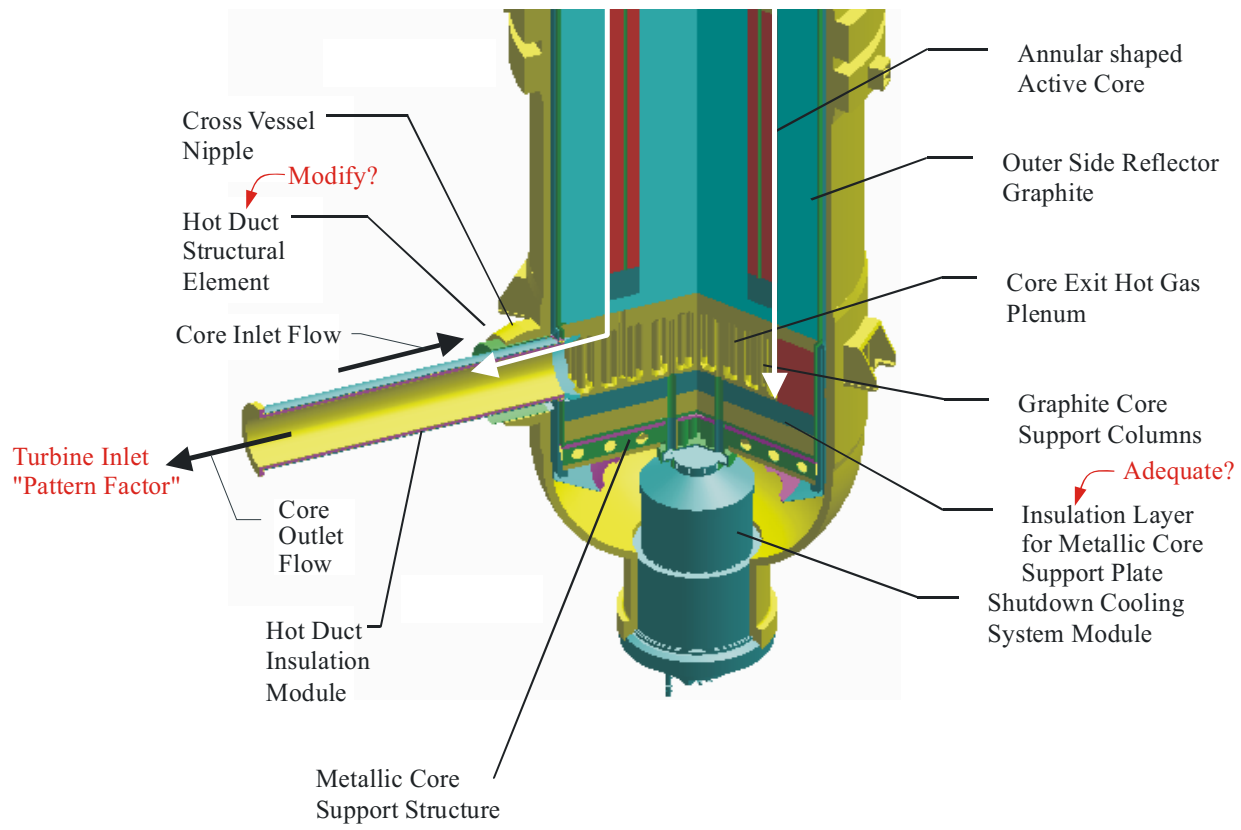

Fig. 3. Relation of "hot channel" and "hot streaking" issues.

The prediction of the turbulent mixing of the high temperature coolant jets that enter the lower plenum requires further development. Conditions of the flow through the lower plenum of the core during normal operation are expected to be in the following ranges:

$$
\begin{array}{ll}
\text { Helium temperature } & 700-1000^{\circ} \mathrm{C} \\
\text { Helium pressure } & 40-80 \mathrm{~atm} \\
\text { Flow type } & \text { Near stagnant to highly turbulent }
\end{array}
$$

The design issue in this case is the need for predicting the rates of turbulent mixing occurring between the hotter coolant jets and the rest of the flow before these hot jets impinge on the metallic components at the exit or on the insulation layer on the floor of the core lower plenum (Figure 3). Due to the complexity of the flow path in the lower plenum, computational techniques with supporting test data are needed to address this turbulent mixing process.

The Modular Helium Reactor (MHR), which serves as the design predecessor of the prismatic VHTR [MacDonald, et al., 2003], is considered to be an ultra-safe, meltdown-proof, 
helium-cooled reactor which is based on thirty years of high temperature gas-cooled reactor experience and is representative of a Generation IV advanced reactor design. The MHR takes advantage of the unique properties of helium gas as coolant, graphite as moderator and coated particles as fuels. The Gas Turbine-Modular Helium Reactor (GT-MHR) couples the heliumcooled modular reactor core with a gas turbine to produce electricity directly from the hightemperature helium coolant at efficiencies approaching fifty per cent. One of the inherent safety features of gas-cooled reactors is their capability of maintaining a gas environment for cooling the core under a major loss of containment. During normal operation the thermal energy from the core is removed by forced convection and during severe accidents, in which the coolant forced flow and/or the coolant containment is lost, it is removed by conduction, radiation and/or natural circulation.

\section{Present R\&D project for improved modeling and benchmark studies}

The goal of this ongoing R\&D effort is to ensure the software tools are available to enable the VHTR to be designed and licensed to achieve Generation IV Program standards and objectvies. The primary objectives of this coordinated experimental and computational research are:

- to build accurate, reliable numerical simulation models of important VHTR thermalhydraulic phenomena

- to provide benchmark data for the assessment and improvement of thermal-hydraulic codes proposed for evaluating the VHTR designs and

- to begin preliminary code development and assessment tasks based on identified modeling needs and existing data.

This study builds on the accomplishments of recent NERI and INERI projects led by INEEL [McEligot et al., 2002, 2003, 2004]. Its unique Matched-Index-of-Refraction flow system will be utilized for benchmark measurements to assess current and future modeling techniques to benefit NGNP and VHTR programs.

Meaningful feasibility studies for VHTR designs will require accurate, reliable predictions of material temperatures to evaluate the material capabilities. In a prismatic VHTR these temperatures depend on the thermal convection in the coolant channels for the core and in other important components. Unfortunately, correlations in one-dimensional system codes for gascooled reactors typically underpredict these temperatures, particularly in reduced power operations and hypothesized accident scenarios. Likewise, most turbulence models in generalpurpose CFD (computational fluid dynamics) codes provide optimistic predictions in the sense that surface temperatures are typically underpredicted [Mikielewicz et al., 2002; Richards, Spall and McEligot, 2004]. These treatments are further complicated by the non-homogeneous power distributions with strong peaking that can occur and buoyancy, strong pressure gradients and gas property variations in the channels ("hot channel" issue). DoE needs improved modeling capabilities, independently from the sometimes simplistic approaches employed by reactor vendors; these computational capabilities need, in turn, to be validated by comparison to experimental and analytical benchmark data. 
The VHTR concepts feature complex geometries and wide ranges of temperatures, leading to significant variations of the gas thermodynamic and transport properties plus possible effects of buoyancy during normal and reduced power operations and loss-of-flow scenarios. The complex geometries proposed have included non-circular fuel channels, high-temperature exit regions, plenum regions, regenerative heat exchangers, reactor cavities with cooling panels, etc.

Existing system safety codes provide reasonable predictions for high-Reynolds-number flows but their correlations can give misleading results for low-Reynolds-number gas flows with buoyancy, as in accident scenarios, even with simple circular tubes. Conceptually, CFD codes with turbulence models can yield predictions for improvement of correlations and preliminary design; however, as noted above recent assessments have shown that most turbulence models used in general purpose codes give unreliable, optimistic predictions for these cases. Further benchmark data are needed for complex geometries - to avoid this problem and to improve predictive capabilities. These bases can be obtained from direct numerical simulations (DNS) or large eddy simulations (LES), after validation with measurements, or by experiments. (DNS calculations are not currently part of this project but useful DNS databases are available from our current I-NERI project [McEligot et al., 2003].)

Six areas of thermal hydraulic phenomena -- in which the application of improved CFD (computational fluid dynamics) and system thermal-hydraulic analytical techniques can be used in the design and safety analyses of a prismatic VHTR -- have been identified [McEligot et al., 2002] as indicated in Figure 4. Several of these phenomena are pertinent to pebble bed versions of the VHTR as well. Our initial studies will concentrate on "Coolant flow distribution through reactor core channels" and "Mixing of hot jets in the reactor core lower plenum," phenomena that are important both in normal operation and in accident scenarios. The present task and report address the latter.

Accurate predictions of the thermal mixing in the lower plenum are needed to predict the temperature distribution of the coolant exit duct and its material behavior (Figure 3). Due to the variation of the heat generation across and along the core, the jets from the cooling channels into the plenum may vary in temperature substantially; if the turbulent mixing of these flows is incomplete, high temperature gas may impinge on lower plenum surfaces and / or the entrance of the core outlet flow duct causing potential structural problems ("hot streaking" issue). Nonuniformity of the gas temperature distribution in the outlet duct will also affect the high pressure turbine adversely. The geometric transition from the circular cooling channels in the core to the lower plenum is complex as is the configuration of the lower plenum itself with its array of posts supporting the core. Hence, reliable, accurate predictive techniques are needed for the flow and mixing in the plenum and of the temperature and flow distributions of the hot jets entering the plenum. 


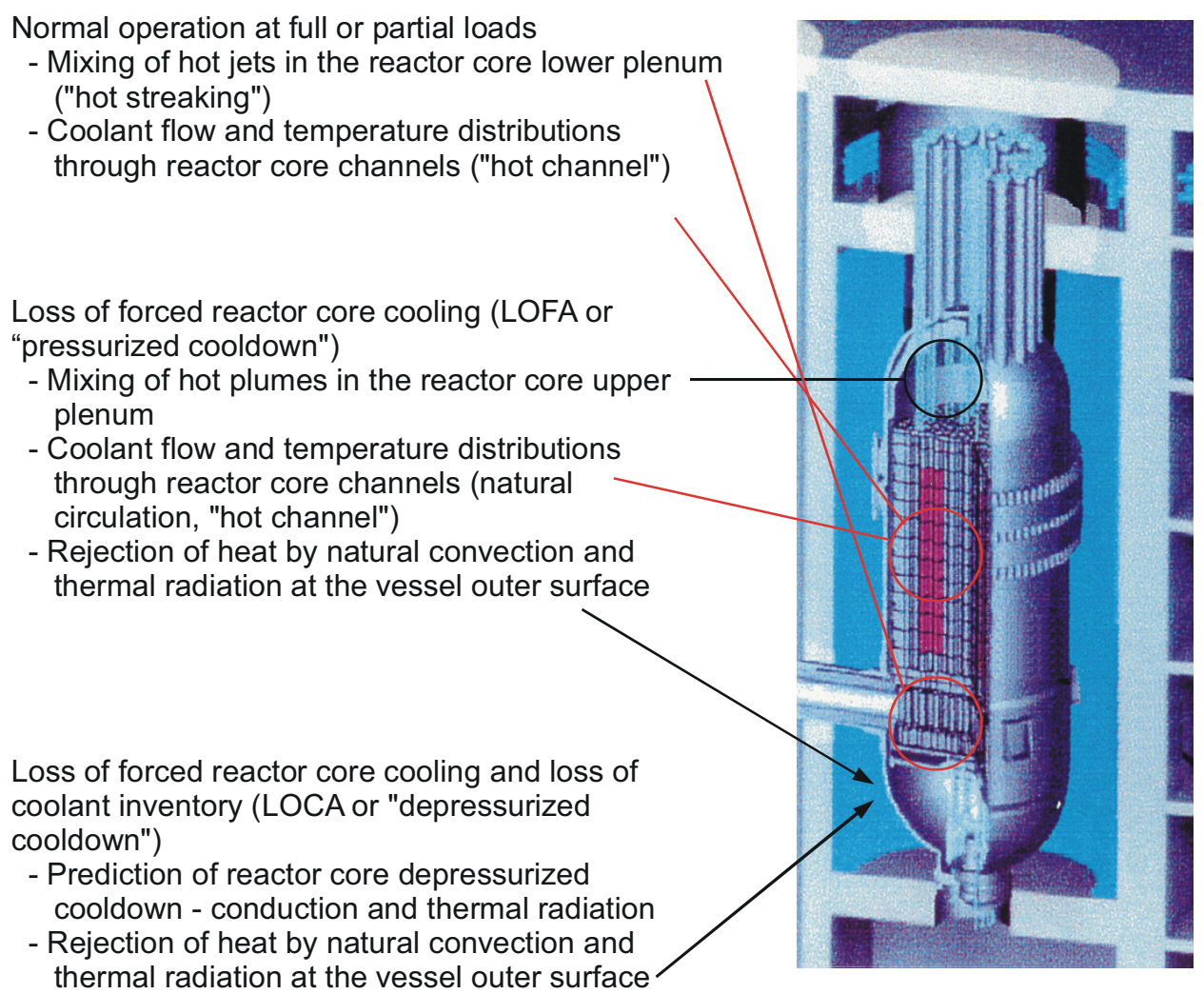

Fig. 4. Pertinent areas of thermal hydraulic phenomena for prismatic VHTRs.

INL is extending the ATHENA/RELAP5-3D codes to treat flows in VHTRs. Under an LDRD program, ATHENA/RELAP5-3D has been linked to the Fluent CFD code to provide a tool capable of providing a macroscale flow resolution where adequate (core, piping, balance-ofplant) with a microscale flow resolution where it is necessary (inlet or outlet plenum). INL has recently led pertinent research projects for the NERI program ("Fundamental thermal fluid physics of high temperature flows in advanced reactors systems" [McEligot et al., 2002]) and the Korean I-NERI program ("Advanced computational thermal fluid physics and its assessment for supercritical reactors" [McEligot et al., 2003]). These computational and experimental projects both addressed effects of fluid property variation and complex geometries, key features of flows in VHTRs. INL partners developed LES (large eddy simulation) and DNS (direct numerical simulation) codes for low-Reynolds-number, strongly-heated, buoyant gas flows in channels to serve as benchmarks in those situations in gas-cooled reactors [McEligot et al., 2002, 2003].

INL has developed the World's largest Matched-Index-of-Refraction (MIR) flow system (http://www.inel.gov/env-energyscience/physics/mir/). By using optical techniques, such as laser Doppler velocimetry (LDV) and particle image velocimetry (PIV), measurements can be obtained in complex passages without disturbing the flow. The refractive indices of the fluid and the model are matched so that there is no optical distortion. The large size provides good spatial and temporal resolution. It was employed for velocity / turbulence data in scaled fuel channels for a VHTR concept and an SCWR concept. This facility provides means to measure flow fields, turbulence and mixing in the complex geometry of a prismatic VHTR lower plenum. The resulting data can be employed to assess CFD codes and their turbulence models for the limiting 
case of dominant forced convection where temperature can be considered to be a passive scalar; a code must satisfy this test before it can be considered for extension to include more complicated phenomena (e.g., buoyancy influences).

The general approach of the project is to develop new benchmark experiments for assessment in parallel with CFD and coupled CFD systems code calculations for the same geometry. Velocity and turbulence fields will be measured in INL's unique Matched-Index-ofRefraction (MIR) flow system, the World's largest; these data will be used to assess the capabilities of the CFD code and its turbulence models and to provide guidance in improving the models. Heat transfer experiments will also be developed and accomplished for the same purposes. Existing databases from experiments, direct numerical simulations and large eddy simulations will also be utilized where appropriate. A "lower plenum model," based on the Point Design of the NGNP [MacDonald et al., 2003], will be developed for the coupled CFD/ATHENA/RELAP5-3D codes and calculations will be performed to identify potential mixing problems ("hot streaking").

Outcomes of this proposed research will be (1) validated predictive techniques for gas flows with property variation and buoyancy effects through the complex geometries important in VHTR development, (2) benchmark data - both computational and experimental - for assessing existing and future CFD codes and (3) improved quantitative understanding of the limitations of current and proposed system and CFD codes.

The objective of the present report is to document the design of an experiment to obtain benchmark data for flow phenomena expected to occur in the lower plenum of typical NGNP concepts. These data should be valuable for CFD code assessment in the NGNP task on methods development. Appendix A provides the fabrication sketches which are deliverables for the current experimental task.

\section{Scaling studies for experiment design}

The objective of the benchmark experiments is to provide careful measurements to assess the capabilities and performance of the modeling approaches of CFD codes and systems codes. Two aspects of the complex flow in an VHTR are being addressed: (1) flow and thermal mixing in the lower plenum and (2) turbulence and resulting temperature distributions in reactor cooling channels. The present report concentrates on the former.

The relations between these two regions have been demonstrated schematically in Figure 3. In the prismatic NGNP Point Design the cooling channels are simple vertical, circular tubes with complexity entering the problem due to the spatial variations in local fission rate and the temperature dependencies of the gas properties. The channels connecting the cooling channels to the lower plenum (Figure 5) and the lower plenum configuration itself introduce a variety of complex geometrical flow passages. Scaling studies and conceptual experiment designs for applications to both the lower plenum and hot channel issue are presented in a recent report by McEligot and McCreery [2004]. 


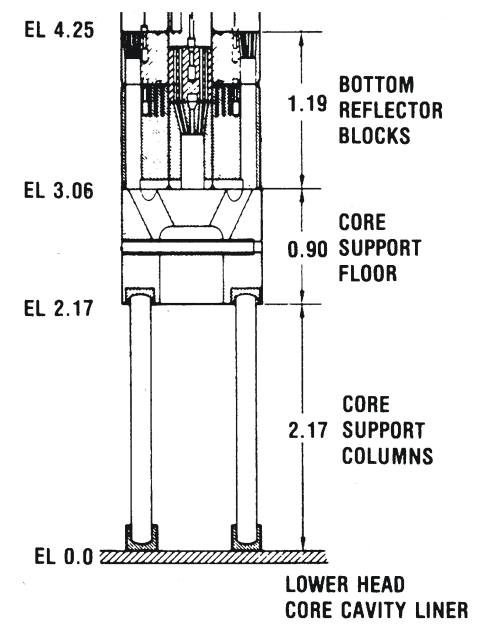

HTGR, FSV

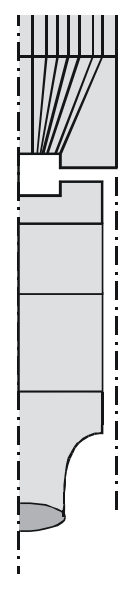

MHTGR

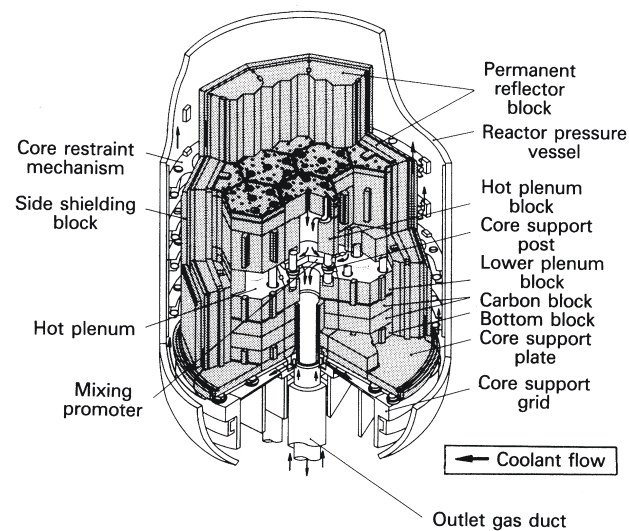

HTTR

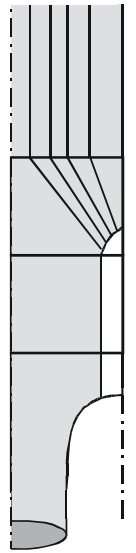

GT-MHR

GC00 05033

Fig. 5. Examples of designs for the geometric transitions from coolant channels to hot jet flows in the lower plenum of typical gas-cooled reactor cores.

Estimates of the values of some of the non-dimensional parameters have been made for the NGNP Point Design at full power and at reduced power for both sizes of coolant channels proposed [McEligot and McCreery, 2004]. In the standard fuel block there are 102 "large" coolant channels of 0.625 inch diameter and six "small" ones of 0.5 inch diameter. The control or shutdown blocks have 88 large channels and seven small channels. Of the 102 columns of blocks, 72 have standard blocks and the remaining thirty are either control or shutdown blocks (Figure 6). The channel lengths in individual blocks are about 62 and 50 diameters for small and large tubes, respectively; the nominal heated lengths for a core with ten active blocks vertically are therefore about 620 and 500 diameters, Thus, for turbulent flows, quasi-fully-developed conditions are expected to be reached. Conceptual designs have been developed for full power from 600 to $840 \mathrm{MWth}$, average inlet temperature of $491^{\circ} \mathrm{C}$, average outlet temperature of $1000^{\circ} \mathrm{C}$ and corresponding helium flow rates [MacDonald et al., Table 12, 2003]. The estimates allowed a bypass flow fraction of 0.1 with heat fluxes calculated for nominal (average) conditions and for a peaking factor of 1.625 from radial and axial approximations.

The non-dimensional parameters $\mathrm{Re}, \mathrm{q}^{+}, \mathrm{K}_{\mathrm{V}}$ and $\mathrm{Bo}^{*}$ were estimated at the entrance, midheight and exit of the coolant channels for nominal full power and reduced powers of fifteen and ten per cent. The reduced power values were calculated for proportional reductions in gas mass flow rate. Highest gas bulk temperatures occur at the outlet from the active core. The range of outlet Reynolds numbers varied from about 57,000 for a high power core to about 2300 at ten per cent power. 


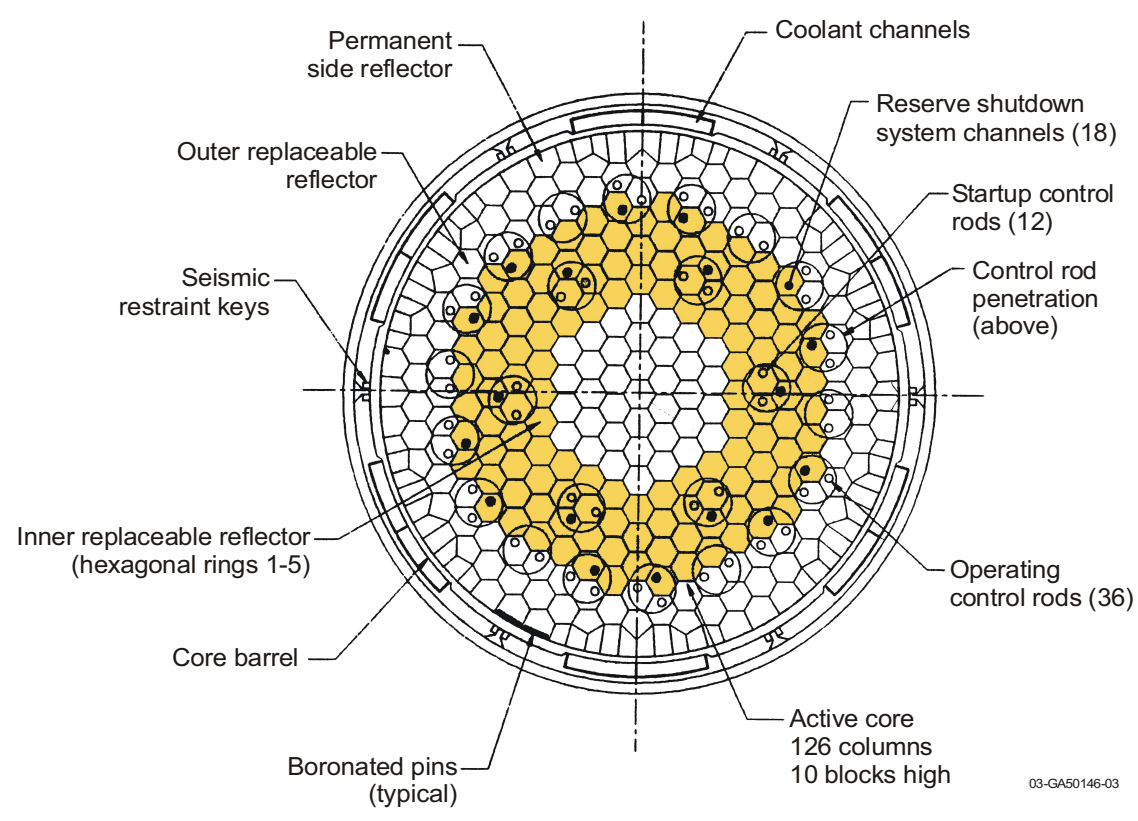

Fig. 6. Cross sectional view of GT-MHR and NGNP reactor cores [MacDonald et al., 2003].

As is evident in Figure 3, the hot flow from the coolant channels through the lower plenum to the hot core outlet duct encounters a very complicated geometry. Figure 7 demonstrates some of the details via a plan view. Flow from the coolant channels is brought to the corners of the lower reflector blocks supporting the active core. At these corners short ducts carry the flow vertically down into the plenum where it emerges as hot jets. The cross sections and flow rates of these ducts differ depending on whether the corners -- at which they are located -- are common to three, two or one active column. The temperatures of these jets will vary spatially due to variations in the local fission rate in the core and material histories. In the plenum, circular graphite posts support the active core and the inner and some outer reflector columns; differing diameters of these posts lead to differing pitch-to-diameter ratios in the array of posts.

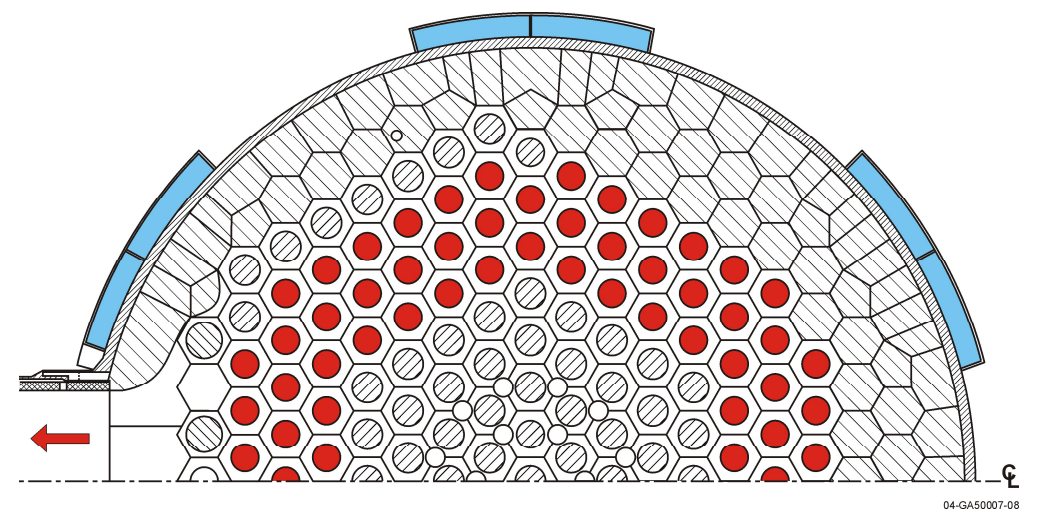

Fig. 7. Typical geometry of the lower plenum in a prismatic VHTR concept, showing locations of support posts, support blocks, etc.

The flow in the lower plenum can locally be considered to be a situation of multiple buoyant jets into a confined density-stratified crossflow -- with obstructions. Since the flow 
converges ultimately to a single outlet, the hot jets encounter different crossflow velocities depending on their locations relative to the outlet. The jets furthest from the outlet essentially exhaust into stagnant surroundings between the adjacent posts with the exception of the flow which they induce and some leakage flow. These furthest jets become wall jets (along the corner formed by prismatic outer reflector support blocks) that then impinge on the floor of the plenum. On the other hand, the last row of jets before the outlet encounters crossflow from all the other jets. Figure 8 illustrates this complicated situation via predictions from a CFD model of flow in the lower plenum of a General Atomics GT-MHR reactor [Schultz and Schowalter, 2004]. Further complicating matters are (1) "slot"-type jets from the leakage flow through spaces along the sides of the hexagonal columns in both the reflectors and active core and (2) leakage of cooler gas through the ducts connecting the Shutdown Cooling System Module (Figure 1) to the center of the lower plenum.

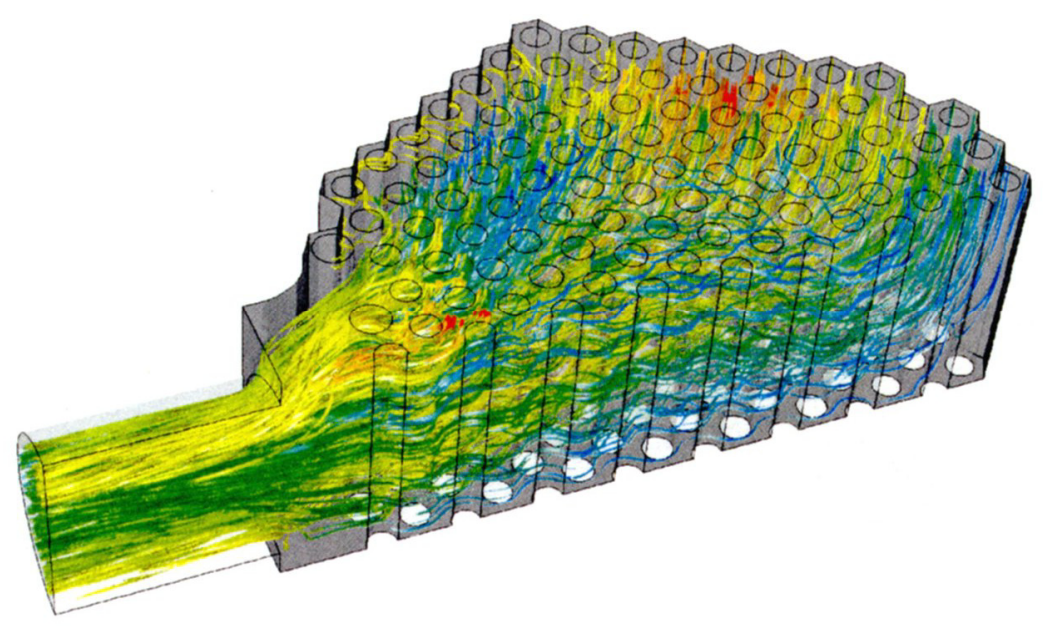

Fig. 8. CFD predictions of flow paths and temperatures in a computer model of the lower plenum of a GT-MHR (courtesy of General Atomics Co).

As indicated in Figure 3, if a "hot channel" region is exhausted via one of the furthest jets, there is concern that its impingement on the floor of the lower plenum may be too hot for the insulation layer protecting the metallic Core Support Plate below. The "hot streaking" issue pertains primarily to the entrance of the hot outlet duct to the turbomachinery. If a "hot channel" region exhausts through one of the last jets before the outlet duct, there is concern that it may not mix (and thereby cool) sufficiently before flowing along the metallic outlet duct.

To assess CFD codes and their turbulence models for their capabilities to handle lower plenum flows and mixing, one needs measurements (and predictions) of the temperature, velocity components and Reynolds stresses as functions of the three dimensions involved, heat transfer coefficients and wall shear stresses along the surfaces and the non-dimensional frequency of any possible eddy shedding from the posts. For systems or integral codes, if feasible (for example, well-mixed conditions), comparable integral quantities and loss coefficients are desired. 
For the lower plenum, the solutions for flow and mixing are determined by the geometry, by the non-dimensional parameters appearing in the governing equations and by the inlet and boundary conditions. For equivalent shapes, the geometry can be represented by ratios of appropriate length scales such as pitch-to-diameter $\mathrm{p} / \mathrm{D}_{\mathrm{p}}$ for the support posts. In an idealized plenum, additional length scales include the jet hole diameter $\mathrm{D}_{\mathrm{j}}$ and the height $\mathrm{H}$ of the plenum; so, for scaling, the ratios $\mathrm{D}_{\mathrm{j}} / \mathrm{D}_{\mathrm{p}}$ and $\mathrm{H} / \mathrm{D}_{\mathrm{p}}$ or related quantities (such as $\mathrm{H} / \mathrm{D}_{\mathrm{j}}$ ) should be preserved as well. If the flow from the jets were uniform, a governing overall Reynolds number could be defined in terms of the gas mass flow rate, one of the length scales and the gas viscosity at the entering (jet) temperature. A number of Reynolds numbers can be defined, such as jet Reynolds numbers Rej, post Reynolds numbers Rep, plenum Reynolds numbers based on a hydraulic diameter ReDh, Reynolds numbers based on the minimum free-flow area as in heat exchangers [Kays and London, 1955], etc. However, for the idealized overall case, once one Reynolds number is fixed all the others are determined since the various geometric ratios are fixed. To subdivide the problem into characteristic local regions, separate "inlets" are considered -- such as a jet inlet duct and a plenum cross flow -- thereby introducing two independent Reynolds numbers as governing parameters to be preserved in the scaling (e.g., Rej and $R e D h$ ). For "compressed" gases, a Mach number M or an Eckert number could be required as a scaling parameter; however, if $\mathrm{M}$ is less than about 0.3 , the gas can be considered to be "noncompressed" and the compressibility effects can be neglected (i.e., it behaves as an incompressible fluid with $\Delta \mathrm{p} / \mathrm{p}<<1$ ).

Heat transfer or differences in temperature introduce additional governing parameters. The Prandtl number occurs in the thermal energy equation but for helium and other common gases, its variation is slight. Temperature variation can affect the gas density if the variation is sufficiently large and, thereby, introduce buoyancy influences. If the buoyancy effects are "large" relative to thermal mixing or diffusion, the flow may stratify with the hotter gas remaining near the upper surface of the plenum and preferentially impinging on the upper surface of the metal outlet duct. An overall Richardson number $\mathrm{Ri}=\mathrm{g}\left(\rho_{2}-\rho_{1}\right) \mathrm{H} /\left(\rho_{1} \mathrm{Vb}^{2}\right)$ can be defined and be evaluated to investigate the likelihood of stratification and importance of buoyancy. (The Richardson number can loosely be considered to relate buoyancy effects to viscous effects, e.g., forces or related frequencies depending on the specific Ri definition.) Or a jet Richardson number can be evaluated for examining the expected behavior of a hot jet injected into a stratified cross flow (without posts). Gradient Richardson numbers are utilized to treat pointwise buoyant effects but they typically cannot be predicted in advance and, therefore, become dependent variables rather than controlling parameters.

Jets in cross flows are typically characterized by velocity ratios, such as $\mathrm{V}_{\mathrm{j}} / \mathrm{V}_{\mathrm{p}}$, or mass or momentum flux ratios. Knowing one of these ratios and the gas properties, one can calculate the others as appropriate for comparison to other studies. As implied above, these ratios will vary significantly from one side of a lower plenum to the other as the jet inflow remains approximately the same magnitude and the crossflow increases as more and more jets interact.

The near-field behavior of a jet is dependent on its entering profiles of mean velocity and turbulence quantities. These variables are in turn dependent on the geometry of the duct in which this entering flow develops. Many (most?) experiments on free jets, impinging jets and wall jets have been conducted with orifices or flow nozzles to form uniform, non-turbulent 
entering jet profiles. Consequently, classical wisdom and textbook descriptions for jet characteristics are not necessarily valid for the near-field mixing of jets in industrial applications such as a VHTR flow geometry (Figure 9). Few studies of impinging jets have utilized fullydeveloped turbulent flows for the jet inlet [Cooper et al., 1993; Condie, McCreery and McEligot, 2001]. Figures 5 and 9 show that the flow transitions from cooling channels to lower plenums in typical gas-cooled reactors involve short ducts. For example, in the GT-MHR design shown in Figure 9, the jet entry duct is only about four diameters long with its inflow conditions being dependent on the Reynolds numbers of the flows from the cooling channels; the resulting jet entry profile is not likely to be uniform nor fully-developed.

To obtain insight into the phenomena expected in the lower plenum of a prismatic VHTR concept, some of the non-dimensional parameters have been estimated for normal operation at a full power of $600 \mathrm{MWth}$.

Approximate nominal conditions have been employed so the reader should consider the values to be only order-ofmagnitude estimates. Geometric ratios below the active core are

$$
\mathrm{D}_{\mathrm{j}} / \mathrm{D}_{\mathrm{p}} \approx 0.7, \mathrm{p} / \mathrm{D}_{\mathrm{p}} \approx 1.7 \text { and } \mathrm{H} / \mathrm{D}_{\mathrm{p}} \approx 7
$$

For a single-hole "corner channel" (i.e., the duct along the corner of a single active outer column with two inactive solid columns adjacent), the bulk velocity at $1000^{\circ} \mathrm{C}$ is about $25 \mathrm{~m} / \mathrm{sec}(80 \mathrm{ft} / \mathrm{sec})$ and the resulting jet Reynolds number is about 90,000. Due to the high sound speed of helium, the Mach number is about 0.01 so the flow can be considered to be "non-compressed." For corner channels formed at two and three active columns (say two- and three-hole), the mass flow rate and cross sectional area increase proportionately but the hydraulic diameter does not. The plenum flow at the far side away from the outlet duct goes from two single-hole jets then between solid supporting blocks and supporting posts towards the first two-hole jet (Figure 7 and later Figure 17). At this location the horizontal bulk velocity in the plenum is about $0.4 \mathrm{~m} / \mathrm{sec}(1.4 \mathrm{ft} / \mathrm{sec})$, giving $\mathrm{V}_{\mathrm{j}} / \mathrm{V}_{\text {plenum }} \approx 50$ so jet penetration into the cross flow is expected to be high. One might expect these jets to travel along the adjacent solid vertical corner as wall jets and then to impinge on the plenum floor. A plenum Reynolds number at the passage between the first row of posts encountered would be about 24,000, based on the hydraulic diameter of the opening.

Comparable estimates may be made for the other extreme, the region near the exit to the outlet duct. For the flow between the row of posts before the last row of jets, the plenum bulk velocity would be about $40 \mathrm{~m} / \mathrm{sec}(130 \mathrm{ft} / \mathrm{sec})$, still a low Mach number. The jet-to-crossflow 
velocity ratio would be about 0.6 , more in the range of typical crossflow experiments such as those by Ramsey and Goldstein [1971] and Andreopoulos and Rodi [1984]. Even without buoyancy effects (if the jet is hot relative to the crossflow) and drag by nearby posts, the jet penetration would be expected to be less than two jet diameters which would be less than a fifth of the distance to the plenum floor. The plenum Reynolds number in this region would be about $3 \times 10^{6}$.

In operation at reduced power, the flow rates, velocities and Reynolds numbers would be reduced proportionately but the velocity ratios would remain the same. Thus, at ten per cent power, the plenum Reynolds number for flow between the first row of posts would be of the order of 2400; the convergence between these posts may induce a tendency towards laminarization there at this Reynolds number [Chambers, Murphy and McEligot, 1983] but most of the plenum could be expected to have turbulent flow. If the temperature differences from hot channels are approximately the same at reduced power, buoyancy effects could become more significant.

Approximate analyses were conducted to examine whether significant influences of buoyancy should be expected for the jets entering the lower plenum and for the near horizontal flow within it. Nominal operating conditions were considered. A crude analysis -- for the height $\mathrm{H}_{\mathrm{b}}$ a column of buoyant gas would have to be in order to balance the momentum flow rate coming from a jet -- led to the approximation that $\left(\mathrm{H}_{\mathrm{b}} / \mathrm{D}_{\mathrm{j}}\right)$ is given by a Froude number $\mathrm{Fr}$ ( $\left.\left(\mathrm{V}_{\mathrm{j}}{ }^{2}\right) /\left[\mathrm{g}\left(\left(\mathrm{T}_{\mathrm{j} / \mathrm{T}_{\infty}}\right)-1\right) \mathrm{D}_{\mathrm{j}}\right]\right)$ based on jet diameter $\mathrm{D}_{\mathrm{j}}$. If $\mathrm{Fr}_{\mathrm{j}}>>1$, it would be expected to be effectively a momentum-driven jet. For a $300^{\circ} \mathrm{C}$ temperature difference and $\mathrm{T}_{\infty}=1000^{\circ} \mathrm{C}$, the approximations give $\mathrm{Fr}_{\mathrm{j}} \approx 2800$ at full power and about 28 at one-tenth power, both cases indicate domination by the jet momentum flow rate. That is, buoyancy would not be expected to have a significant influence on the jet interaction with the flow in the plenum.

A second approximate analysis was conducted to estimate when a temperature gradient will be likely to stabilize a horizontal turbulent channel flow, thereby leading to reduced thermal transport near the upper surface. For the lower plenum this situation probably would be a pessimistic estimate since one expects turbulence from the jets and flow around the posts to counter the stabilizing influence of buoyancy. Gage and Reid [1968; Turner, 1973] found that for pointwise gradient Richardson numbers Ri greater than about 0.0554 the flow is stable for all Reynolds numbers. For turbulent wall flows, the highest temperature (density) gradients occur at the wall so the highest gradient $\mathrm{Ri}$ values may be there or nearby. Therefore, we defined

$$
\mathrm{Ri}_{\mathrm{Wall}}=-\mathrm{g} \beta(\partial \mathrm{T} / \partial \mathrm{z})_{\mathrm{Wall}} /\left((\partial \mathrm{U} / \partial \mathrm{z})_{\mathrm{Wall}}\right)^{2}
$$

to characterize this situation - and we hypothesize that it can be used as an order-of-magnitude measure to indicate whether we need to worry about flow stabilization or "laminarization" by buoyancy. For fully-established flow of a gas, one can approximate this parameter as

$$
\mathrm{Ri}_{\text {Wall }} \approx 13.5 \mathrm{Ri}_{\mathrm{O}} \operatorname{Pr} 0.4 / \mathrm{Re}^{0.7}
$$


where $\mathrm{Ri}_{\mathrm{O}}$ is an overall Richardson number defined as $\mathrm{g}\left(\mathrm{T}_{\text {hot }}-\mathrm{T}_{\text {cold }}\right) \mathrm{H} /\left(2 \mathrm{~T}\right.$ bulk $\left.\mathrm{Ubulk}^{2}\right)$.

We suggest that, if $\mathrm{Ri}_{\text {wall }}<<0.05$, then the flow is probably well-mixed and buoyancy effects are negligible. If $\mathrm{Ri}_{\text {wall }}$ is about 0.05 or greater, then we should worry about buoyancy effects and try to treat them. For nominal full power conditions and $\mathrm{T}_{\text {hot }}-\mathrm{T}_{\text {cold }}=100^{\circ} \mathrm{C}$, one may estimate $\mathrm{Ri}_{\text {Wall }} \approx 0.015$ (probably "well-mixed") in the region of the plenum away from its outlet. For the same temperatures near the outlet, $\mathrm{Ri}_{\text {wall }} \approx 7 \times 10^{(-8)}$. At one-tenth power, $\mathrm{Ri}_{\text {wall }} \approx 7.7$ (stabilizing) away from the outlet and $\mathrm{Ri}_{\text {wall }} \approx 4 \times 10(-5)$ near the outlet (wellmixed). Consequently, our preliminary conclusions are that

- for full power, buoyancy influences are probably not important

- for reduced power (ten per cent), buoyancy probably is important at the side of the lower plenum away from the outlet but not near the outlet.

Thus, experiments without buoyancy effects (as in those proposed for the INL Matched-Indexof-Refraction flow system) should provide useful benchmark data for assessing CFD codes for some lower plenum flows, particularly at normal full power. Likewise, in those cases the turbulence models in the CFD codes should not need to incorporate buoyancy influences.

The acceleration parameter, $\mathrm{K}_{\mathrm{V}}=\mathrm{v}(\mathrm{dVb} / \mathrm{dx}) / \mathrm{Vb}^{2}$, was estimated for the convergence into the hot outlet duct from the lower plenum. For nominal full power operation, the estimates give $\mathrm{K}_{\mathrm{V}} \approx 5 \times 10^{(-7)}$, about the order-of-magnitude of the threshold for reduction of turbulence in a turbulent boundary layer. At a reduced power of ten per cent, $K_{V}$ would increase by a factor of ten to about $5 \times 10^{(-6)}$. Laminarization is expected to occur at about $3 \times 10^{(-6)}$ and above so it would be probable in this case as in some rocket nozzles and turbine blade passages. In this case, laminarization would be expected to reduce the heat transfer rate to the surfaces of the hot outlet duct but might worsen the "pattern factor" of the flow into the turbomachinery.

In summary, the flow within the vertical ducts to the lower plenum is expected to be turbulent as is the horizontal crossflow in the plenum. The velocity ratio of the resulting jets $\mathrm{V}_{\mathrm{j}} / \mathrm{V}_{\mathrm{p}}$ will range from about $1 / 2$ to fifty; these jets will be momentum-driven with negligible buoyancy influences. At reduced power, laminarization or buoyancy-induced stabilization may be possible in some regions of the lower plenum.

\section{Experimental needs}

The thermal hydraulic needs for assessment of codes for the prismatic VHTRs have been determined in the above section on "Scaling studies for experiment design." Once the appropriate non-dimensional parameters are identified and their magnitudes are evaluated, the question becomes whether useful benchmark data are already available in the ranges covered by VHTR operations. So existing experimental knowledge must be reviewed to see if there are any gaps in the required knowledge. The gaps identified can be considered to describe further experiments necessary to permit assessment over the full range of possible operating conditions. 
The purpose of this section is to accomplish those determinations for the lower plenum ("hot streaking" issue).

The flow in the lower plenum can locally be considered to be a situation of multiple buoyant jets into a confined density-stratified crossflow -- with obstructions. While -- to the authors's knowledge -- no benchmark experiments are available that treat all complicated lower plenum phenomena together, many studies have been conducted for individual phenomena separately. King [2004] of Oregon State has surveyed available literature and has compiled lists of pertinent studies for the following related situations:

- Flow through tube bundles

- A single jet in an unconfined crossflow

- Multiple parallel jets in a stagnant environment

- Multiple jets in an unconfined crossflow

- A single jet in a confined crossflow

- Multiple jets in a confined crossflow

The references and investigators that King identified can provide significant tests of codes and their turbulence models for a wide variety of flow and mixing phenomena occurring in a lower plenum.

King concluded that it has typically been found that the anisotropy of the turbulence in these situations leads to a failure of popular k- $\varepsilon$ turbulence models to predict the proper scalar mixing. Thus, the k- $\varepsilon$ model likely cannot be used if good accuracy is desired. However, for approximate results and qualitative insight, this model might be employed with the realization that it can be expected to underestimate the turbulent mixing. It is believed that this underestimation will give conservative results in the context of the "hot streaking" issue of a prismatic VHTR lower plenum.

King suggests that further benchmark experiments on

- Scalar mixing in a tube bank

- Single jet in a confined crossflow

- Multiple jets in a confined crossflow and

- Multiple jets in an unconfined crossflow

would be desirable for assessment of CFD codes predicting turbulent mixing for lower plenum applications. He recommends that simultaneous LDA (laser Doppler anemometry) and PLIF (planar laser-induced fluorescence) measurements of turbulent velocity and scalar fluctuations be 
made so that turbulent scalar transport terms, such as $\mathrm{u}^{\prime} \mathrm{c}^{\prime}$ or $\mathrm{u}^{\prime} \mathrm{t}^{\prime}$, can be deduced for comparison to model predictions.

The literature on heat transfer and flow of impinging jets is vast and growing [Martin, 1977; Downs and James, 1987; Hrycak, 1981; Webb and Ma, 1995; Ma et al., 1997; Lee and Lee, 2000]. The primary application has been for enhancement of convective heat transfer parameters [Gardon and Akfirat, 1965] so much of the literature concentrated on integral heat transfer quantities, such as local or average heat transfer coefficients (e.g., Goldstein and Behbahani [1982], Hrycak [1983], Baughn and Shimizu [1989], Liu and Lienhard [1993], San, Huang and Shu [1997], Ma et al. [1997], Siba et al. [1998], Lee and Lee [2000]). Numerical predictions are provided by Wolfstein [1970], Rubel [1980], Huang, Mujumdar and Douglas [1984], Amano and Brandt [1984], Craft, Graham and Launder [1993], Dianat, Fairweather and Jones [1996], Heyerichs and Pollard [1996], Lee et al. [1997], Olsson and Fuchs [1998], Satake and Kunugi [1998], Craft [1998], Morris, Garimella and Fitzgerald [1999], Parneix, Behnia and Durbin [1999], Behnia et al. [1999] and others. To maintain effectiveness, often arrays of impinging jets are employed with small pitch-to-diameter spacings, so the non-dimensional radial extent is not large [Womac, Incropera and Ramadyani, 1994; Slayzak, Viskanta and Incropera, 1994; Lienhard et al., 1996]. For gas turbine cooling [Simon et al., 1999], the jet is formed by passage through a short orifice passage so the initial velocity profile of the jet is near uniform; this uniform profile is typical of many experiments where the jet is formed from a converging nozzle and of many numerical predictions.

Condie, McCreery and McEligot [2001] summarized the fluid physics references found for simple axisymmetric impinging jets in general. With the exception of the outflow study of Moller [1963], the jets from fully-developed flows were measured in semi-infinite surroundings [Cooper et al., 1993; Kim, Wiedner and Camci, 1995; Lee and Lee, 2000]. The early studies of confined flows, such as those of Kreith and colleagues [1963, 1965], concentrated on the outflow at large distances from the impinging jet.

At $\mathrm{Re}_{\mathrm{j}} \approx 2500$, Nelson [1987] employed an LDV to obtain phase-averaged velocity measurements to map coherent spatial characteristics of a flow from a nozzle four diameters above the plate. Landreth and Adrian [1990] used particle image velocimetry to obtain instantaneous velocity fields and averaged quantities for a jet at $\operatorname{Re}_{j} \approx 6600$ situated four diameters above their plate; however, their field extended only about two diameters from the centerline. Cooper et al. [1993] conducted a relatively wide range of measurements focusing on data from a long tube to assist turbulence modeling. At $\mathrm{Rej}_{\mathrm{j}}=2.3 \times 10^{4}$ and $7 \times 10^{4}$, they obtained data for a jet located two to ten diameters above the plate to a radius of about eight diameters from the centerline. Results include mean and fluctuating velocities and turbulent shear stresses. They comment that, while the topic has been the subject of many experiments, none could have been said to have been designed with the needs of turbulence modeling in mind. Usually the flow conditions at the nozzle exit are insufficiently prescribed or too far above the plate to be useful. Even for confined jets, only Fitzgerald and Garimella [1996] appear to have measured turbulence quantities outside the impinging jet and its wall jet; they present rms radial velocity fluctuations, primarily in and near the wall jet at high Reynolds numbers. Emphasis on the region outside the wall jet is lacking in their study. 
Numerical studies show that impinging jet flows are difficult to predict reliably. Craft, Graham and Launder [1993] attempted four turbulence models -- one k- $\varepsilon$ model and three second-moment closures -- and found none to be entirely successful. Morris, Garimella and Fitzgerald [1999] showed a standard high-Re k- $\varepsilon$ model and an RNG k- $\varepsilon$ model to be inferior to a Reynolds stress approach. Behnia et al. [1999] indicated that the flow characteristics at the jet inlet strongly affect the heat transfer rate (so the use of the appropriate jet velocity profile is important for applications). Advanced numerical techniques are beginning to be employed. Olsson and Fuchs [1998] studied the use of large eddy simulations (LES), examining the effects of spatial resolution and different sub-grid-scale models. Satake and Kunugi [1998] extended an axi-symmetric direct numerical simulation (DNS) technique to treat approximately the confined jet flow experiment of Nishino et al. [1996] at a Reynolds number near 10,000. Provided spatial resolution is adequate, DNS can be a means to avoid problems with turbulence modeling but computational requirements are extensive even for low-Reynolds-number flows.

The interactions between buoyant jets and crossflows have been studied by Campbell and Schetz [1973], Wright [1984], Zhang and Ghoniem [1994], Hwang, Chiang and Yang [1995], Huq [1997], Hunt, Cooper and Linden [2001] and Jirka [2004]. Wright gives a useful treatment of the various associated length scales.

Heat transfer and friction parameters for cross flow through bundles have been available for many years for a wide range of arrays [Grimison, 1937; Kays and London, 1955; Zukauskas, 1972]. Pressure drop and local heat transfer coefficients were obtained by Achenbach [1989] for staggered tube bundles at high Reynolds numbers. Velichko, Pronin and Yassin [1993] measured heat transfer and friction parameters for non-traditional tube bundle arrangements. Stanescu, Fowler and Bejan [1996] determined optimal spacing of the cylinders to maximize the average heat transfer conductance for an entire bundle. Barsamian and Hassan [1996] have applied large eddy simulation (LES) to spatially-periodic flow across a tube bundle at $\operatorname{Re} \approx 1.7 \mathrm{x}$ 105; fluctuating lift and drag spectra were calculated and compared to the limited data available [Chen and Jendrzejczyk, 1987]. Mean and fluctuating velocity components were measured at 2 x $10^{5}<\operatorname{Re}<2 \times 10^{6}$ by Poskas and Survila [1983] for staggered and in-line bundles of tubes. Katinas et al. [1990] measured tube vibrations induced at turbulence levels from one to twelve per cent in the upstream flow to staggered and in-line tubes; although the Reynolds number supposedly was varied from $10^{3}$ to $2 \times 10^{5}$, effects were not presented in terms of Reynolds number. Fluctuations of heat transfer and velocity have been measured in a staggered tube array by Scholten and Murray [1998]. Beale and Spalding [1998] numerically predicted laminar flow and heat transfer across a variety of tube bundle geometries. Watterson et al. [1999] applied a low-Reynolds-number k- $\varepsilon$ model to flow around an array of staggered tubes. A k- $\varepsilon$ model was also applied by Wilson and Bassiouny [2000] to predict the laminar and turbulent flow of air across tube banks with apparently satisfactory agreement to data.

Turner [1973] has provided some insight concerning instability of heated horizontal flows. Thorpe [1987] has reviewed transitional phenomena and development of turbulence in stratified fluids for oceanographic applications. Gage and Reid [1968; Turner, 1973] found that for pointwise gradient Richardson numbers Ri greater than about 0.0554 a horizontal laminar flow is stable for all Reynolds numbers. The stabilization of a turbulent flow by heating from above does not seem to have been examined extensively. Townsend [1957] employed the wind tunnel 
data of Nicholl [1970] to support an analytical treatment; he concluded that there is an upper limit of 0.5 on the flux Richardson number and of about 0.08 on an "ordinary" Richardson number beyond which a collapse of turbulent motion would occur. A related problem of flow into an open-ended cavity with a heated upper plate has been addressed experimentally by Guidotti et al. [2000].

In addition to the suggestions of King [2004], experiments are needed for the combined features of the lower plenum flows. In particular, missing from the typical jet experiments are interactions with nearby circular posts and with vertical posts in the vicinity of vertical walls with near stagnant surroundings at one extreme and significant crossflow at the other. The experiments proposed in the present research would address these needs.

In order to obtain further insight into flow phenomena occurring in a lower plenum, a qualitative flow visualization experiment was conducted at INEEL. Jet injection into a region of similar geometry as a section of the GT-MHR lower plenum was investigated using a simply constructed water flow apparatus. The objective of the experiment was to identify and prioritize flow phenomena, such as jet entrainment, multiple jet interactions, eddy formation, post crossflow and eddy shedding frequency, wall flow effects and overall flow patterns -- for scaling analyses and future experiment design. The simplified study is also useful for identifying features that experiments need to include in more refined designs and for identifying scaling and design problems that need to be resolved or avoided.

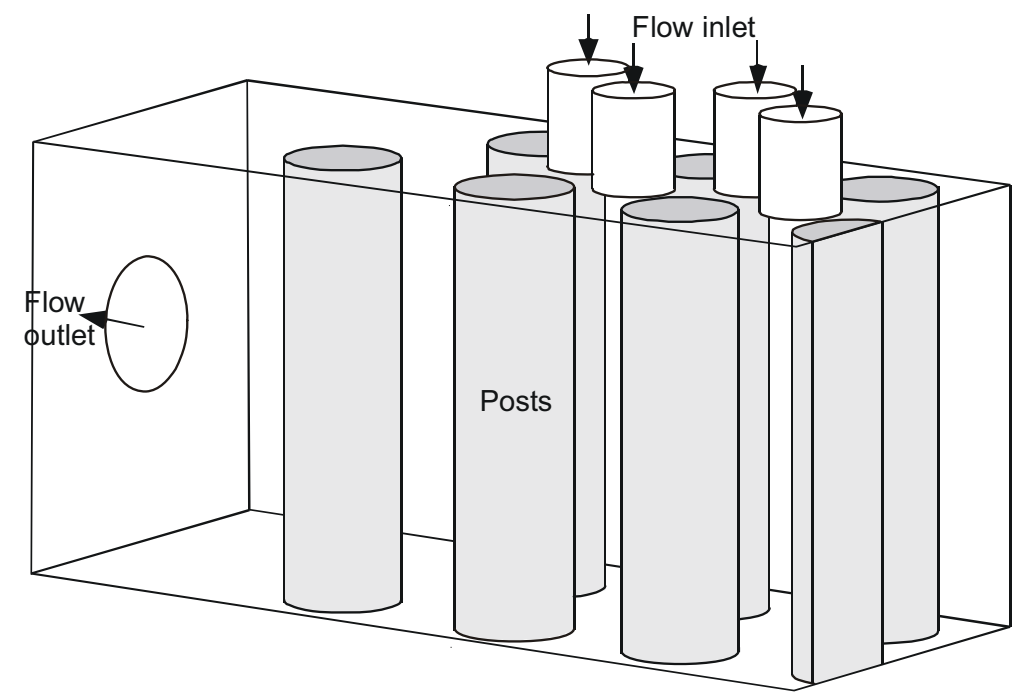

Fig. 10. Schematic drawing of apparatus for qualitative flow visualization of lower plenum phenomena away from the outlet duct.

The apparatus consists of an acrylic plastic box of rectangular cross-section (Figure 10) with inside dimensions of $73.9 \mathrm{~mm}$ (2.91 in.) width by $200 \mathrm{~mm}(8 \mathrm{in}$.) length by $175 \mathrm{~mm}(6.9$ in.) height. Support posts are represented by six acrylic tubes of $25.4 \mathrm{~mm}$ (1.0 in.) outside diameter --plus one half-tube -- with pitch/diameter ratio equal to 1.71 and height/diameter ratio equal to 6.9, the approximate ratios of the support pedestals in the active core region of the GTMHR lower plenum. Flow is injected uniformly into four inlet tubes with $15.7 \mathrm{~mm}(0.62 \mathrm{in}$.) inside diameter. The maximum water flow rate through the four tubes (supplied through an inlet 
plenum connected to a building water spigot) is approximately six gpm. The jet inlet Reynolds numbers are approximately 1280 at the maximum flow rate. The Reynolds number based on the hydraulic diameter of the open channel and total flow rate (i.e., downstream of all four jets) is approximately 3300 . Flow visualization is obtained by injecting food coloring dye through a tube connected to a syringe. The dye injection position may be traversed through the regions of jet injection. Figure 11 shows sequential images of dye injection from three of the four jets.
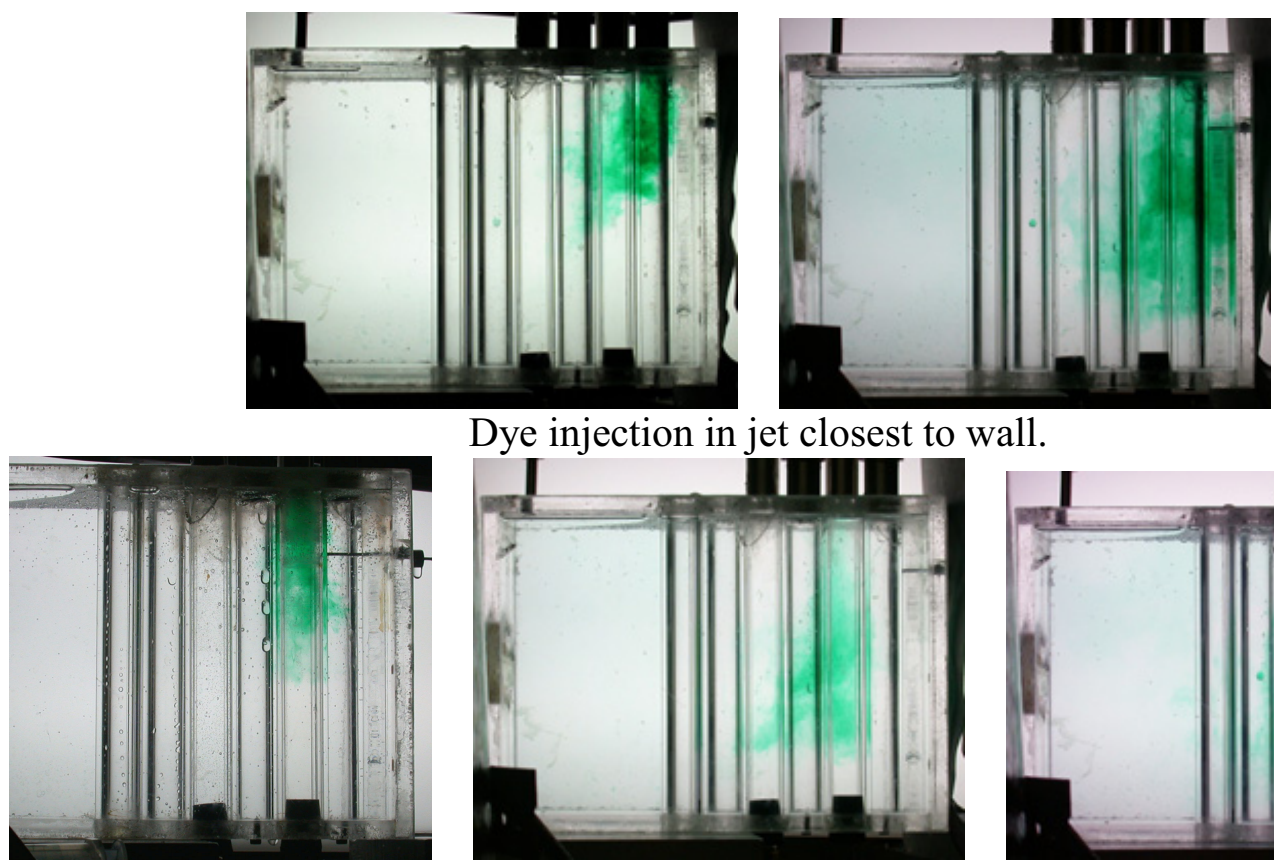

Dye injection in jet closest to wall.
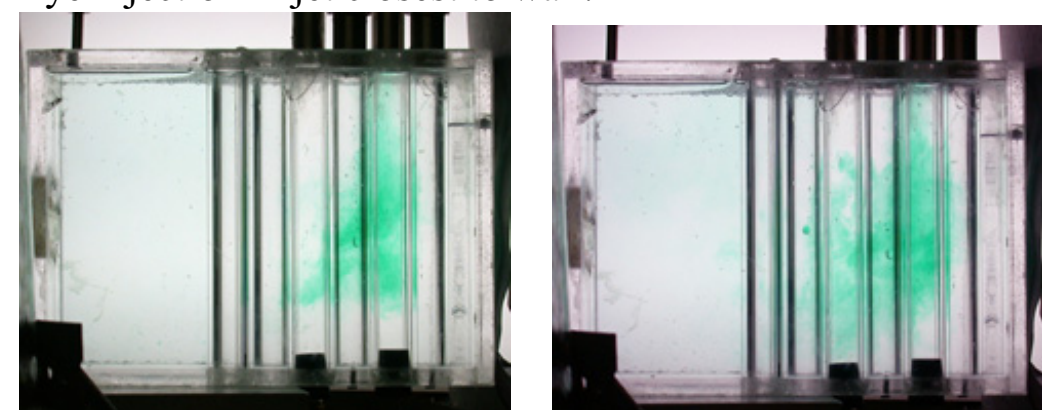

Dye injection in second jet from wall.
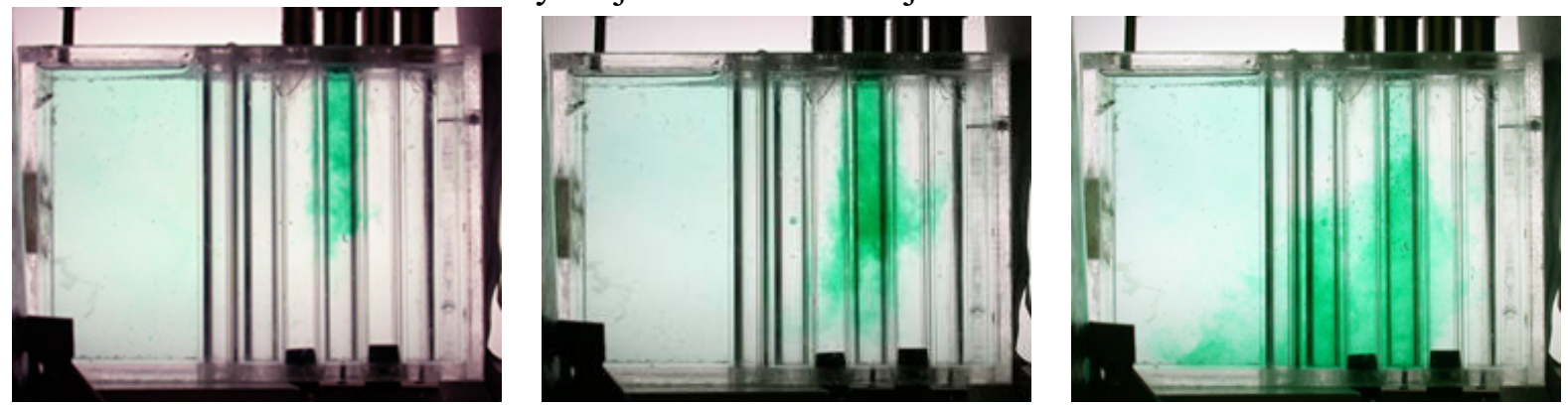

Dye injection in third jet from wall

Fig. 11. Sequential images of jet interactions revealed by flow visualization.

The flow situation simulated corresponds to some aspects of the lower plenum at the far side away from the outlet duct. Phenomena observed in the experiment include jet entrainment of fluid, jet attachment to the upstream wall possibly due to a Coanda effect, eddy formation in the lower and upper upstream corners of the channel, merging of jets, crossflow of fluid around posts and fluid recirculation near the front and rear walls. No indication of periodic eddy shedding downstream of posts was observed. These observations are consistent with the data and observations of Iwaki et al. [2004] who measured velocity fields for crossflow in tube bundles with rectangular and triangular pitches. Periodic eddy shedding was seen for flow in their rectangular geometry but not in the triangular case. 
In the present experiment, recirculation of fluid along the front and rear walls was caused by insufficient jet flow near the walls and is not expected to be prototypical. A conceptual sketch of apparent mean streamlines and spreading regions is presented in Figure 12 as our interpretation of the sequential images of Figure 11. The jets were not observed to impinge on the bottom surface before mixing with adjacent jets -- at least partially. This mixing between jets appeared to be enhanced by the flow across the posts. The experiment points to the importance of jet entrainment of fluid on the flow pattern and mixing phenomena.

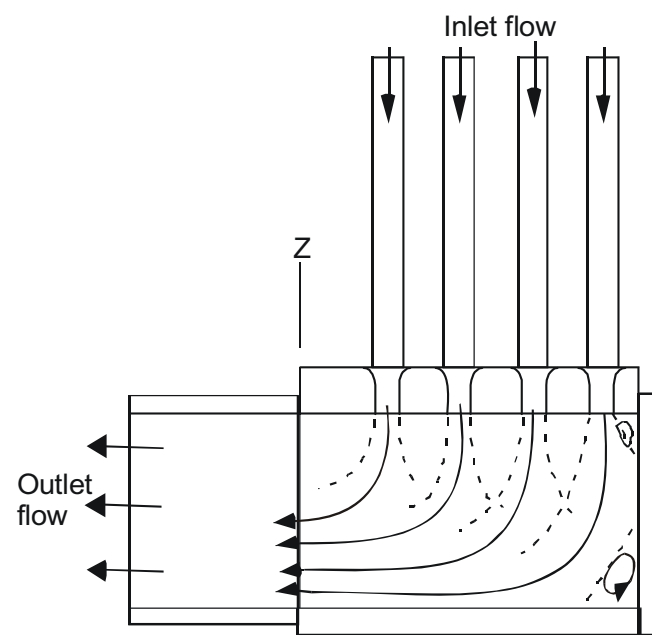

Fig. 12. Conceptual interpretation of experimental results presented in Figure 11.

\section{Fluid dynamics experiments for lower plenum}

The purpose of the fluid dynamics experiments is to develop benchmark databases for the assessment of CFD solutions of the momentum equations, scalar mixing and turbulence models for typical prismatic VHTR plenum geometry in the limiting case of negligible buoyancy and constant fluid properties. As indicated in the section on Scaling studies, in normal full power operation of a typical prismatic VHTR conceptual design, buoyancy influences should be negligible in the lower plenum. For reduced power operation they are expected to be negligible near the hot outlet duct where the "hot streaking" issue arises. Consequently, fluid dynamics experiments are expected to be useful beyond the limiting case.

\section{INEEL Matched-Index-of-Refraction flow system}

Unheated MIR (Matched-Index-of-Refraction) experiments are first steps when the geometry is complicated. One does not want to use a computational technique which will not even handle constant properties properly. The MIR experiment will simulate flow features of the paths of jets as they mix in flowing through the array of posts in a lower plenum en route to the single exit duct. Useful optical flow measurements in this realistic configuration would be impractical without refractive-index-matching.

The benefit of the MIR technique is that it permits optical measurements to determine flow characteristics in passages and around objects to be obtained without locating a disturbing transducer in the flow field and without distortion of the optical paths. With a transparent model 
of different refractive index than the working fluid, the optical rays can be refracted in such a manner that measurements are either impossible (e.g., cannot "see" the desired location) or require extensive, difficult calibrations. Thompson, Bouchery and Lowney [1995] demonstrated this situation conceptually when laser Doppler velocimetry is applied to a rod bundle; with refractive-index-matching the measurement and determination are relatively straight forward while without matching the beams may not cross to form the LDV measurement control volume at the desired focal length, if they cross at all. These ideas are demonstrated in Figure 13; another demonstration of the benefits of refractive-index-matching is shown in Figure 14 with a test model for an idealized ribbed annulus [McCreery et al., 2003] in our recent NERI project. The MIR technique is not new itself; Corino and Brodkey [1969] employed it to measure turbulence structure in a circular tube earlier. Recent applications of the technique include, but are not limited to, those of Durst, Jovanovic and Sender [1993], Parker and Merati [1996], Cui and Adrian [1997] and Becker et al. [2002].
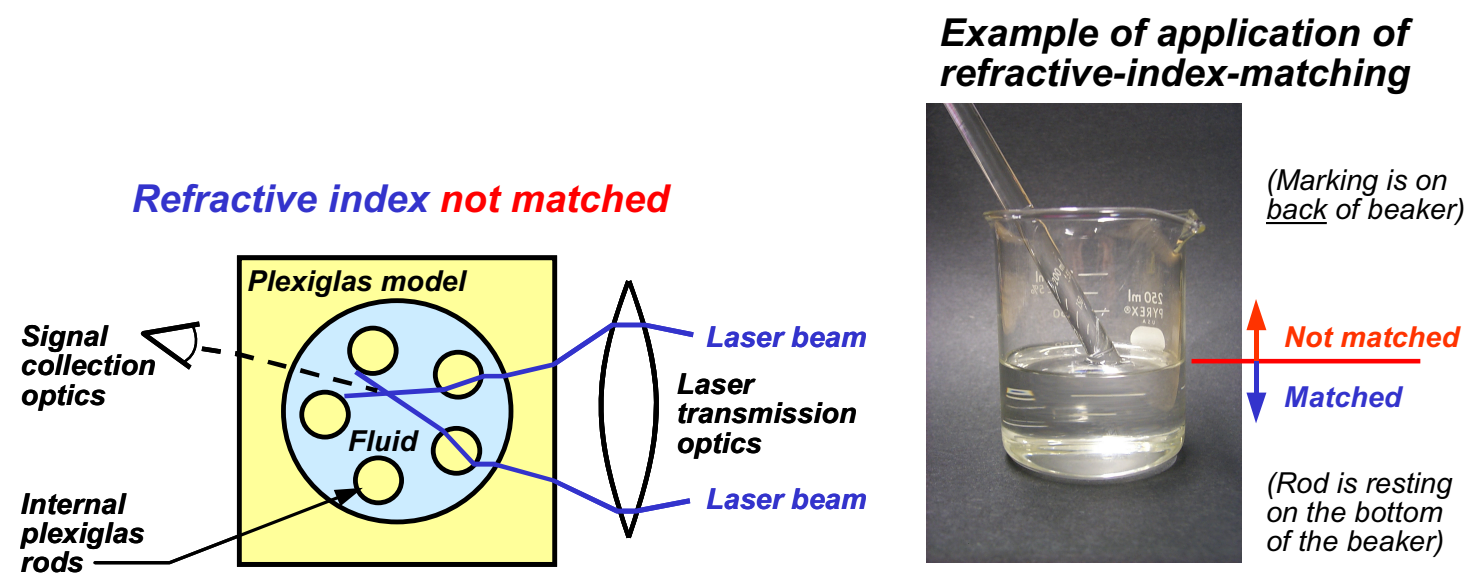

Fig. 13. The difficulties of optical fluid measurements without refractive-index-matching [Thompson, Bouchery and Lowney, 1995] and a simple demonstration of the benefits with transparent models having curved interfaces

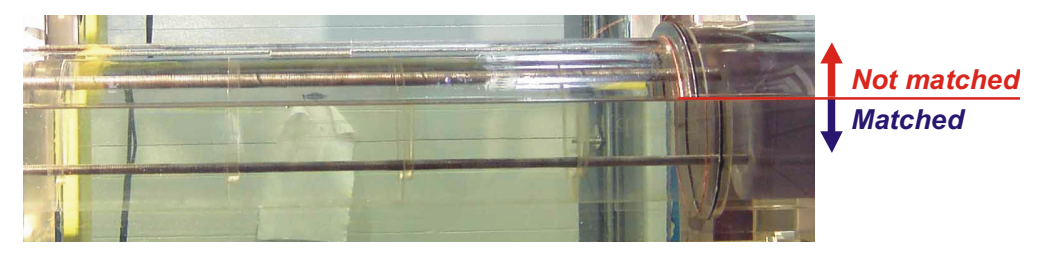

Fig. 14. A demonstration of the benefits of refractive-index-matching with a transparent model having curved interfaces (flow through a horizontal ribbed annulus of $164 \mathrm{~mm}$ diameter). Horizontal structural rods are steel and therefore opaque; the right end is plastic which is not matched.

The innovative advantage of the INL system is its large size, leading to improved spatial and temporal resolution compared to others. To date most other experiments with index matching have been small, with characteristic lengths of the order of five cm or less. In contrast, the INL MIR test section has a cross section of about $60 \mathrm{~cm} \times 60 \mathrm{~cm}$ and is about two meters long, allowing the use of models of substantial size (Figure 15). Since the system volume is over 
3000 gallons, a light mineral oil ("baby oil without perfume") was selected as the working fluid due to environmental and safety considerations; its refractive index matches that of some quartz. With the fluid temperature controlled, the quartz model can barely be seen at some wave lengths in the visible spectrum (e.g., Figure 14); indices are typically matched for the $532 \mathrm{~nm}$ green light sheet of a PIV laser or the blue or green beams of an argon-ion laser for an LDV. The design flow rate can give Reynolds numbers up to about $10^{5}$ based on the cross section of the MIR test section. The refractive index of the fluid is maintained at the desired value by a parallel temperature control system which maintains a constant temperature in the test section to within $0.1 \mathrm{C}$. In measurements in an experiment on transition induced by a square rib, meaningful velocity and turbulence data were obtained as close to the surface as $\mathrm{y}^{+}=\left(\mathrm{y} \mathrm{u}_{\tau} / \mathrm{v}\right) \approx 0.1$ and less [Becker et al., 2002].

Since the refractive index varies with temperature, it is necessary to conduct MIR experiments with a constant, uniform temperature in both any internal flow model and the external flow around it in the main test section. To maintain the flow through the model at the required temperature, a "Model (Auxiliary) Flow Loop Temperature Control System" (Figure 16) has been developed to be comparable in operation to the successful temperature control system for the main flow loop. It includes a heat exchanger to remove the energy introduced by the model loop pump, an electrical heater and its control for fine adjustment and a pump and flowmeter units. The temperatures of both the main loop and the model loop are controlled through a LabView program.

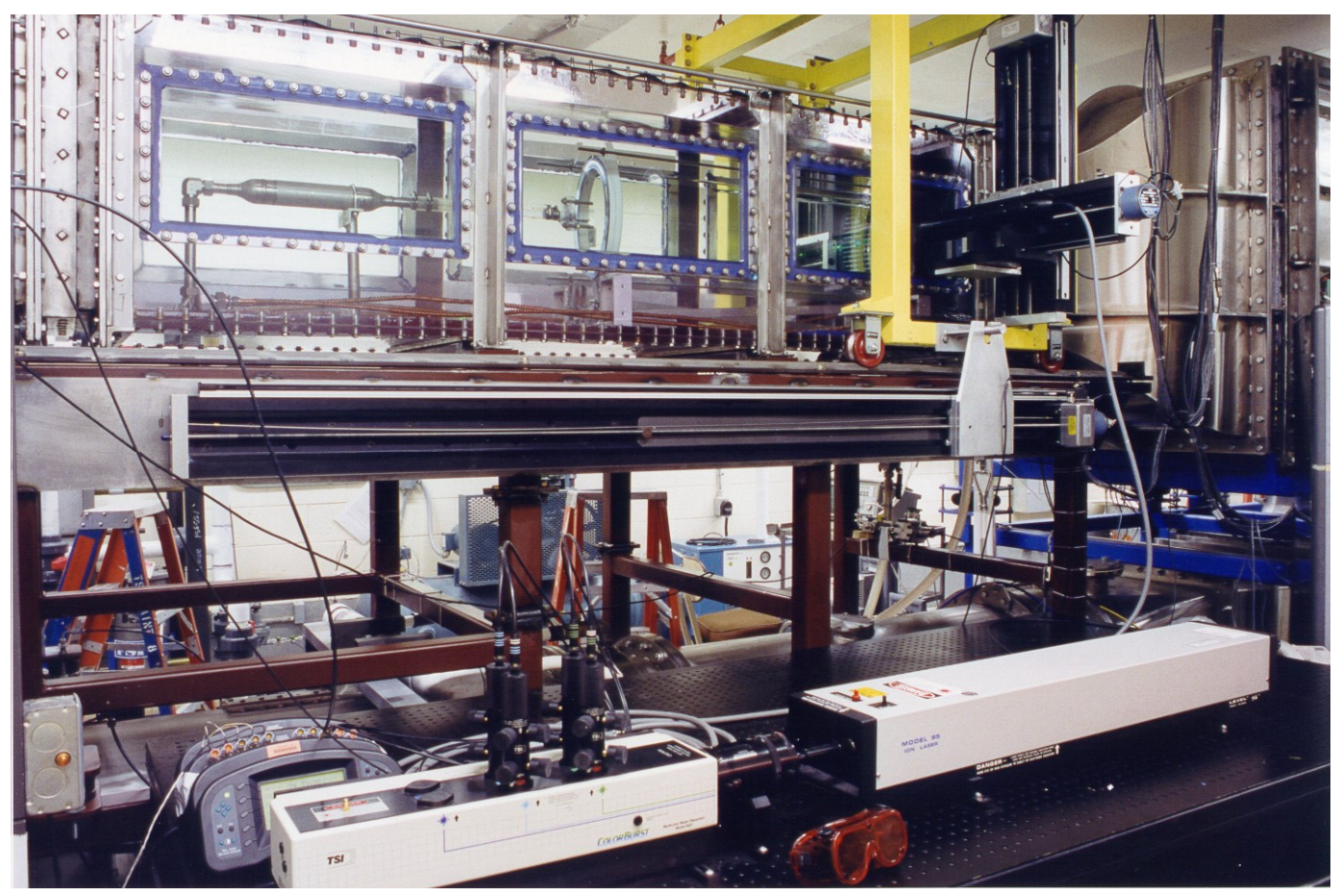

Fig. 15. The World's largest Matched-Index-of-Refraction flow system using laser Doppler velocimetry to study fluid physics phenomena in an idealized SNF storage canister for an EM Science project [Stoots et al., 2001; McCreery et al., 2002] 


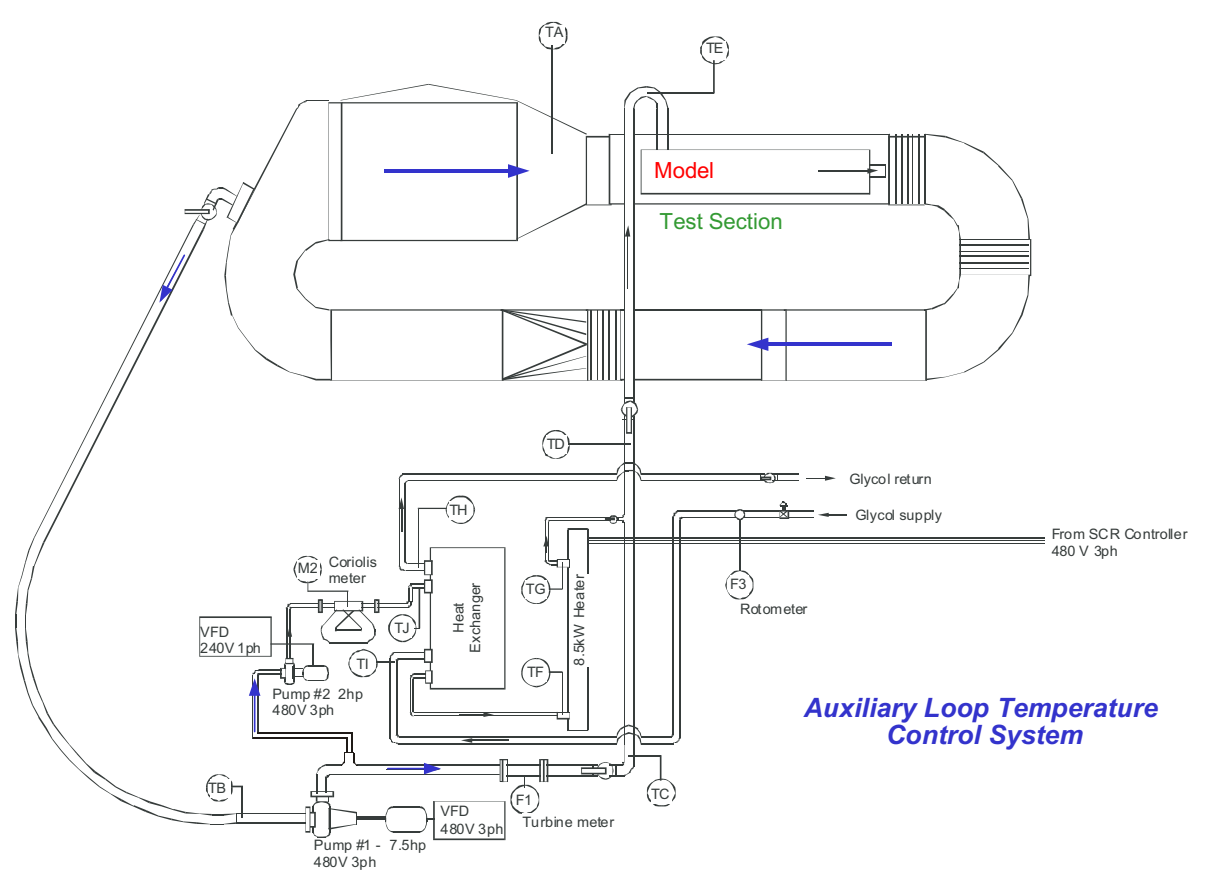

Fig. 16. Schematic diagram of temperature control system for typical internal flow experiment in INL Matched-Index-of-Refraction (MIR) flow system

Durst, Keck and Kleine [1979] have suggested that the refractive index must be maintained within \pm 0.0001 for high quality LDV measurements. For the mineral oil in the INL MIR system, this criterion translates to the requirement that the oil temperature must be held steady and uniform to within about $0.3 \mathrm{C}$; in general, we aim at a limit of about $0.1 \mathrm{C}$. Experience has shown that, after the initial transients, it is possible to maintain the test section temperature as close as about $\pm 0.02^{\circ} \mathrm{C}$ and the model temperature range to about $\pm 0.05 \mathrm{C}$, well within the desired limitations. It has been found that at the maximum model flow rate and room temperature of about $32^{\circ} \mathrm{C}(90 \mathrm{~F})$, the system could maintain the desired oil temperature of approximately $24^{\circ} \mathrm{C}(75 \mathrm{~F})$ to within about $\pm 0.08 \mathrm{C}$.

This versatile facility [Stoots et al., 2001] has been used for fundamental and applied measurements in a variety of recent research programs:

- Transition in boundary layers with the Lehrstuhl für Strömungsmechanik of Uni. Erlangen, Germany [Becker et al., 2002]

- Flow phenomena in SNF canisters for a DoE EM Science project [McCreery et al., 2002]

- Flow fields around buildings for assessment of Bechtel R\&D computer simulations for fate and transport of biological agents [McCreery et al., 2001]

- Effects of realistic surface roughness on turbomachinery flows with U. Idaho for the Air Force Office of Scientific Research [Budwig et al., 2001] 
- Complex flows relating to advanced gas-cooled nuclear reactors for the DoE NERI program [McCreery et al., 2003]

- Boundary layer interactions with synthetic jet actuators with U. Wyoming for the Air Force Office of Scientific Research [Shuster, et al., 2005]

Additional studies now include examination of complex flows relating to supercritical water reactors for the DoE US/Korea I-NERI program.

Flow field and turbulence measurements are primarily conducted by optical techniques: particle image velocimetry (PIV) and laser Doppler velocimetry (LDV). Also available is our three-dimensional particle tracking velocimetry (3D-PTV) system with a Moving Particle Tracking system (MPT). Both LDV and PIV (and PTV) have advantages. We consider them to be complementary approaches. Visualization of mean flows and instantaneous measurement of three velocity components are available via the PIV system. For flow visualization and for measuring mixing, the PTV may be useful. LDV gives time-resolved measurements. With the PIV (and PTV) one needs many realizations to deduce means and the higher-order moments. We apply LDV a point at a time; 3-D measurements are obtained by traversing (taking profiles) in three directions in turbulent flows that are steady in the mean. Provided the application can be considered to be at least quasi-steady (residence times quicker than other response times), useful data for assessment can be obtained from such steady flows. Typical results include timeresolved, pointwise distributions of the mean velocities, U, V, W, and their Reynolds stress components. With LDV, the time series are also available for spectral and wavelet analysis to investigate potential shedding of eddies from blunt bodies, such as support posts in a lower plenum.

The LDV system is a two-component, TSI fiberoptic-based laser Doppler velocimeter. Transmitting (and receiving) optics are provided by a Model 9832 two-component fiber optic probe with a lens of $350 \mathrm{~mm}$ focal distance. Included in the probe is a Model 9832-XX-Lens collimating lens option to reduce the measuring control volume; the diameter is estimated to be about $60 \mu \mathrm{m}$ in the MIR mineral oil. Signal analysis and data processing are accomplished via a Model S65-2 two component signal analysis system including a two-channel IFA 655 digital

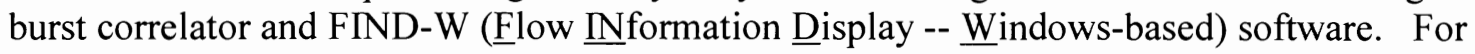
acquiring additional signals such as flow rate, temperature and hot-film measurements simultaneously, a TSI Model DL4 four-channel "Datalink" multichannel interface is available. Data acquisition is controlled via the FIND-W software for the LDV system. Desired traversing locations plus measuring parameters are specified by the operator and then the sequence is initiated or positions may be adjusted via manual control. Data reduction to determine mean quantities and/or spectra is accomplished later, using other FIND-W subprograms.

While the backscattering LDV mode [Durst, Melling and Whitelaw, 1976] is more convenient in operation, the validated data rate is much lower than when using forward scattering for the same conditions. To obtain statistically meaningful results, longer measuring times are required with backscatter than forward scatter. Since its low velocities lead to inherently "slow" characteristic times for flow phenomena in the MIR system, it is desirable to employ forward scattering to avoid longer measuring times than needed. The three-directional traversing mechanism was designed to use the LDV in the forward scattering mode and to avoid 
relative motion between the test section and the optics (Figure 15). For vertical motion, platforms on each side of the test section are moved simultaneously under precise computer control to maintain alignment of the transmitting and receiving optics. The position is determined with an "Accu-Rite" indicator with manufacturer's specifications of an accuracy of \pm 0.0001 inch or about $2.5 \mu \mathrm{m}$; its meter reads in increments of $2 \mu \mathrm{m}$. Indicated variation in position while the system is warming is about $5 \mu \mathrm{m}$. The positional accuracy becomes important in deducing the wall shear stress and the wall location from fitting measurements for $\mathrm{y}^{+}<\sim 3$. Thus, the absolute uncertainty of a position is of the order of $5 \mu \mathrm{m}$ but for positioning during a continuous traverse the relative positioning uncertainty is less.

The PIV system from LaVision, Inc. (Ypsilanti, Mich. 48197) can be used for twocomponent or three-component instantaneous and mean velocity component measurements in a two-dimensional laser light sheet. A vertical light sheet is provided by a dual cavity pulsed Nd:YAG laser from Big Sky Laser Technologies (Bozeman, Mont. 59715) -- with maximum powers of $120 \mathrm{~mJ} /$ pulse at $532 \mathrm{~nm}$ at a maximum pulse rate of $15 \mathrm{~Hz}$-- with adjustable light sheet optics. Minimum light sheet thickness is about one $\mathrm{mm}$. The lasers and optics are mounted on a two-directional traversing system under the MIR test section so that the light sheet can be positioned by a stepping motor to within $0.013 \mathrm{~mm}$ in the cross stream direction; its position is measured to within about $0.01 \mathrm{~mm}$ with a linear caliper. One or two cameras view the light sheet from mountings on the LDV traversing mechanism, giving 2-D and 3-D capability, respectively. The cameras are the LaVision "Imager Pro Plus 2M" model with $1648 \times 1214$ pixel resolution and 14-bit dynamic range with two-stage Peltier cooling and the possibility of better than $100 \mathrm{nsec}$ interframe time. Lenses with $50 \mathrm{~mm}$ and $105 \mathrm{~mm}$ focal lengths are available for "large" and "small" fields of view, respectively. The system computer is a dual processor PC with $\mathrm{P} 4$ processors having speeds of $2.8 \mathrm{GHz}$ and storage of $1 \mathrm{~GB}$ RAM, $120 \mathrm{~GB}$ and $300 \mathrm{~GB}$ internal hard drives, read/write DVD, $1.44 \mathrm{MB}$ floppy drive, an external $300 \mathrm{~GB}$ Maxtor OneTouch II hard drive and an external Sony AIT-1 tape drive for 91 GB tapes. A Windows XP operating system is employed. Software has both PIV and PTV algorithms and provides instantaneous and mean velocity components, turbulence statistics and velocity gradients across the image from the two-dimensional light sheet.

Also available is a moving particle tracking (MPT) system developed by Profs. R. S. Brodkey and Y. G. Guezennec at Ohio State. Equipment for the MPT technique includes a PCcontrolled camera system with variable focal length and directional control, mounted on a longitudinal traversing system. When held in a fixed position the MPT method reverts to the successful 3D-PTV (three-directional particle tracking velocimetry) technique of Profs. Guezennec and Brodkey [Guezennec et al., 1994 ]. The PTV technique is a subset of the PIV approach but uses lower particle concentrations to be able to follow individual particles [Adrian, 1991]. To characterize overall flow fields, flow visualization and related overall statistics can be derived from analysis of a large number of MPT records at the same inlet flow conditions. Typical results include mean streamlines and velocity vectors plus qualitative turbulence quantities corresponding to and extending those measured with the LDV system.

Further details of the MIR flow system are provided in a technical paper by Stoots et al. [2001] and on an INL web site (http://www.inel.gov/env-energyscience/physics/mir/). Estimated 
experimental uncertainties for LDV operation are summarized by Becker et al. [2002] and in a technical report by Condie, McCreery and McEligot [2001].

\section{Experiment concept}

Possible flow routes in the lower plenum of a typical prismatic VHTR concept are demonstrated in plan view in Figure 17. The large shaded circles represent support posts while the smaller ones identify locations of the inlet ducts from the cooling channels in the active core. Some bypass flow can also be expected to enter the lower plenum after passing vertically between the hexagonal graphite blocks both in the core and the reflectors. The arrows give intuitive examples of some paths the flow could be expected to take through the lower plenum from the far side to the outlet duct. In some regions the flow pattern would be comparable to crossflow over a triangular array of rods as in a shell-and-tube heat exchanger; in other locations the flow may tend along passageways formed by parallel rows of posts. The flow rate (or Reynolds number) increases from the right side of the figure to the left as more incoming jets participate.

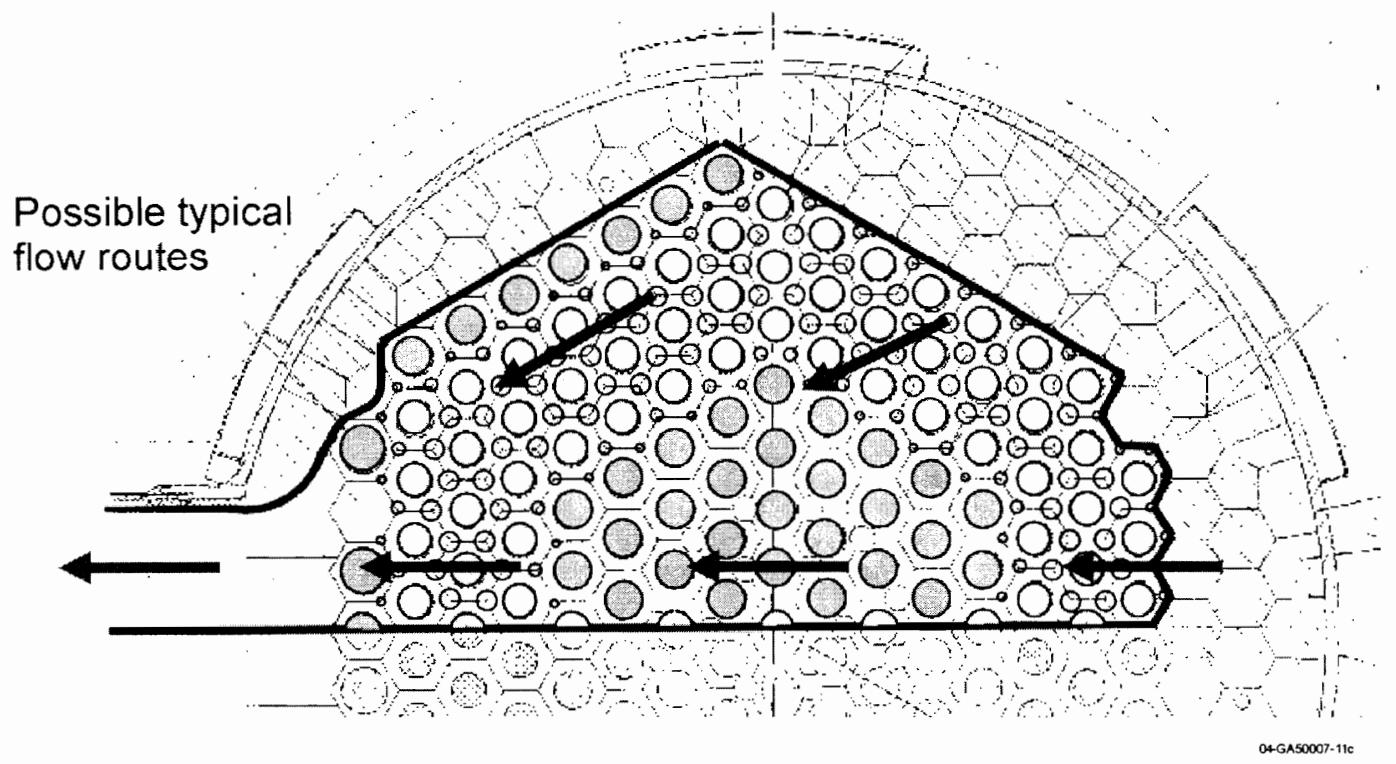

Fig. 17. Examples of some possible flow paths in the lower plenum of a typical prismatic VHTR concept.

Plenum studies are pertinent to pebble bed reactors as well as prismatic block versions (and GFRs and SCWRs) although the details of the designs can differ substantially.

Some general characteristics of a typical prismatic VHTR lower plenum and its flow during normal full power operation can be approximated as

- Geometry - array of short obstructing cylinders (posts)

array of momentum-driven jets from inflow upper and lower horizontal surfaces - "channel" some confining vertical walls 
"small" geometric ratios

"short" geometric transitions

- Inflow - heated, (partly) developed turbulent duct flow from core - becomes jets some "bypass" flows possible "cool" jets in central floor from Shutdown Cooling System "leaks"

- Lower plenum flow - turbulent or mixed flow regime negligible buoyancy, stabilization unlikely mixing of jets possible gas property variation possible vortex shedding from posts

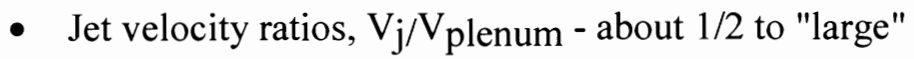
momentum-driven jets impinging/wall jets ---> crossflow

- Outflow - geometric convergence from channel flow to circular duct via 3-D nozzle shape laminarization unlikely

- Temperature (property) variation "hot (or cool) channel" flows from core thermal conduction in graphite thermal radiation across lower plenum

These characteristics are the ones we desire to represent in experiments to be used as benchmarks for the assessment of CFD codes and their turbulence models. Without full-scale experiments at prototypical conditions it is not anticipated that all will be represented in individual experiments; instead, a range of varied studies will be required. As noted in the Section on Experimental needs, data from a number of separate effects experiments appear to be available for initial assessment of the capabilities of CFD codes to handle some individual phenomena adequately. The proposed MIR studies are aimed at taking the next step = providing databases for some key coupled phenomena occurring, such as jet interactions with nearby circular posts and with vertical posts in the vicinity of vertical walls - with near stagnant surroundings at one extreme and significant crossflow at the other.

The primary benefits of refractive-index matching in physical models of lower plenum phenomena are to permit LDV measurements very close to the surface, where one laser beam passes through the transparent wall, as well as in the curved tubes and posts and to provide undistorted views for particle image velocimetry (PIV) and / or our 3D-PTV system. Key results will be visualization of the flow patterns, determination of mixing between jets and pointwise velocity and turbulence distributions.

Based on the scaling studies and general characteristics of a typical prismatic VHTR lower plenum and its flow, one may identify some desired features for idealized experiments aimed at assessment of CFD codes for VHTR applications (no order of priority implied): 
- Well-defined, idealized geometry; approximate geometric ratios as in typical VHTR concepts

- Obstructing posts

- Appropriate range of jet velocity ratios, $\mathrm{V}_{\mathrm{j}} / \mathrm{V}_{\text {plenum }}$

- Fully- or partly-developed turbulent flow in jet inlet channels, $\mathrm{L} / \mathrm{D} \approx 4$ and $\mathrm{Re}_{\mathrm{j}}>\sim 3500$

- Mixed turbulent flow in lower plenum for crossflow cases

- Limited domain to ease initial CFD modeling -- while retaining characteristic features

- Measurements (concentrating in important regions)

- U, V, W, $\mathrm{u}^{\prime}, \mathrm{v}^{\prime}, \mathrm{w}^{\prime}, \overline{\mathrm{u}} \overline{\mathrm{v}}$, etc. as functions of $\mathrm{x}, \mathrm{y}, \mathrm{z}$

- flow visualization

- mixing of passive scalars (particle tracking?)

- inlet flow quantities / profiles for entry boundary conditions

- Fit in existing MIR test section with optical access

- Hexagonal periodicity, streamwise periodicity for modelers

- Economical -- fabrication, labor, measurement matrix, etc.; reasonable cost

- Reasonable flow rates; accurate measurements

- Able to rotate for measurements in third direction

With the INL MIR flow system, the model flow loop will be used to provide the flow to the jets. As seen in Figure 16, this flow is driven by a pump with a $7.5 \mathrm{hp}$ motor. Unfortunately, it is anticipated that the total jet flow rate required in some experiment concepts by McEligot and McCreery [2004] would exceed the capability of this pump -- so two simplified concepts were considered for initial experiments instead (Figures 39 and 40 in the technical report by McEligot and $\mathrm{McCreery}$ ). More extensive or more prototypical models may be appropriate for later stages of the present project.

The first MIR lower plenum experiment will model flow across an array of posts near the outlet duct or in line with the duct centerline at the opposite side of the reactor as indicated by near horizontal arrows in Figure 17. A plan view is shown in Figure 18 with open circles representing the locations of jet inlets and cross hatching indicating the support posts, approximately to scale. (From these relative sizes, one may expect the crossflow in the plenum to interact with the incoming flow in the ducts, modifying the inlet profiles.) The drag on the sidewalls of the model will cause acceleration of the flow between the walls and the central posts 
as the (missing) jets at these wall locations would. With crossflow from the right, flow is simulated from across the central region of the lower plenum (below a central reflector) into the last rows of jets from the active core. For the region furthest from the outlet, a solid wall can be inserted at the position indicated by the dashed line. In this case, flow would be completely provided by the jets as at the simulated location. This latter configuration is comparable to the preliminary flow visualization model of Figure 10. This experiment design should satisfy most of the desired features mentioned above.

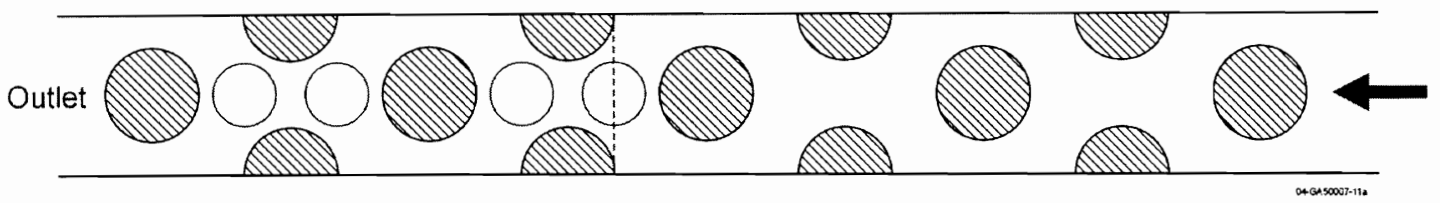

Fig. 18. Conceptual design of model for the anticipated first MIR lower plenum experiment (plan view).

The final test matrix will be developed interactively in collaboration with investigators who will be conducting the related numerical analyses. Throughout the experimental phase, the resulting data will be provided to these collaborators as soon as they become available. These data will assist in the development of necessary models and mesh structure in the numerical analyses as well as giving the bases for code assessment. The results of the numerical predictions by the collaborators will, in turn, be used for guidance in selection of test conditions, measuring locations and additional data needed. This "real-time" interactive collaboration will be particularly useful so that synergistic progress will be made in both experimental and analytical phases.

In addition to documentation of the experiment and the results of the measurements by technical papers, by presentations at technical meetings and by technical reports for more detail, the data will be stored in electronic form for ease of comparison by computational fluid dynamists using other codes. The format of the electronic data storage will be developed interactively in collaboration with the CFD investigators in the course of the comparison tasks of the proposed work.

\section{Experiment design}

The objective of the present report is to document the design of our first experiment to measure generic flow phenomena expected to occur in the lower plenum of a typical prismatic VHTR concept. In the process, fabrication sketches will be provided for the use of CFD analysts wishing to employ the data for assessment of their proposed codes (Appendix A).

The first experiment addresses flow in the region on the central plane away from the plenum outlet duct as shown on the right-hand side of Figure 17. Conceptually, there is no significant flow from the outer reflector (except some bypass flow from between the prismatic blocks) and the dominant flow comes from the jets issuing from short coolant ducts at the corners of the hexagonal blocks ("corner channels" -- Figure 9). The main plenum crossflow evolves from these jets in the active core and then passes below the central reflector which lacks the corner coolant ducts (i.e., no additional jet inflow). The configuration is comparable that of 
the preliminary flow visualization experiment (Figures 10 and 11). The second experiment will examine phenomena for the region near the outlet of a plenum where there is significant upstream crossflow as in the left-hand side of Figure 17; currently, it is planned to initiate the second experiment during FY-06. The main difference between the two situations is the ratio

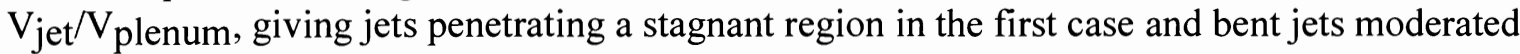
by the posts in the second. The model has been designed so that it should be possible to use it for both experiments.

Figure 19 provides a schematic overview of the experimental apparatus as it will be mounted with the MIR test section. The subfigure on the left demonstrates the inlet flow system (for the jet inlet ducts simulating "corner channels") relative to the MIR frame, PIV light sheet and LDV carriage viewed from the upstream end of the MIR test section. As shown in the righthand figure, up to four inlet jets will be accommodated with individual control and flow metering. The choice of four jet inlet ducts is consistent with the number near the centerplane in Figure 17 with three rings of hexagonal blocks in the active core. Flow will pass from the existing "Auxiliary (model) loop temperature control system" (Figure 16) to the inlet manifold and then to four individual control valves. Temperature and pressure drop instrumentation is provided. Two inlet flow conditioning blocks provide flow to two jet inlet ducts each. Current plans are to exhaust the flows from the jets through the model and into the main channel flow at the downstream end of the model.
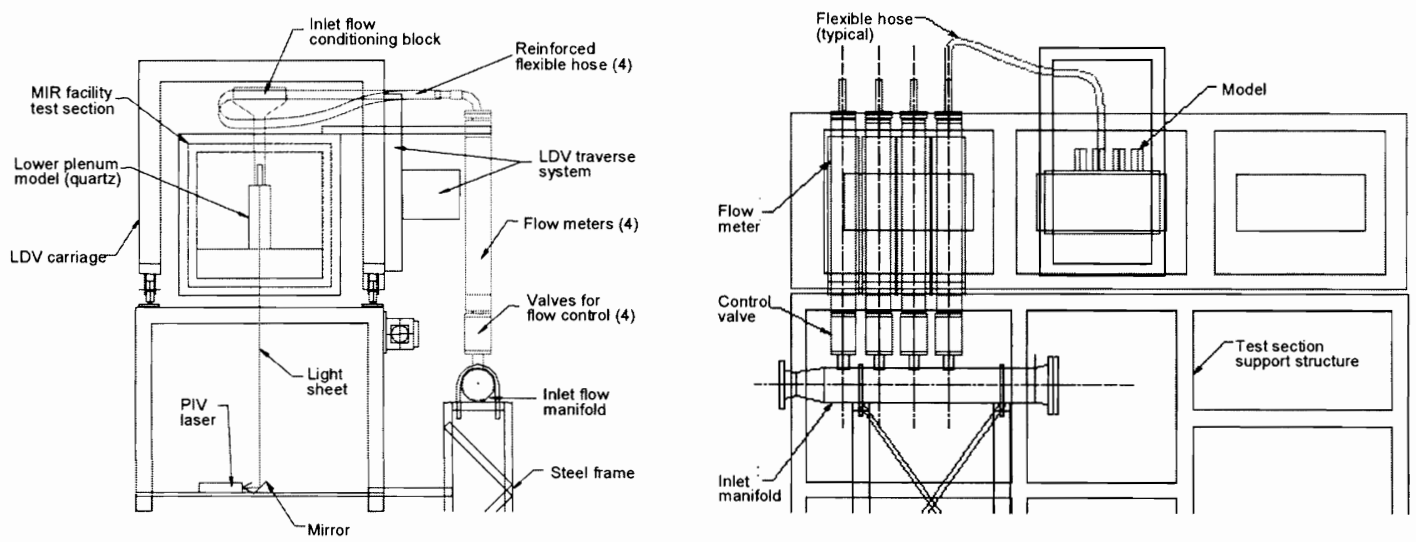

Fig. 19. Overview of MIR test section demonstrating planned arrangements of model, model flow system and instrumentation: (a) end view looking downstream and (b) side view with flow from left to right.

\section{Model}

The model is scaled to the geometric dimensions of the NGNP Point Design [MacDonald et al., 2003] as an example of a typical prismatic VHTR. Desired features of the model are listed in the earlier section entitled "Experiment concept." The maximum model size was constrained by the vertical range of optical access through the MIR windows. It is desired to measure the vertical velocity component from the lower inner surface of the model into the jet inlet ducts at the top; the latter position allows determination of the entering jet profiles for CFD analysts. It is also desired that the PIV camera be able to record in a single frame the full vertical extent 
between the inner horizontal surfaces. With a desired height-to-diameter ratio of about seven, these constraints led to a post diameter $D_{p}$ of 1.25 in. $(31.8 \mathrm{~mm})$. The resulting nominal dimensions are

$$
\left(\mathrm{p} / \mathrm{D}_{\mathrm{p}}\right)=1.7,\left(\mathrm{H}_{\mathrm{plenum}} / \mathrm{D}_{\mathrm{p}}\right)=6.85 \text { and }\left(\mathrm{D}_{\mathrm{jet}} / \mathrm{D}_{\mathrm{p}}\right)=0.7
$$

The model consists of a row of full circular posts along its centerplane with half-posts on the two parallel walls to induce flow features somewhat comparable to those expected from the staggered parallel rows of posts in the reactor design. The posts and half-posts form an equilateral triangular pattern as in supporting a core consisting of hexagonal blocks. Posts, side walls and end walls are fabricated from quartz to match the refractive-index of the working fluid. A photograph of the model with one inlet block mounted is shown in relation to a code developer in Figure 20. In addition to the circular posts a wedge-shaped quartz element has been fabricated to block the channel by replacing a post; it simulates the plenum wall formed by the outer reflector and is temporarily located in the center of the model in the photograph (in the experiment it will be mounted at the upstream end).

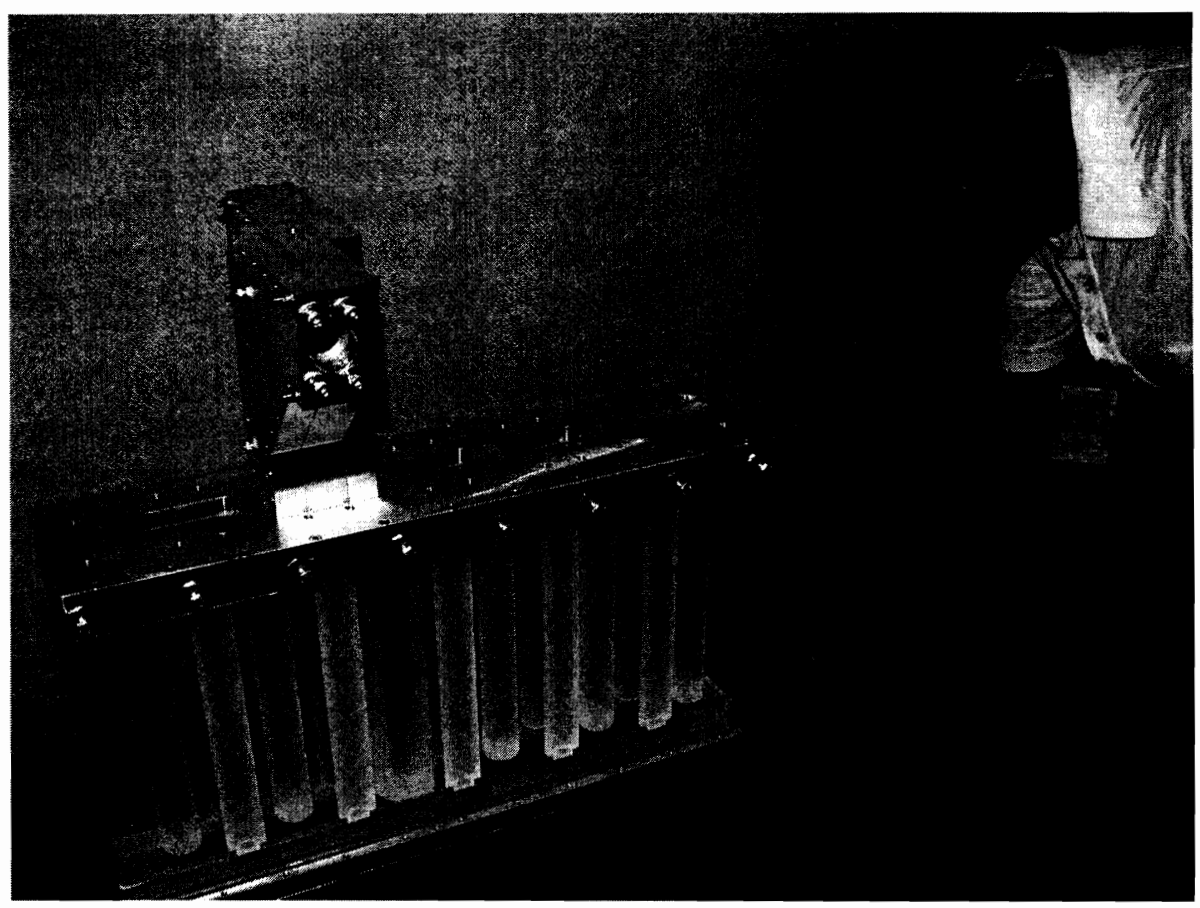

Fig. 20. Demonstration of size of MIR model assembled with one jet inlet block mounted.

Figure 21 provides a plan view of the post and jet inlet locations in terms of the fabrication sketch for the upper wall. The posts appear as the larger circles with single inner circles where their anchoring ends are located. Comparable half posts at the side walls appear as half circles. The smallest circles represent the jet inlets with two circles around them for o-ring grooves and the inside of the larger flow conditioning tube beyond the jet inlet ducts. The wedge at the righthand side simulates the corner of a hexagonal support block for the outer reflector. Further details and specified dimensions of the model and its components are provided in Appendix A. 


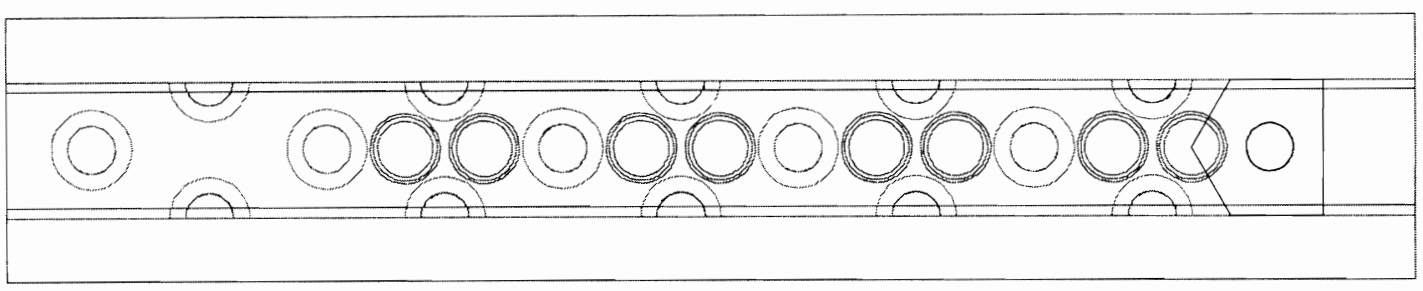

Fig. 21. View of top wall of model showing locations of posts and jet inlet ducts ("corner channels").

\section{Approximate analyses}

Several desired features determine the ranges of oil flow rates (and flow meters) required in the experiments:

- Jet velocity ratio: $0.5<\left(\mathrm{V}_{\text {jet }} / \mathrm{V}_{\text {plenum }}\right)<$ "large"

- Turbulent flow in jet inlet ducts

- Inlet crossflow in second experiment in "mixed flow" or "turbulent regime [Zukauskas, 1972]

For the first experiment, maximum jet flow rates will be limited by the capacity of the existing pump for the model flow system, by the number of jets and by the flow resistance of the jet supply system. The nominal diameter of the jet entry ducts is $7 / 8 \mathrm{in} .(22.2 \mathrm{~mm})$ for $\left(\mathrm{D}_{\mathrm{jet}} / \mathrm{D}_{\text {post }}\right)$ $=0.7$ and the 1.25 inch posts.

The first experiment has no imposed crossflow at the jet nearest the wall formed by the simulated outer reflector (i.e., the "wedge" element) so it corresponds to the condition that $\left(\mathrm{V}_{\text {jet }} / \mathrm{V}_{\text {plenum }}\right)$ be "large." The key requirement becomes having turbulent flow in the jet inlet ducts. With a "grid" to induce turbulence at the duct entry, it is expected that a Reynolds number of 3500 to 4000 (based on diameter) will reliably give sustained turbulent flow. At an oil temperature of $\mathrm{T} \approx 23.2^{\circ} \mathrm{C}$-- to match the refractive indices at the $532 \mathrm{~nm}$ wave length of the pulsed Nd:YAG laser for the PIV system -- the kinematic viscosity is $v \approx 1.42 \times 10^{-5} \mathrm{~m}^{2} / \mathrm{sec}$ $\left(0.549 \mathrm{ft}^{2} / \mathrm{hr}\right)$. At $\operatorname{ReD} \approx 4000$, a mean velocity of about $2.6 \mathrm{~m} / \mathrm{sec}(8.4 \mathrm{ft} / \mathrm{sec})$ and a flow rate of about $9.91 \times 10^{-4} \mathrm{~m}^{3} / \mathrm{sec}\left(126 \mathrm{ft}^{3} / \mathrm{hr} \approx 16 \mathrm{gpm}\right)$ will be needed for each jet entry duct.

Currently, the maximum flow rates possible are estimated to be about $0.003 \mathrm{~m}^{3} / \mathrm{sec}$ ( $48 \mathrm{gpm}$ ) per jet entry, giving $\mathrm{Re}_{\mathrm{D}} \approx 12,000$ [McCreery, 2005].

For the second experiment, the requirement that $0.5 \approx\left(\mathrm{V}_{\mathrm{jet}} / \mathrm{V}_{\text {plenum }}\right)$ corresponds to flow near the outlet duct. The required value of $V_{j}$ et then depends on the Reynolds number necessary for the upstream crossflow to be in the "mixed flow" regime in the model. While transition data are available for infinite arrays of long, closely-packed rods [Zukauskas, 1972], it is not clear that they are valid for the confined geometry of this model design. Therefore, one question evolving in the design of the experiment flow systems is how high the Reynolds number must be in the scaled model to provide the flow regime expected with crossflow in a prismatic VHTR lower plenum. To answer this question for the basic flow without jet inflow, a small subcontract 
was issued to Prof. Barton L. Smith of Utah State University. He replicated the geometry of our model in slightly larger scale (about 1.6 times). Using laser-based PIV with seeded airflow, he measured instantaneous velocity and turbulence fields.

The data of Prof. Smith also include two-dimensional mean and turbulence distributions from the PIV system and pressure drop data to deduce the hydraulic resistance K over a range of flow rates with Reynolds numbers from 240 to 56,000. Here the Reynolds number is based on the definition used by Zukauskas, $\mathrm{Re} Z u=V_{\max } \mathrm{D}_{\text {post }} / \mathrm{v}$, with $\mathrm{V}_{\max }$ being the bulk velocity at the minimum cross section. Results have been reported in a technical report [Smith, 2005] and some examples are posted on his web site (www.mae.usu.edu/faculty/bsmith/EFDL/array/ Array.html). These results are also valuable for assessment of CFD codes. Based on evaluation of his data, he categorizes the flow regimes to be expected in the crossflows of the INL MIR model approximately as

a) steady laminar, $\operatorname{Re} \mathrm{Zu}<400$,

b) unsteady laminar, $400<\operatorname{Re} \mathrm{Zu}<510$,

c) mixed partially-turbulent $600<\mathrm{ReZu}<1900$ and

d) mixed turbulent, $1900<\mathrm{ReZu}<56,000$.

The mixed turbulent flow regime describes the case where a laminar boundary layer remains on the upstream face of a post but the flow is otherwise turbulent.

For $\mathrm{ReZu}=2000$ in the INL MIR model, $\mathrm{V}_{\max } \approx 0.89 \mathrm{~m} / \mathrm{sec}(2.9 \mathrm{ft} / \mathrm{sec})$ so at $\left(\mathrm{V}_{\text {jet }} / \mathrm{V}_{\text {plenum }}\right) \approx 0.5$ the jet velocity would be $\mathrm{V}_{\mathrm{j}} \approx 1.8 \mathrm{~m} / \mathrm{sec}(5.8 \mathrm{ft} / \mathrm{sec})$. However, a jet velocity of about $2.6 \mathrm{~m} / \mathrm{sec}$ is needed to ensure turbulent flow in the jet inlet duct so, for the condition $\left(\mathrm{V}_{\text {jet }} / \mathrm{V}_{\text {plenum }}\right) \approx 0.5$, a higher plenum velocity and Reynolds number will be needed. For a corresponding plenum velocity of $5.1 \mathrm{~m} / \mathrm{sec}(16.8 \mathrm{ft} / \mathrm{sec})$, the Reynolds number ReZu would be about $1.1 \times 10^{4}$ and the oncoming crossflow would be in the mixed turbulent regime. At $\mathrm{ReZu}=2000$ for the plenum and $\mathrm{Re}_{j e t}=4000$, a ratio $\left(\mathrm{V}_{\mathrm{jet}} / \mathrm{V}_{\text {plenum }}\right) \approx 2.9$ would be obtained and at higher ratios the requirement of mixed turbulent flow in the plenum would be determining (i.e., minimum $\mathrm{ReZu}>1900$ or so).

\section{Jet inlet system}

For a typical lower plenum for a prismatic VHTR concept, the flow from the coolant channels is collected in short ducts at the corners of the hexagonal blocks as shown in Figure 9 ("corner channels"). The flows from the coolant channels are fully-turbulent and have approximately the same bulk velocities. A design goal for the jet inlet ducts is to simulate this situation so that the jets formed will have flow features comparable to those in a typical prismatic VHTR. Accordingly, aims for the design include an approximately uniform velocity with a "high" turbulence level and no significant swirl at the entry to a jet inlet duct (about four diameters from its exit into the plenum). At least four ducts/jets are desired; one will have twothirds the cross section of the others to represent flow along an external corner of a hexagonal confining block supporting an outer reflector ("two-hole corner channel"). Other desired features include 
- Separate flow control for individual jets

- Individual flow measurement to within one per cent of measured flow rate or better

- Temperature sensing and control for refractive-index matching

- "Low" flow resistance to enable "high" jet flow rates

- Simplified geometry for computer code representation

- Appropriate symmetry

- Capability to introduce PIV seeding particles into individual jet flows

The close spacing of pairs of jet inlet ducts led to design of "inlet flow conditioning blocks" as shown in Figure 19. One such block appears in the photograph of Figure 20. Reinforced flexible hose connects the variable area flowmeters to the blocks (Figure 19). A tubular hole is machined into the block to redirect the horizontal flow from the hose to the vertical inlet duct; it has a gentle curve of large radius plus a central vane to reduce secondary flow induced by the bend. A position for a thermistor to measure the inlet temperature is located in line with the leading edge of the central vane. In the vertical flow conditioning section are a honeycomb, a screen and a turbulence-generating grid (another screen). The honeycomb is intended to reduce any swirl or secondary flow. The purpose of the screen is to reduce distortions in the mean velocity profile coming from the honeycomb. The second screen will reduce distortions of the mean velocity profile further while increasing the turbulence level locally at the entrance to the jet inlet duct.

Approximate analyses and correlations were employed to predict the effects of the honeycomb and screens quantitatively and to relate the jet flow rate to the pressure drop required. Predictions were made primarily for two jet Reynolds numbers, Rejet $=6000$ and 10,000 , for the variety of screen sizes available.

Analyses by Prandtl [1933] and by Taylor and Batchelor [1949] consider the effect of a general flow resistance on a sinusoidal mean flow disturbance passing through it. They also treat effects on isotropic turbulence but we are not concerned with reducing turbulence here. For a mean flow $\mathrm{U}$ with a disturbance of the form $\mathrm{u}=\mathrm{u} 1 \cos \{$ py $\}$ they predict

$$
\left(\mathrm{u}_{2} / \mathrm{u}_{1}\right) \approx \mathrm{fn}\{\mathrm{K}\}=(1+\alpha-\alpha \mathrm{K}) /(1+\alpha+\mathrm{K})
$$

where $\mathrm{u}_{2}$ is the amplitude of the disturbance downstream of the resistance, $\mathrm{K}=2\left(\mathrm{p}_{1}-\mathrm{p}_{2}\right) /\left(\rho \mathrm{U}^{2}\right)$, and $\alpha$ is the change in angle of the flow due to the resistance (screen). They suggest that $\alpha \approx 1.1(1+\mathrm{K})^{-1 / 2}$. Conceptually, this relation could be applied to honeycombs as well as screens.

Quantitative treatments of honeycomb performance are limited. Lumley [1964; Lumley and McMahon, 1967] analyzed the effect of a honeycomb on a turbulent stream and the turbulence produced by a honeycomb but he was primarily concerned with the reduction of turbulence. Loehrke, Nagib and coworkers [1976; Wigeland, Ahmed and Nagib, 1978; TanAtichat, Nagib and Loehrke, 1982] examined control of turbulence and swirl by honeycombs and screens. 
If the thickness of the honeycomb material is small compared to the cell openings, the Reynolds numbers in the cells can be related to the circular tube upstream as

$$
\operatorname{Re}_{H}=\left(\mathrm{G} \mathrm{Dh}_{\mathrm{h}} / \mu\right)=\operatorname{ReD}\left(\mathrm{Dh}_{\mathrm{h}} / \mathrm{D}\right)
$$

where $\mathrm{Dh}$ is the hydraulic diameter of the cells and ReD is the Reynolds number in the upstream tube based on its diameter. For a hexagonal honeycomb its hydraulic diameter is equal to the distance between opposite flat surfaces. In the present design, the diameter in the flow conditioning section is slightly larger than the jet inlet duct so its Reynolds number is lower and Rejet is approximately nine times larger than $\mathrm{ReH}_{\mathrm{H}}$. Consequently, if the flow in the honeycomb became fully-developed, it would be expected to be laminar.

With a thin honeycomb wall, friction may dominate the pressure loss rather than the contraction and expansion losses. For laminar flow in a duct, the velocity profile approaches being fully-developed for $\mathrm{L}^{+}=(\mathrm{L} / \mathrm{Dh}) / \mathrm{ReDh}$ of the order of 0.1 or so. Loehrke and Nagib [1976] concluded that their experiments involved laminar flow and that, in most cases, it was still developing at the honeycomb exit. In the present design, $\mathrm{L}^{+}$is about 0.015 for $\mathrm{Re}_{\mathrm{jet}}=4000$ and less for higher flow rates. Correlations for resistance coefficients for developing flow in honeycomb passages are not generally available as such. While the friction factors for fullydeveloped flow differ with cross sectional shape, at small distances from the leading edge the boundary layer development is approximately the same despite the shape of the cross section. Consequently, for round tubes [Bankston and McEligot, 1970], parallel plates [Schade and McEligot, 1971] and square ducts and equilateral triangles [Shah and London, 1978], the initial variation of $K\left\{L^{+}\right\}$is very close as shown in Figure 22. Shah and London [1978] made a comparable observation in terms of the apparent friction factor for developing laminar flows in ducts [Shah and Sekulic, 2003, Figure 7.21]. As a first approximation, Figure 22 (or Equation 7.94 of Shah and Sekulic with some rearrangement) can be used to estimate the pressure drop caused by a short honeycomb. This approach actually gives reasonable agreement with the pressure drop data of Loehrke and Nagib.

The mean velocity profile immediately downstream from a honeycomb varies from near zero in the wakes of the cell walls to the maximum in the center of the cell passage. In the worst case for a circular tube, this variation is $0<(\mathrm{u}\{\mathrm{r}\} / \mathrm{Vb})<2$ for fully-developed flow. Thus, the disturbance $\left(\mathrm{u}_{2} / \mathrm{Vb}_{\mathrm{b}}\right)$ can be as large as unity. For conservative estimates, we selected this value.

To apply the relation of Taylor and Batchelor [1949] to flow through screens or grids, one needs data or correlations for K, the resistance coefficient. Laws and Livesey [1978] have reviewed this topic. Brundrett [1973] provides a correlation for $\mathrm{f}\left\{\operatorname{Re}_{\mathrm{d}}\right\}$ which, in conjunction with a function of the screen solidity, predicts $\mathrm{K}$. His correlation shows good agreement with the data of Groth and Johansson [1988] and others -- so we have employed it. 


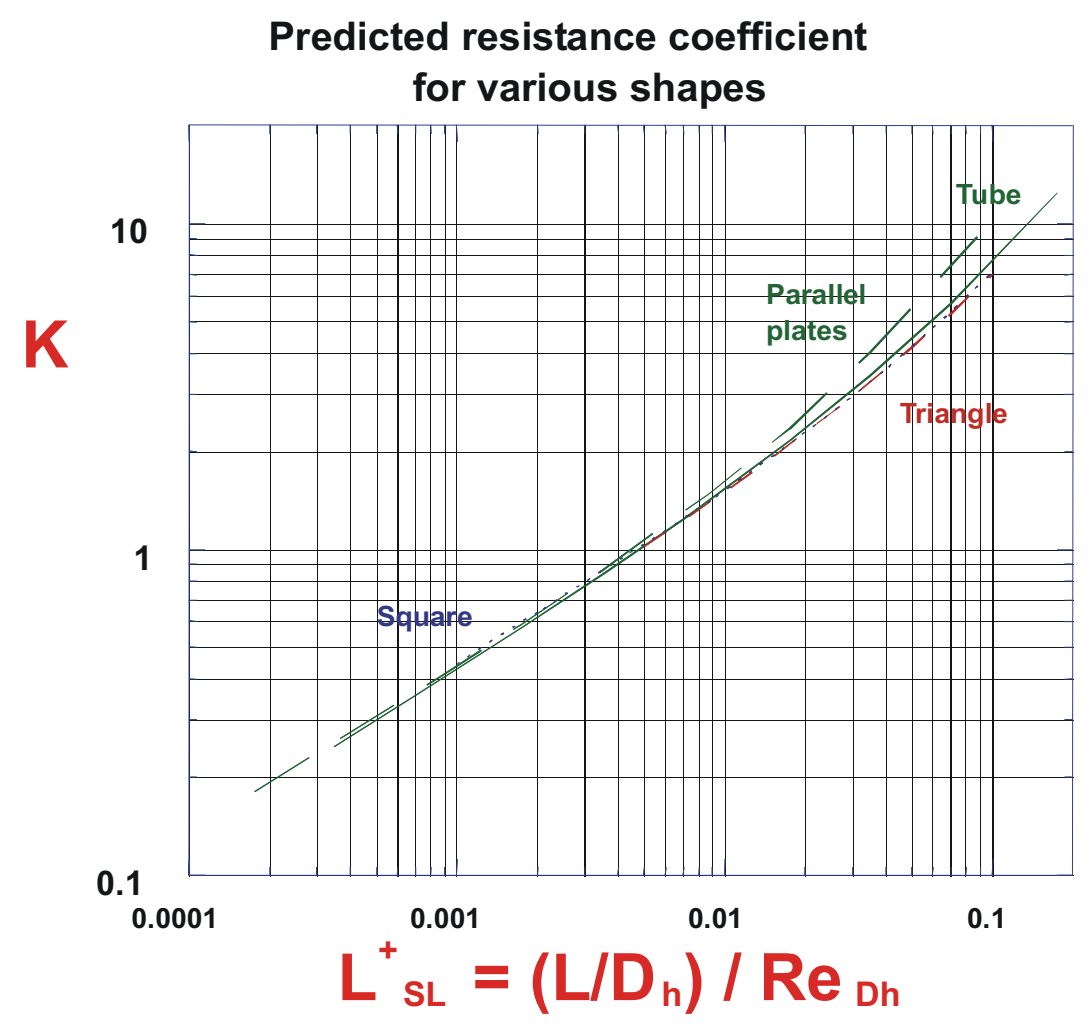

Fig. 22. Predicted resistance coefficients in short ducts of various shapes [Bankston and McEligot, 1970; Schade and McEligot, 1971; Shah and London, 1978].

From the flow conditioning tube to the jet inlet duct, the diameter is reduced. We used the growth of a Blasius boundary layer [White, 1984] as a criterion for the distance between the first screen and the contraction where the turbulence generating grid is placed. For the lowest Reynolds number, we required the boundary layer thickness growing in the tube to be less than the step height at the contraction. This approach is aimed at having the more-uniform core flow impinge on the entrance to the jet inlet duct and a reduction in the effect of the lower velocities in the boundary layer. A recirculating stagnation region should form ahead of the step.

As with turbulence, the mean velocity disturbance downstream of the screen should decay. For example, Schlichting [1960, pp. 604-605] shows that, for a parallel row of bars, the disturbance should decay as $1 / x$. From his analysis and the experiments of GranOlsson, he developed a relation for the decay of the disturbance beyond four mesh lengths $M$ downstream of the bars. To estimate the disturbance approaching the turbulence-generating grid, at $(\mathrm{x} / \mathrm{M})=4$ we set $\left(\mathrm{u} / \mathrm{V}_{\mathrm{b}}\right)$ equal to $\left(\mathrm{u}_{2} / \mathrm{V}_{\mathrm{b}}\right)$ from the first screen (probably conservative) and then assumed that it would decrease as $1 / \mathrm{x}$ (possibly optimistic).

For the turbulence-generating grid, we applied the relation of Taylor and Batchelor [1949] with the correlation of Brundrett [1973] to estimate the resulting mean velocity disturbance to be expected downstream at the entrance to the jet inlet duct.

Groth and Johansson [1988] measured turbulence behavior for wide ranges of mesh sizes and screen wire-diameter Reynolds numbers. For a "supercritical" screen (defined as $\mathrm{Re}_{\mathrm{d}}>40$ ), 
turbulence intensity on the downstream side is higher than it would be without a screen. This result is due to vortex shedding from the wires and the wire-wake shear layers which give rise to high-intensity-small scale turbulence. Thus, a design requirement for the second screen (turbulence-generating grid) is that $\mathrm{Re}_{\mathrm{d}}>40$ for its wires.

The above reasoning was applied via a spread sheet calculation for a variety of combinations of available screen meshes with the honeycomb chosen. The honeycomb is fabricated from Type 304 stainless steel with hexagonal cells 1/8 in. ( $3 \mathrm{~mm}$ ) across and wall thickness of 0.004 in. $(0.1 \mathrm{~mm})$. Length is 0.8 in. $(20 \mathrm{~mm})$. Based on the predictions, we chose stainless steel meshes B-CX-10 and B-CX-16 from Small Parts, Inc., (Miami Lakes, Fla. 330140650) for the first screen and the turbulence grid, respectively. The number in the mesh designation is the number of wires per inch or per $25.4 \mathrm{~mm}$; wire diameters are specified as 0.025 in. for B-CX-10 and 0.018 in. for B-CX-16. The estimated disturbance amplitude after the turbulence grid is about three per cent at $\mathrm{Re}_{j e t}=6000$ and four percent at $\mathrm{Re}_{j} \mathrm{et}=10,000$ while the predicted pressure drop at the higher flow rate is about fourteen psi $(0.9 \mathrm{~atm})$. The wire Reynolds numbers $\mathrm{Re}_{\mathrm{W}}$ of the grid are estimated to be about 120 and 210 for these two flow rates.

Ultimately, the validity of these estimates for flow conditioning will be determined by PIV and/or LDV measurements in the jet inlet ducts during operation of the experiment.

\section{Jet inlet supply system}

An overview of the "Jet inlet supply system" is shown in Figure 19. It distributes controlled, metered flow from the existing "Auxiliary loop temperature control system (Figure 16) to the "Inlet flow conditioning blocks" mounted on the model. Additional details are sketched in Appendix A.

Distribution is accomplished via a manifold and individual ball valves to which the four flowmeters are mounted vertically. The valves are adjusted manually for flow control. Six positions are provided on the manifold for possible future experiments but only four are needed for the first experiment.

Variable-area flowmeters from Flowmetrics, Inc. (Chatsworth, Cal. 91311), part number 2600VF8KVY-P08, provide flow measurement. These flow meters are calibrated for our approximate operating conditions by the manufacturer to within one-half per cent of reading. The effective flow range is 2.5 to $60 \mathrm{gpm}$ of mineral oil.

From the flowmeter the oil flows through a ninety degree elbow and a straight section of stainless steel tubing to connect to approximately-horizontal reinforced PVC tubing which leads to the inlet flow conditioning blocks described in the section above. The elbow has fittings attached to provide access for (1) injection of seeding particles for specific jets (Figure A-17) and (2) sensing the fluid pressure at that location. The pressure measurement is for the purpose of deducing the pressure difference from that location through the flow conditioning block and model to its outlet, a magnitude significantly larger than the error caused by the configuration in the elbow. Oil temperature may be measured by thermistors installed at the entrances to the inlet flow conditioning blocks. 


\section{Concluding remarks}

The objective of the present report is to document the design of our first experiment to measure generic flow phenomena expected to occur in the lower plenum of a typical prismatic VHTR concept. The current major task is development of a MIR (Matched-Indexof-Refraction) experiment simulating flow phenomena in a typical prismatic VHTR lower plenum for assessment of CFD codes intended for this application. Appendix A provides fabrication sketches of the apparatus designed for this purpose so that the CFD analysts have the dimensions needed for input quantities in their codes.

Meaningful feasibility studies for VHTR designs will require accurate, reliable predictions of material temperatures to evaluate the material capabilities. In a prismatic VHTR these temperatures depend on the thermal convection in the coolant channels for the core and in other important components. The VHTR concepts feature complex geometries and wide ranges of temperatures, leading to significant variations of the gas thermodynamic and transport properties plus possible effects of buoyancy during normal and reduced power operations and loss-of-flow scenarios. Unfortunately, correlations in one-dimensional system codes for gas-cooled reactors typically underpredict these temperatures, particularly in reduced power operations and hypothesized accident scenarios. Likewise, most turbulence models in general-purpose CFD (computational fluid dynamics) codes provide optimistic predictions in the sense that calculated wall temperatures are lower than measured ones. These treatments are further complicated by the non-homogeneous power distributions with strong peaking that can occur and possibly buoyancy, strong pressure gradients and gas property variations in the channels ("hot channel" issue). DoE needs improved modeling capabilities, independently from the sometimes simplistic approaches employed by reactor vendors; these computational capabilities need, in turn, to be validated by comparison to experimental and analytical benchmark data.

The general approach of the project is to develop new benchmark experiments for assessment in parallel with CFD and coupled CFD/systems code calculations for the same geometry. Two aspects of the complex flow in a VHTR are being addressed: (1) flow and thermal mixing in the lower plenum ("hot streaking" issue) and (2) turbulence and resulting temperature distributions in reactor cooling channels ("hot channel" issue). This report primarily addresses the former.

Current prismatic VHTR concepts have been examined to identify their proposed flow conditions and geometries over the range from normal operation to decay heat removal in a pressurized cooldown. Approximate analyses have been applied to determine key nondimensional parameters and their magnitudes over this operating range. For example, for turbulent flow in cooling channels, key parameters would include the Reynolds number, Prandtl number, $\mathrm{q}^{+}$(non-dimensional heat flux), Bo* (buoyancy) and $\mathrm{K}_{\mathrm{V}}$ (streamwise acceleration as density decreases). For normal operation the range of outlet Reynolds numbers from coolant channels varied from about 57,000 for a high power core to about 2300 at ten per cent power. Over this range, $\mathrm{q}^{+}, \mathrm{K}_{\mathrm{V}}$ and $\mathrm{Bo}^{*}$ were low relative to their thresholds for significant effects and -- hence -- acceleration, buoyancy effects and gas property variation across the channels are not expected to be important. 
The flow in the lower plenum can locally be considered to be a situation of multiple buoyant jets into a confined density-stratified crossflow -- with obstructions. The hot flow from the coolant channels through the lower plenum to the core outlet duct encounters a very complicated geometry. Since the flow converges ultimately to a single outlet, the hot jets encounter different crossflow velocities depending on their locations relative to the outlet. The jets furthest from the outlet essentially exhaust into stagnant surroundings between the adjacent posts with the exception of the flow which they induce. On the other hand, the last row of jets before the outlet encounters crossflow from all the other jets. If a "hot channel" region is exhausted via one of the jets furthest from the outlet, there is concern that its impingement on the floor of the lower plenum may be too hot for the thickness of the insulation layer protecting the metallic Core Support Plate below. The "hot streaking" issue pertains primarily to the entrance of the hot outlet duct to the turbomachinery. If a "hot channel" region exhausts through one of the last jets before the outlet duct, there is concern that it may not mix (and thereby cool) sufficiently before flowing along the metallic outlet duct.

For a single-hole "corner channel" (i.e., the duct along the corner of a single active outer column with two inactive solid columns adjacent) as the jet inlet duct, the bulk velocity at $1000^{\circ} \mathrm{C}$ is about $25 \mathrm{~m} / \mathrm{sec}(80 \mathrm{ft} / \mathrm{sec})$ and the resulting jet Reynolds number is about 90,000. At this location the horizontal bulk velocity in the plenum is about $0.4 \mathrm{~m} / \mathrm{sec}(1.4 \mathrm{ft} / \mathrm{sec})$, giving $\mathrm{V}_{\mathrm{j}} / \mathrm{V}_{\mathrm{p}} \approx 50$ so jet penetration into the crossflow is expected to be high. One might expect these jets to travel along the adjacent solid vertical corner as wall jets and then to impinge on the plenum floor. A plenum Reynolds number at the passage between the first row of posts encountered would be about 24,000 , based on the hydraulic diameter of the opening.

For the flow between the row of posts before the last row of jets, the plenum bulk velocity would be about $40 \mathrm{~m} / \mathrm{sec}(130 \mathrm{ft} / \mathrm{sec})$, still a low Mach number. The plenum Reynolds number in this region would be about $3 \times 10^{6}$. The jet-to-crossflow velocity ratio would be about 0.6 , more in the range of typical crossflow experiments. Even without buoyancy effects (if the jet is hot relative to the crossflow) and drag by nearby posts, the jet penetration would be expected to be less than two jet diameters which would be less than a fifth of the distance to the plenum floor. Estimation of the acceleration parameter -- for flow from the lower plenum converging into the outlet duct -- indicated that laminarization might occur at reduced power but not in normal full power operations.

Approximate analyses were conducted to examine whether significant influences of buoyancy should be expected for the jets entering the lower plenum or for the near horizontal flow within it. Nominal operating conditions were considered. For a $300^{\circ} \mathrm{C}$ temperature difference and $\mathrm{T}_{\infty}=1000 \mathrm{C}$, the approximations indicate that the jets should be considered to be effectively momentum-driven at full power and at one-tenth power. That is, buoyancy would not be expected to have a significant influence on jet interactions with the flow in the plenum. A second approximate analysis was conducted to estimate when a temperature gradient will stabilize a horizontal turbulent channel flow, thereby leading to reduced thermal transport near the upper surface. We concluded that

- for full power, buoyancy influences are probably not important 
- for reduced power (ten per cent), buoyancy probably is important at the side of the lower plenum away from the outlet but not near the outlet.

Thus, experiments without buoyancy effects (as in those proposed for the INL Matched-Indexof-Refraction flow system) should provide useful benchmark data for assessing CFD codes for some lower plenum flows.

Experiments are needed for the combined features of the lower plenum flows. In particular, missing from the typical jet experiments are interactions with nearby circular posts and with vertical posts in the vicinity of vertical walls - with near stagnant surroundings at one extreme and significant crossflow at the other. The experiments proposed in the present research would address these needs.

In order to obtain further insight into flow phenomena occurring in a lower plenum, a qualitative flow visualization experiment was conducted at INEEL. Phenomena observed in the experiment include jet entrainment of fluid, jet attachment to the upstream wall possibly due to a Coanda effect, eddy formation in the lower and upper upstream corners of the channel, merging of jets, crossflow of fluid around posts and fluid recirculation near the front and rear walls.

Unheated MIR (Matched-Index-of-Refraction) experiments are first steps when the geometry is complicated. One does not want to use a computational technique which will not even handle constant properties properly. The purpose of the fluid dynamics experiments is to develop benchmark databases for the assessment of CFD solutions of the momentum equations, scalar mixing and turbulence models for typical prismatic VHTR plenum geometries in the limiting case of negligible buoyancy and constant fluid properties. As indicated in the section on Scaling studies, in normal full power operation of a typical VHTR conceptual design, buoyancy influences should be negligible in the lower plenum. The MIR experiment will simulate flow features of the paths of jets as they mix in flowing through the array of posts in a lower plenum en route to its single exit duct. General characteristics of the flow in the lower plenum have been listed and, from this information, desirable features of MIR experiments have been identified. Two conceptual model designs have evolved: one will model flow across an array of posts as near the outlet duct or in line with the duct centerline at the opposite side of the reactor and the second partially simulates flow aligned between a row of support posts. The present experiment design addresses the first concept. Measurements will be obtained via particle image velocimetry (PIV) and/or by laser Doppler velocimetry (LDV).

The first experiment addresses flow in the region on the central plane away from the plenum outlet duct. Conceptually, there is no significant flow from the outer reflector (except some bypass flow between the prismatic blocks) and the dominant flow comes from the jets issuing from short coolant ducts at the corners of the hexagonal blocks ("corner channels"). The main plenum crossflow evolves from these jets in the active core and then passes below the central reflector which lacks the corner coolant ducts (i.e., no additional jet inflow).

The model is scaled to the geometric dimensions of the NGNP Point Design [MacDonald et al., 2003] as an example of a typical prismatic VHTR. With a desired height-to-diameter ratio of about seven, optical constraints led to a post diameter $D_{p}$ of $1.25 \mathrm{in}$. $(31.8 \mathrm{~mm})$. The nominal dimensions are 


$$
\left(\mathrm{p} / \mathrm{D}_{\mathrm{p}}\right)=1.7,\left(\mathrm{H}_{\text {plenum }} / \mathrm{D}_{\mathrm{p}}\right)=6.85 \text { and }\left(\mathrm{D}_{\mathrm{jet}} / \mathrm{D}_{\mathrm{p}}\right)=0.7
$$

The model consists of a row of full circular posts along its centerplane with half-posts on the two parallel walls to induce flow features somewhat comparable to those expected from the staggered adjacent rows of posts in the reactor design. The posts and half-posts form an equilateral triangular pattern as in supporting a core consisting of hexagonal blocks. Posts, side walls and end walls are fabricated from quartz to match the refractive-index of the working fluid. In addition to the circular posts a wedge-shaped quartz element has been fabricated to block the channel by replacing a post; it simulates the plenum wall formed by a hexagonal block of the outer reflector and will be mounted at the upstream end.

For a typical VHTR lower plenum, the flow from the coolant channels is collected in short ducts at the corners of the hexagonal blocks ("corner channels"). The flows from the coolant channels in the core are fully-turbulent and have approximately the same bulk velocities. A design goal for the jet inlet ducts is to simulate this situation so that the jets formed will have flow features comparable to those in a typical prismatic VHTR. Accordingly, aims for the design include an approximately uniform velocity with a "high" turbulence level and no significant swirl at the entry to a jet inlet duct (about four diameters from its exit into the plenum).

For $\left(\mathrm{D}_{\mathrm{jet}} / \mathrm{D}_{\text {post }}\right)=0.7$ and 1.25 inch posts, the nominal diameter of the jet inlet ducts is $7 / 8$ in. $(22.2 \mathrm{~mm})$. Up to four inlet jets will be accommodated with individual control and flow metering. The choice of four jet inlet ducts is consistent with the number near the centerplane in a VHTR with three rings of hexagonal blocks in the active core.

For the first experiment, maximum jet flow rates will be limited by the capacity of the existing pump for the model flow system, by the number of jets and by the flow resistance of the jet supply system. With a "grid" to induce turbulence at the duct entry, it is expected that a Reynolds number of 3500 to 4000 (based on diameter) will reliably give sustained turbulent flow. Currently, the maximum flow rates possible are estimated to give $\operatorname{Re} D \approx 12,000$ for each of four jets.

The close spacing of pairs of jet inlet ducts led to design of "inlet flow conditioning blocks." In the flow conditioning sections of these blocks are a honeycomb, a screen and a turbulence-generating grid (another screen). The honeycomb is intended to reduce any swirl or secondary flow. The purpose of the screen is to reduce distortions in the mean velocity profile coming from the honeycomb. The second screen will reduce distortions of the mean velocity profile further while increasing the turbulence level locally at the entrance to the jet inlet duct. The honeycomb is fabricated from Type 304 stainless steel with hexagonal cells $1 / 8 \mathrm{in}$. (3 mm) across and wall thickness of 0.004 in. $(0.1 \mathrm{~mm})$. Length is $0.8 \mathrm{in}$. $(20 \mathrm{~mm})$. Based on approximate predictions, we chose stainless steel meshes B-CX-10 and B-CX-16 for the first screen and the turbulence grid. The number in the mesh designation is the number of wires per inch or per $25.4 \mathrm{~mm}$. The estimated disturbance amplitude after the turbulence grid is about three per cent at $\mathrm{Re}_{\mathrm{jet}}=6000$ and four percent at $\mathrm{Re}_{\mathrm{jet}}=10,000$ while the predicted pressure drop at the higher flow rate is about fourteen psi $(0.9 \mathrm{~atm})$. 
Fabrication sketches are provided in Appendix $\boldsymbol{A}$ for the use of CFD analysts wishing to employ the data for assessment of their proposed codes. 
Appendix A. Fabrication sketches 


\section{Figures}

A-1. End view of planned installation .................................................... 49

A-2. Isometric view of MIR test section demonstrating planned installation of model and one

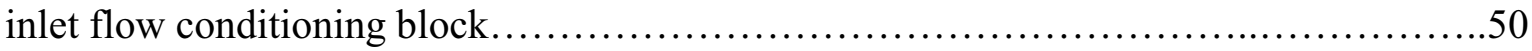

A-3. Isometric view of model with jet inlet ducts.................................... 51

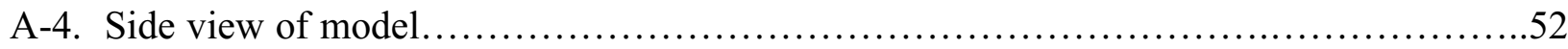

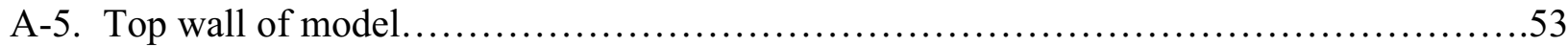

A-6. Bottom wall of model................................................................54

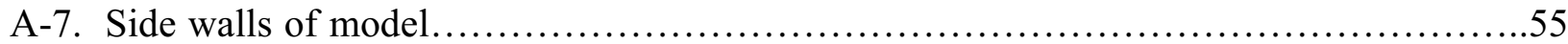

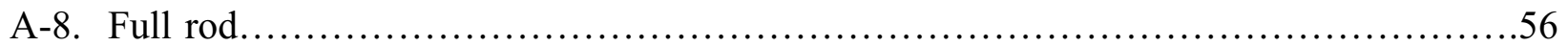

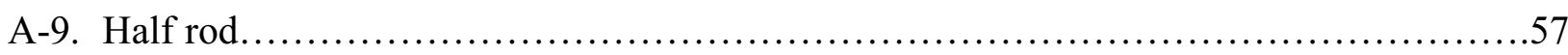

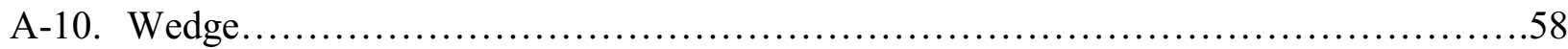

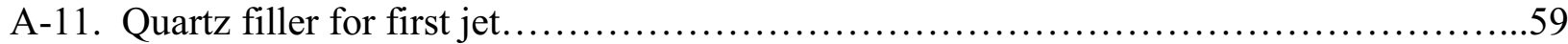

A-12. Isometric view of inlet flow conditioning block................................60

A-13. Isometric view of one side section of inlet flow conditioning block....................61

A-14. Side view of side section of inlet flow conditioning block........................62

A-15. Detail of flow conditioning tube of inlet flow conditioning block....................63

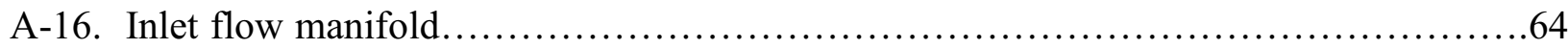

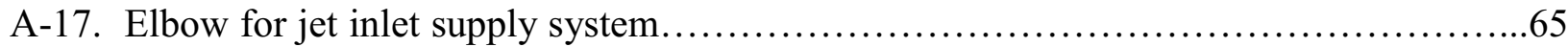




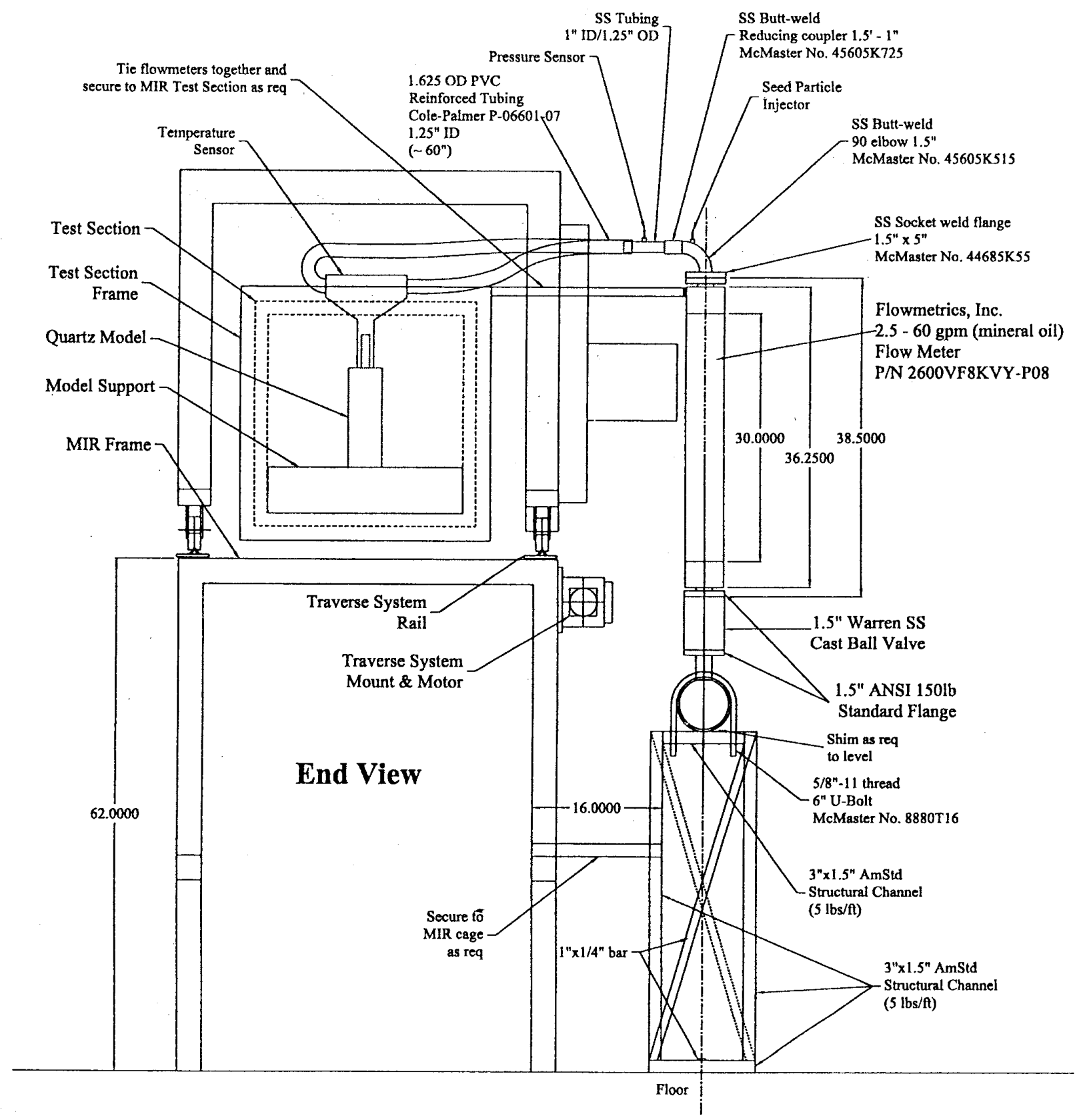

A-1. End view of planned installation. 


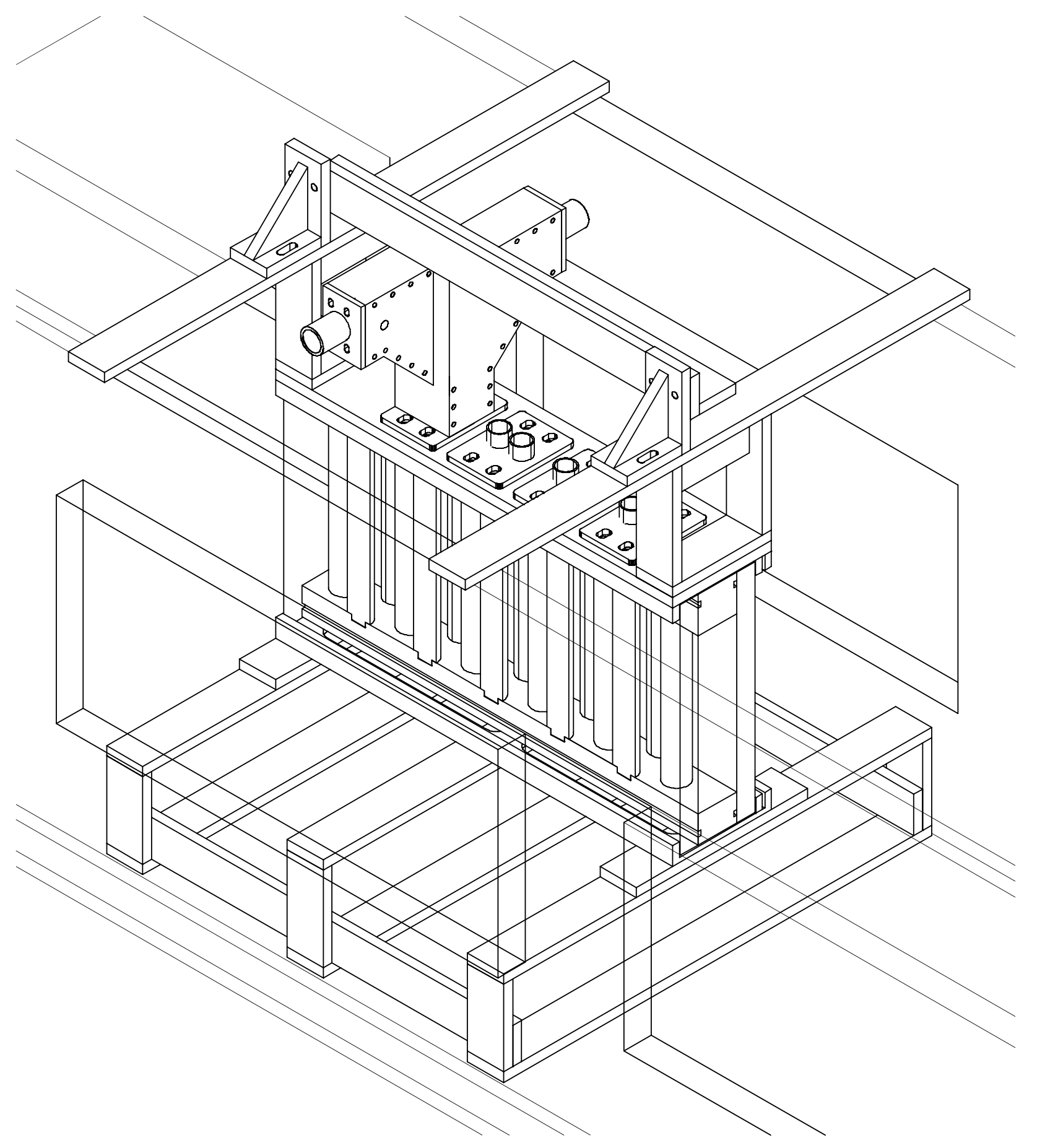

A-2. Isometric view of MIR test section demonstrating planned installation of model and one inlet flow conditioning block. 


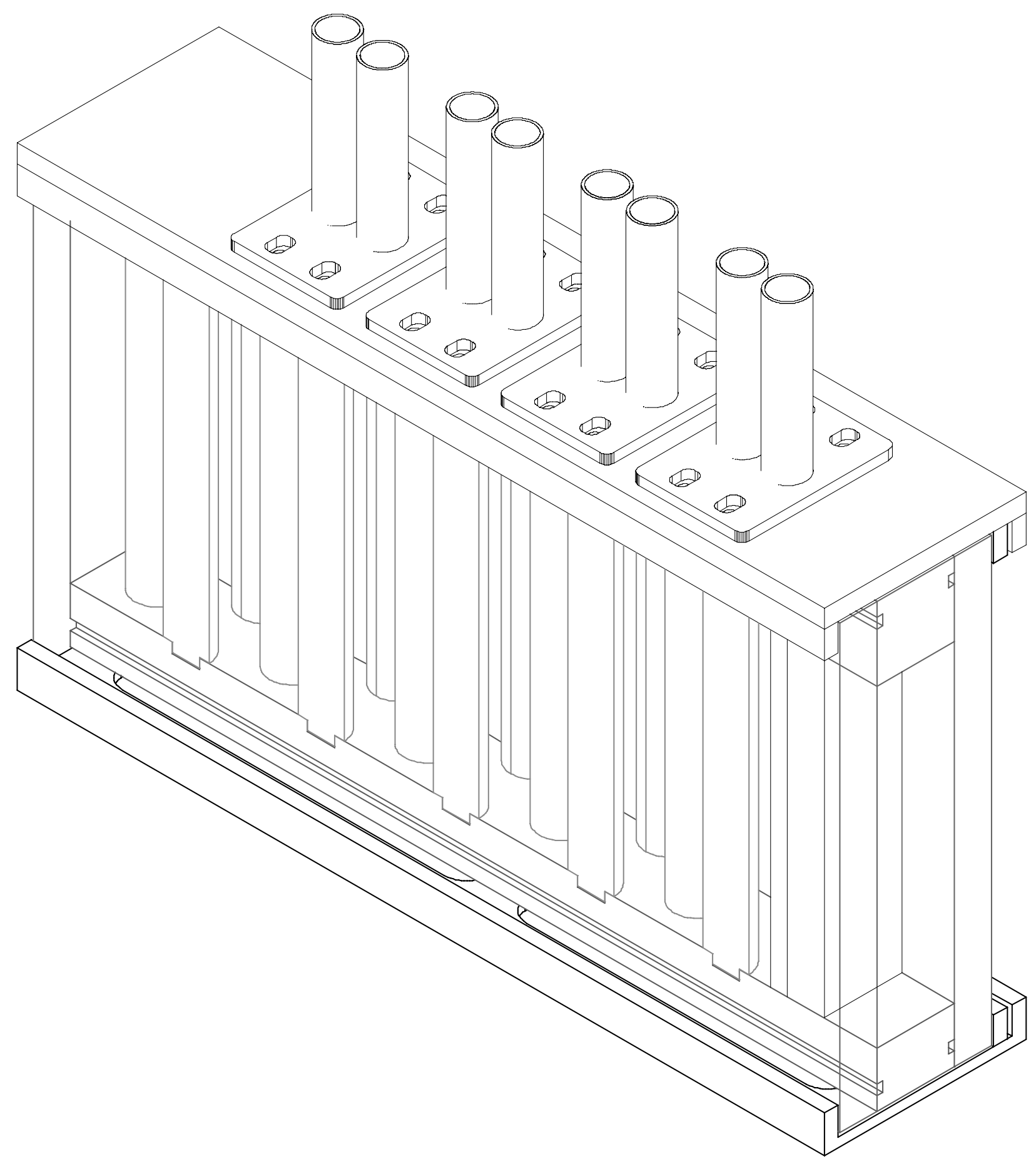

A-3. Isometric view of model with jet inlet ducts. 


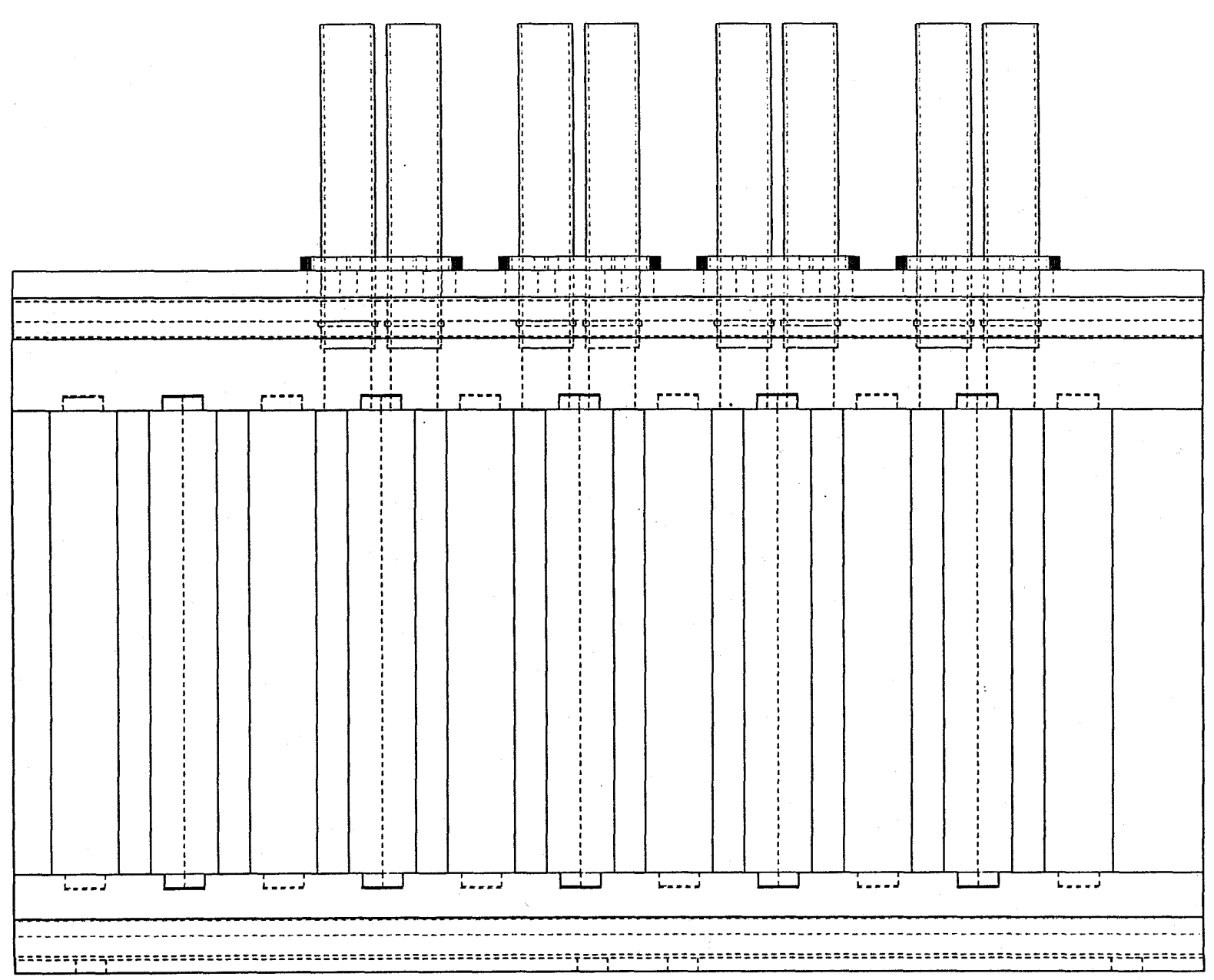

A-4. Side view of model. 


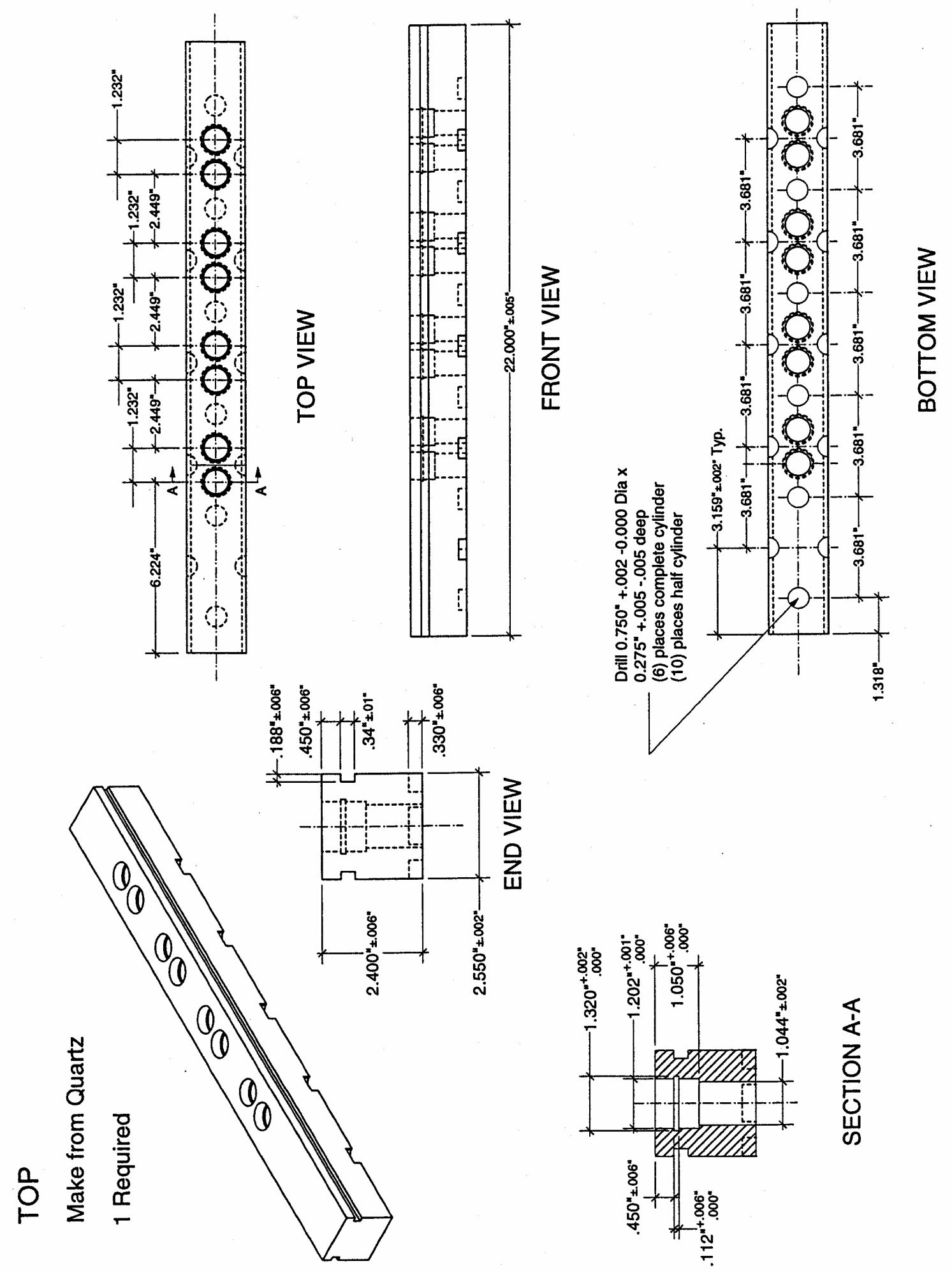

A-5. Top wall of model. 

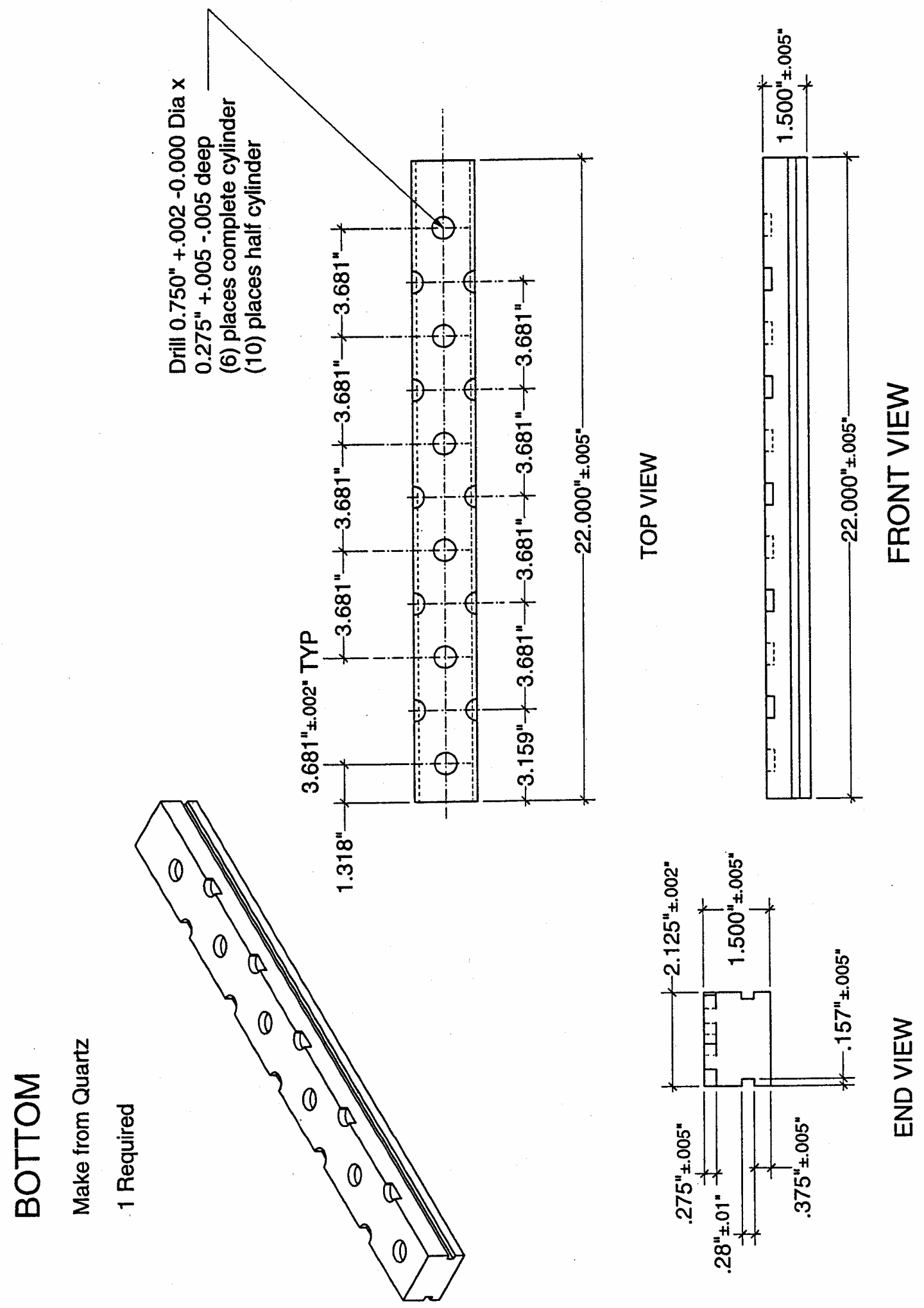

A-6. Bottom wall of model. 

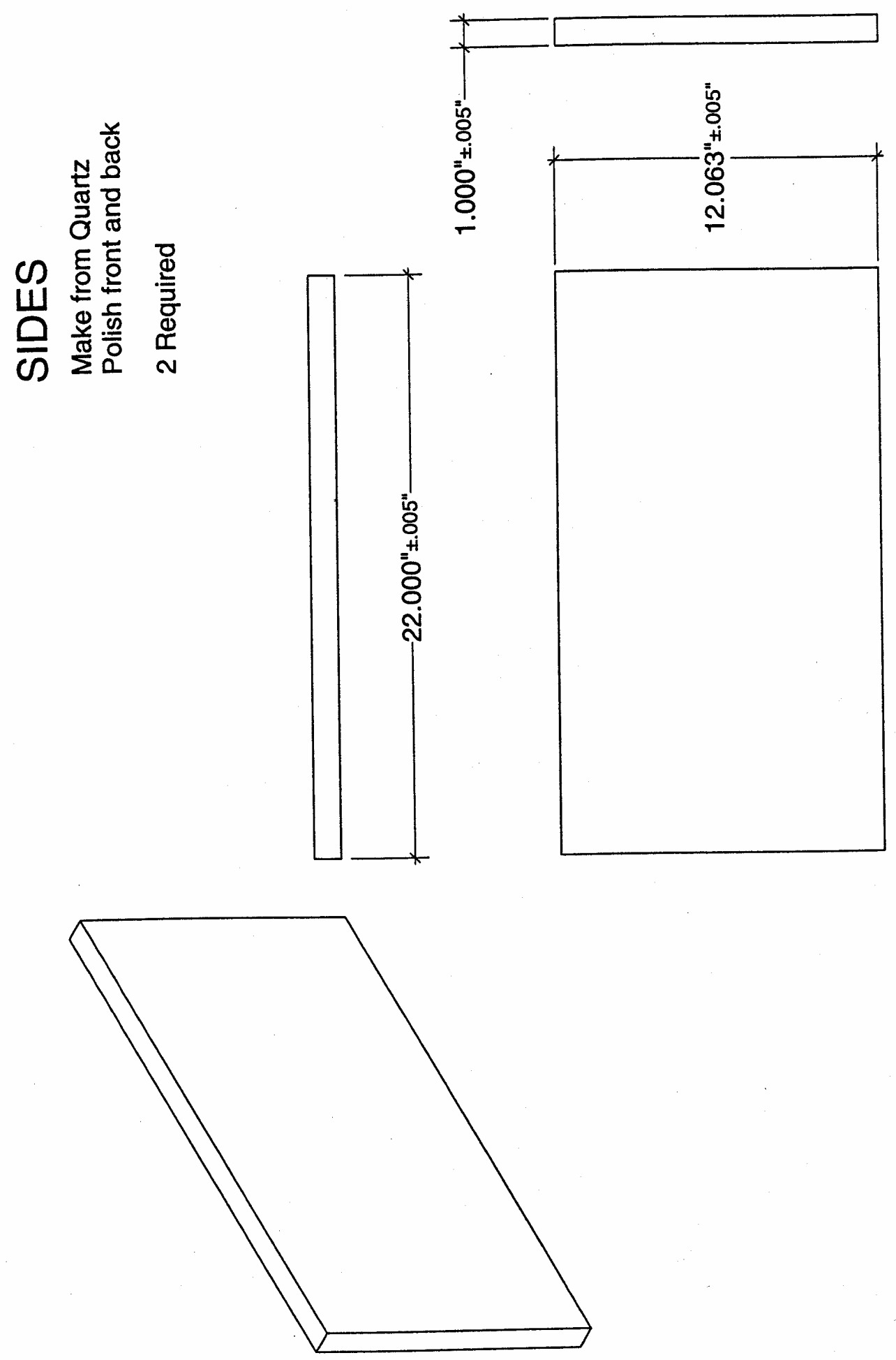

A-7. Side walls of model. 


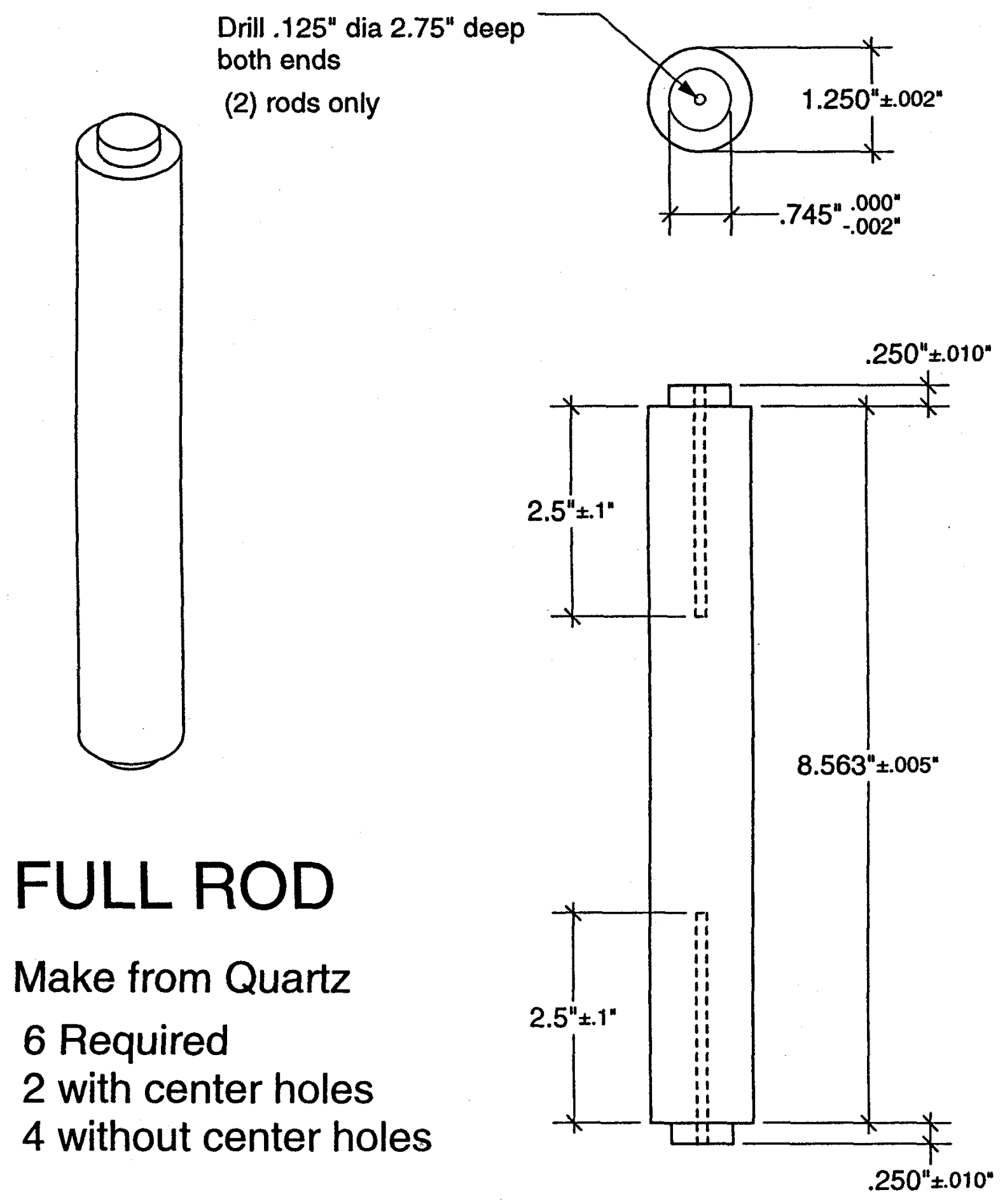

A-8. Full rod. 


\section{HALF ROD}

Make from Quartz

10 Required
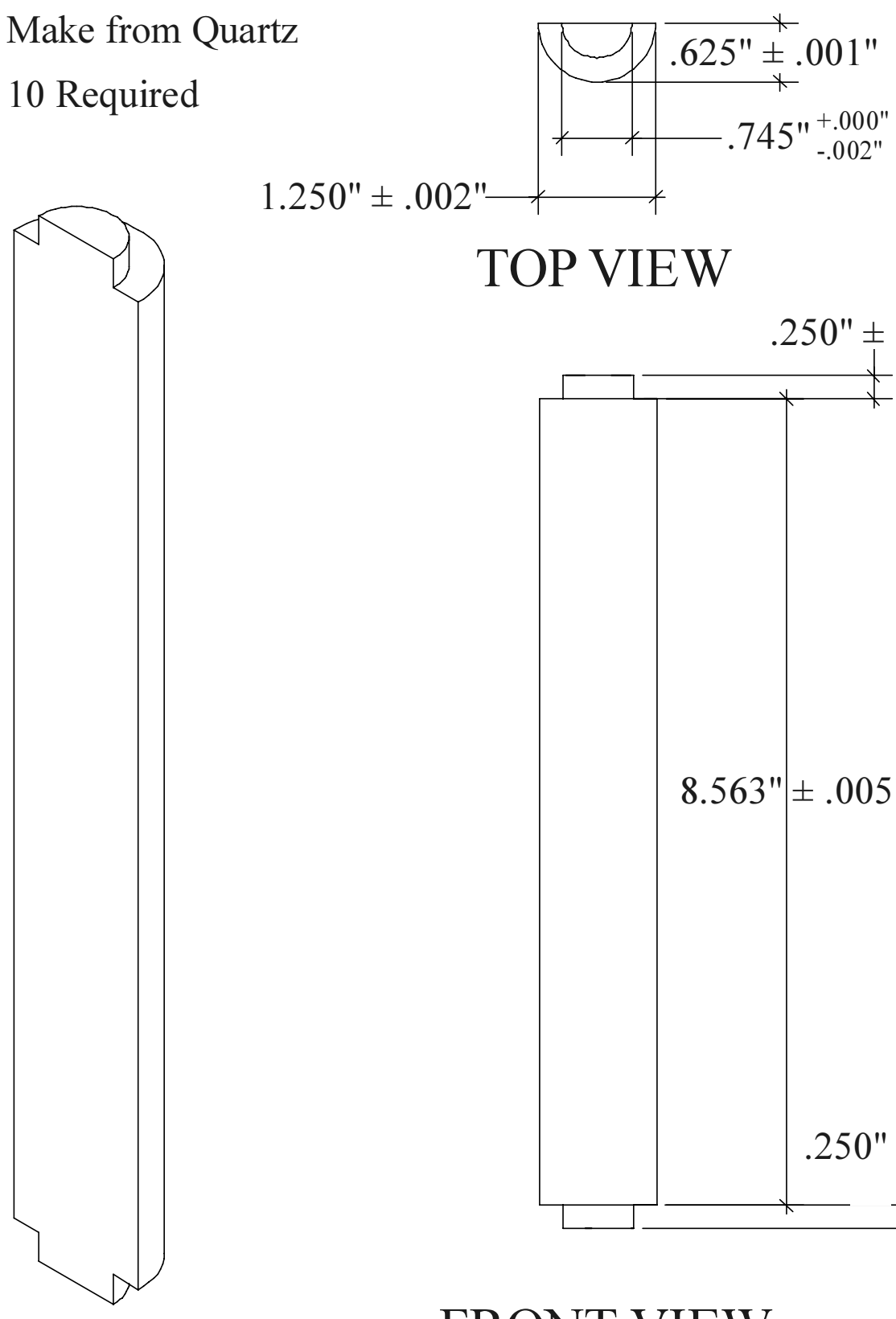

\section{TOP VIEW}

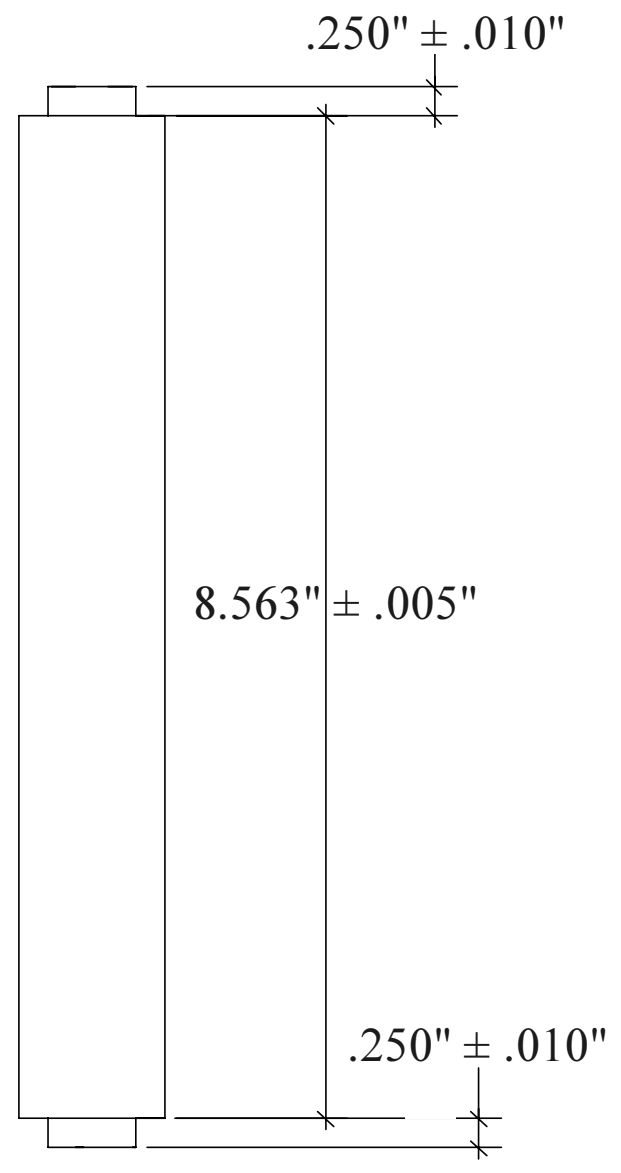

FRONT VIEW

SIDE VIEW

A-9. Half rod. 

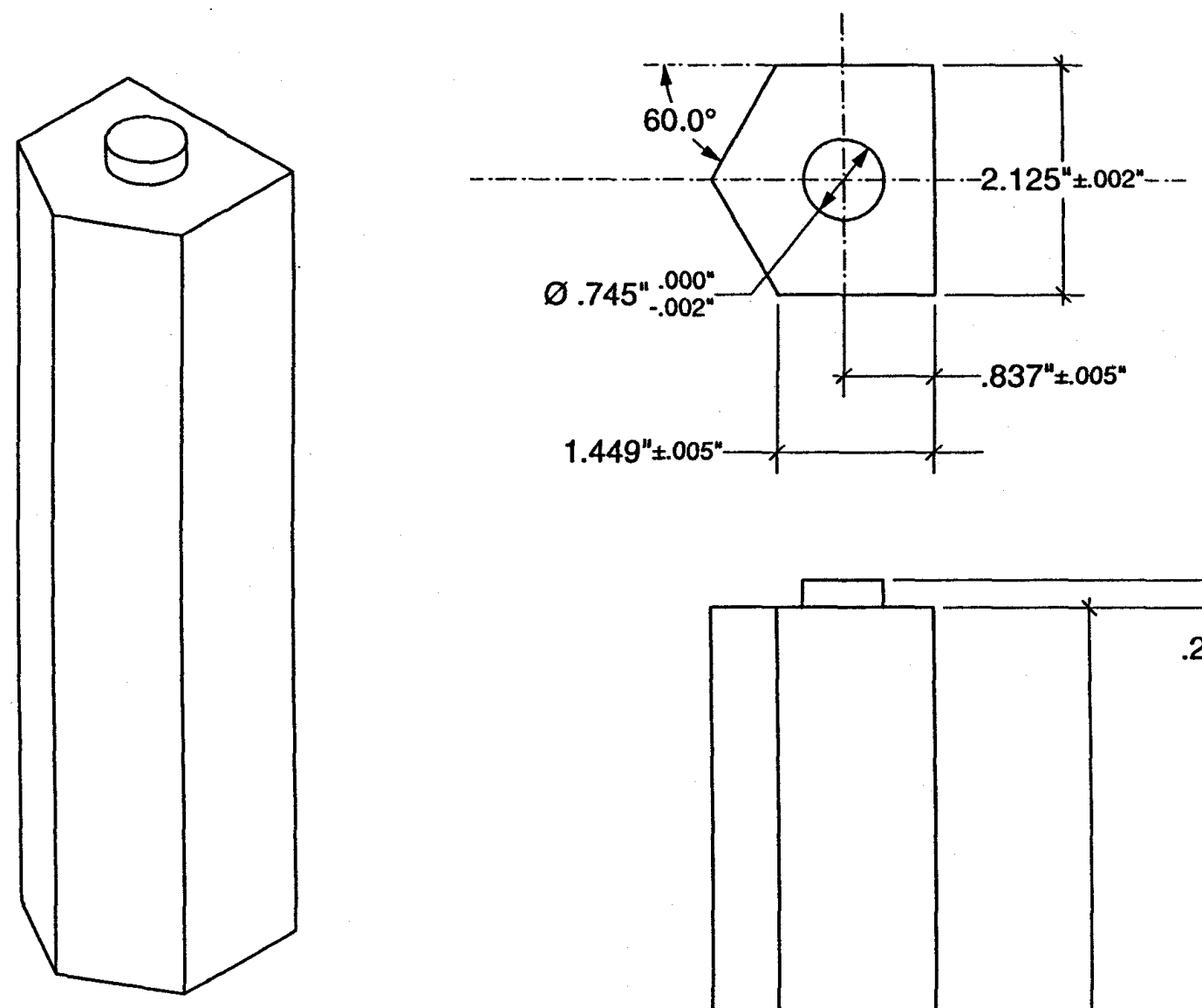

\section{WEDGE}

Make from Quartz

1 Required

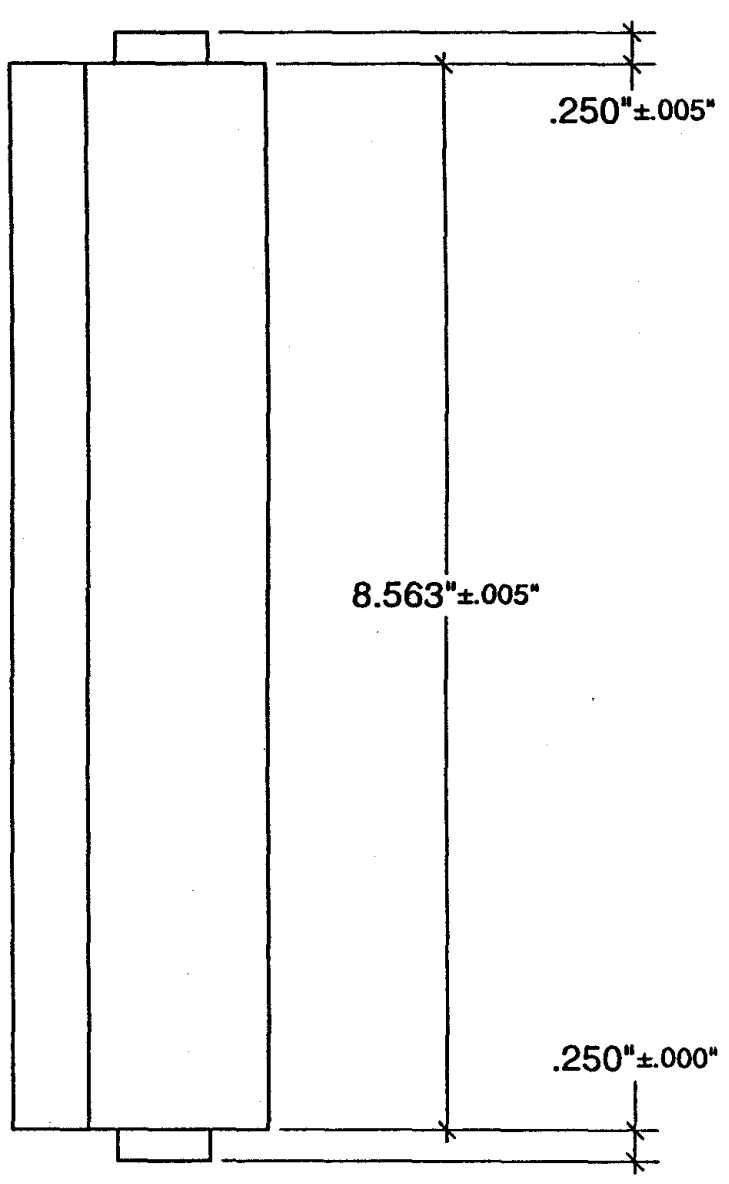

A-10. Wedge. 


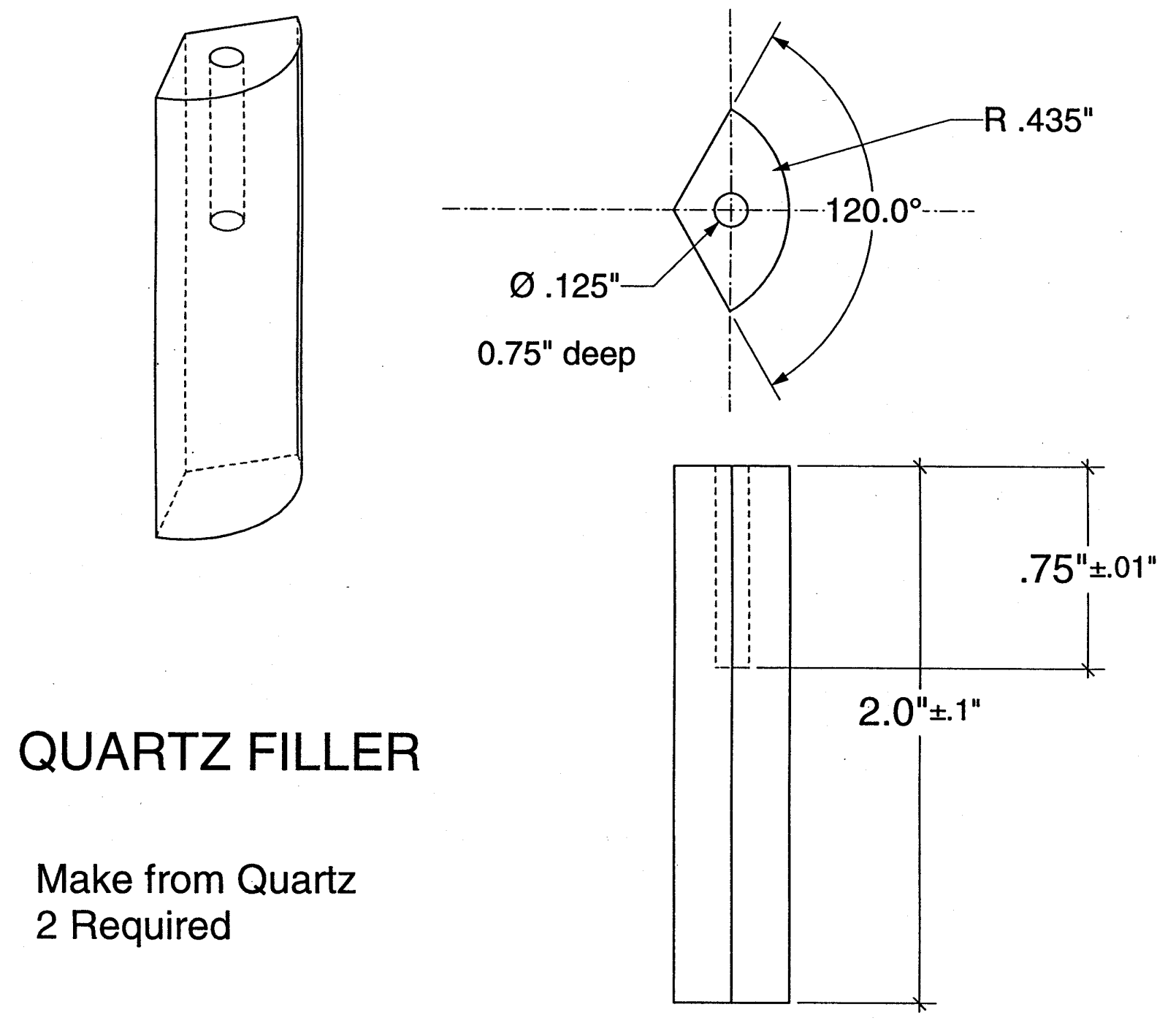

A-11. Quartz filler for first jet. 


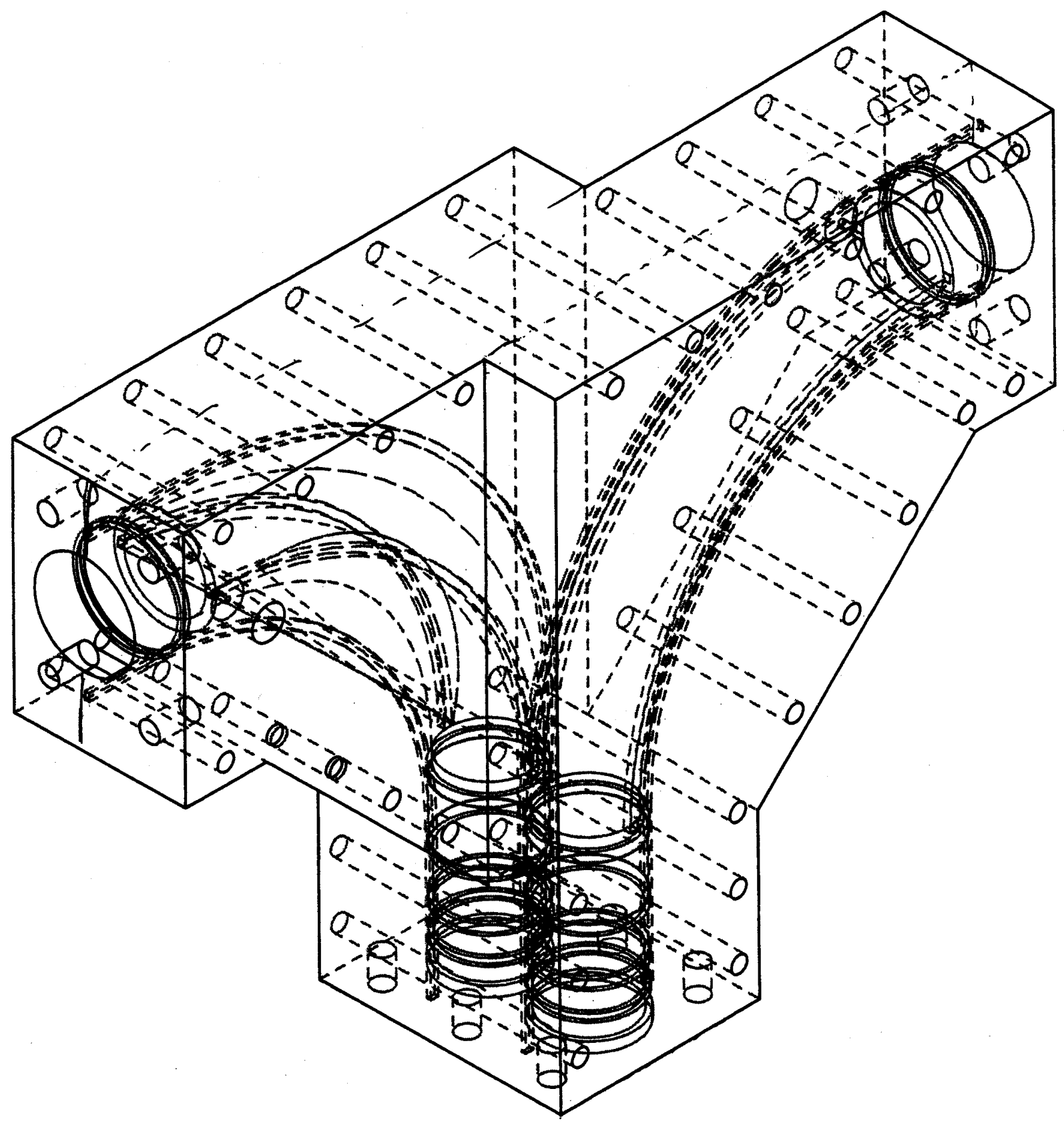

A-12. Isometric view of inlet flow conditioning block. 


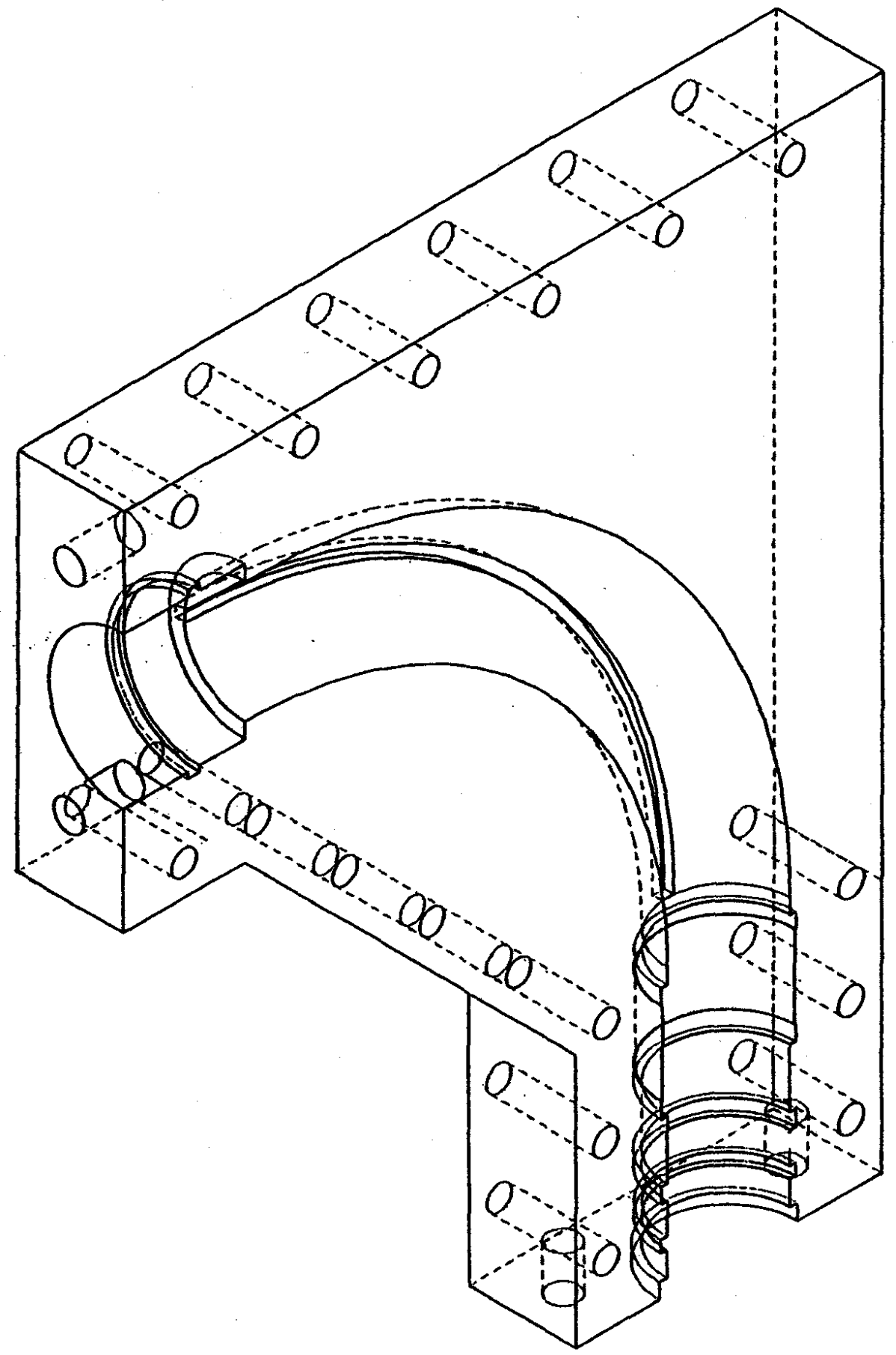

A-13. Isometric view of one side section of inlet flow conditioning block. 


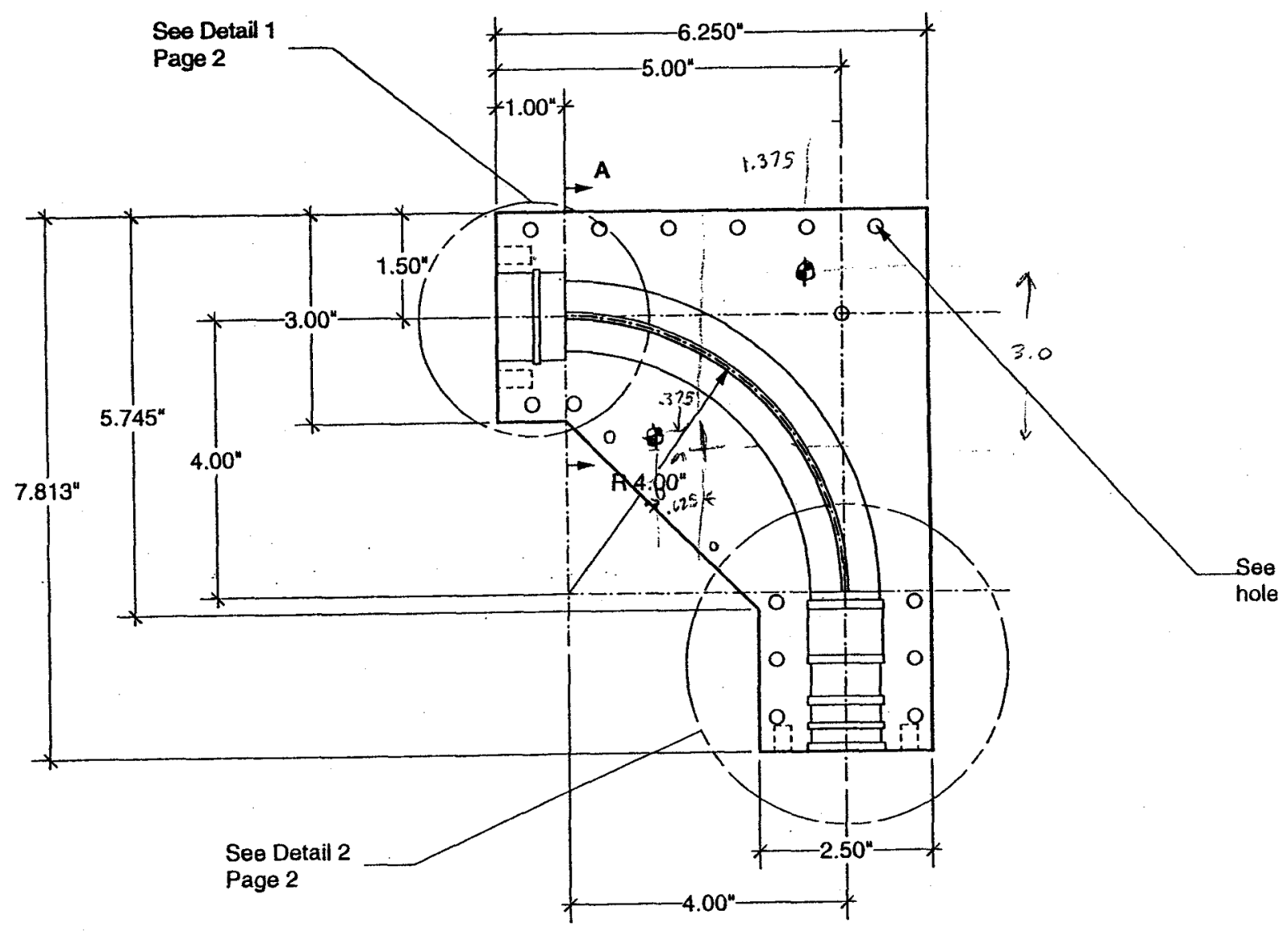

FRONT VIEW

A-14. Side view of side section of inlet flow conditioning block. 


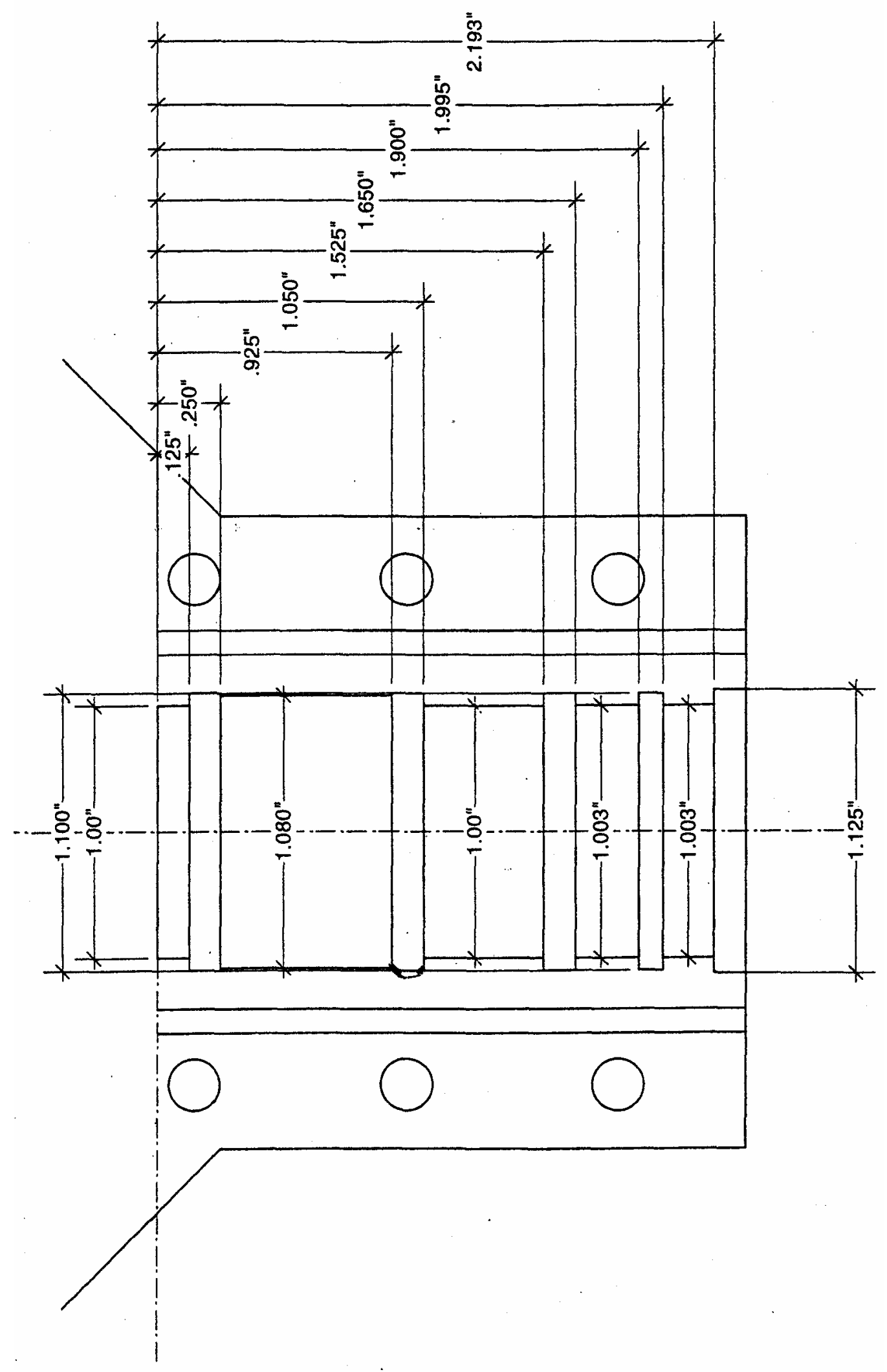

A-15. Detail of flow conditioning tube of inlet flow conditioning block. 


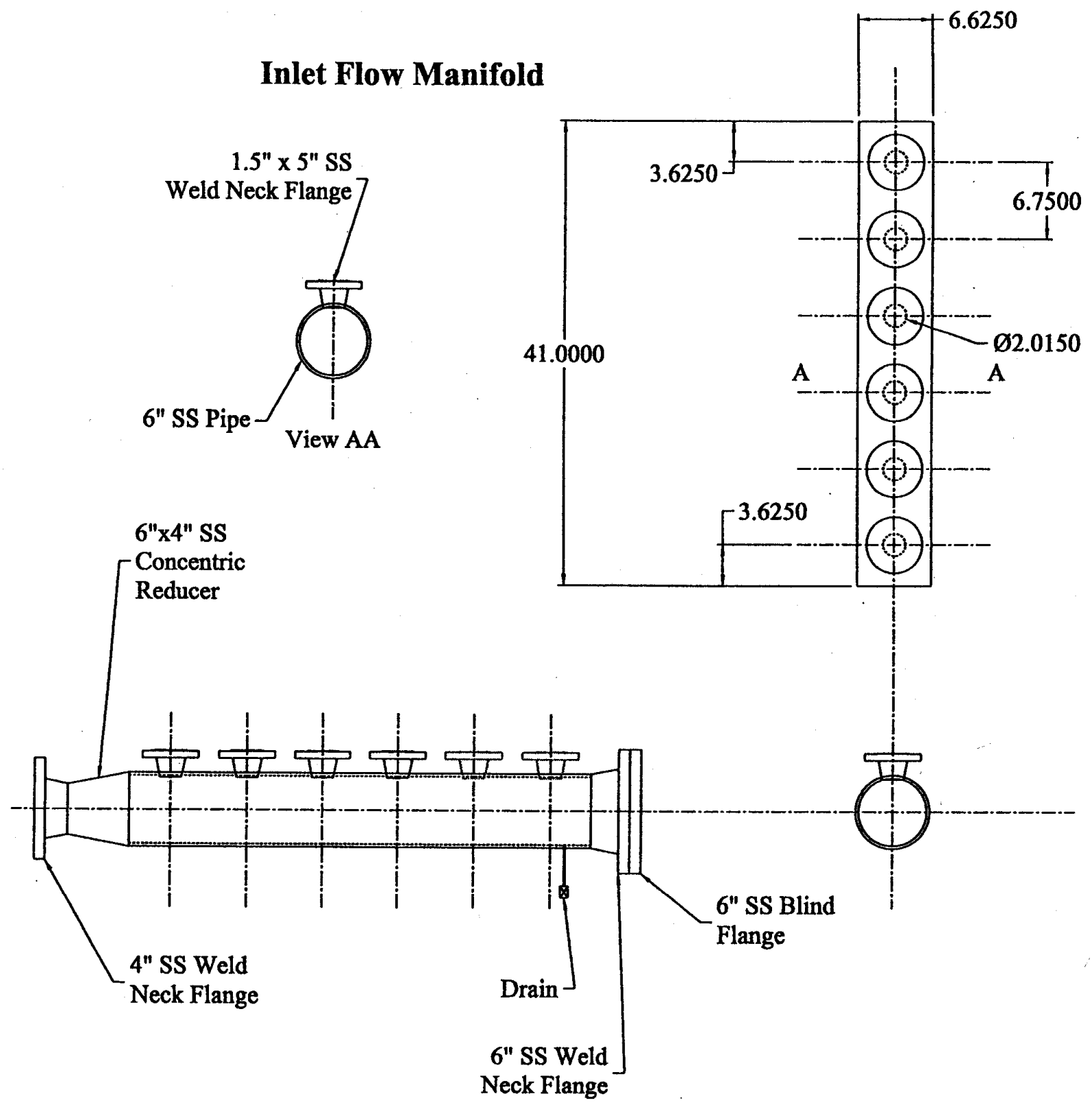

A-16. Inlet flow manifold. 


\section{Particle injection port}

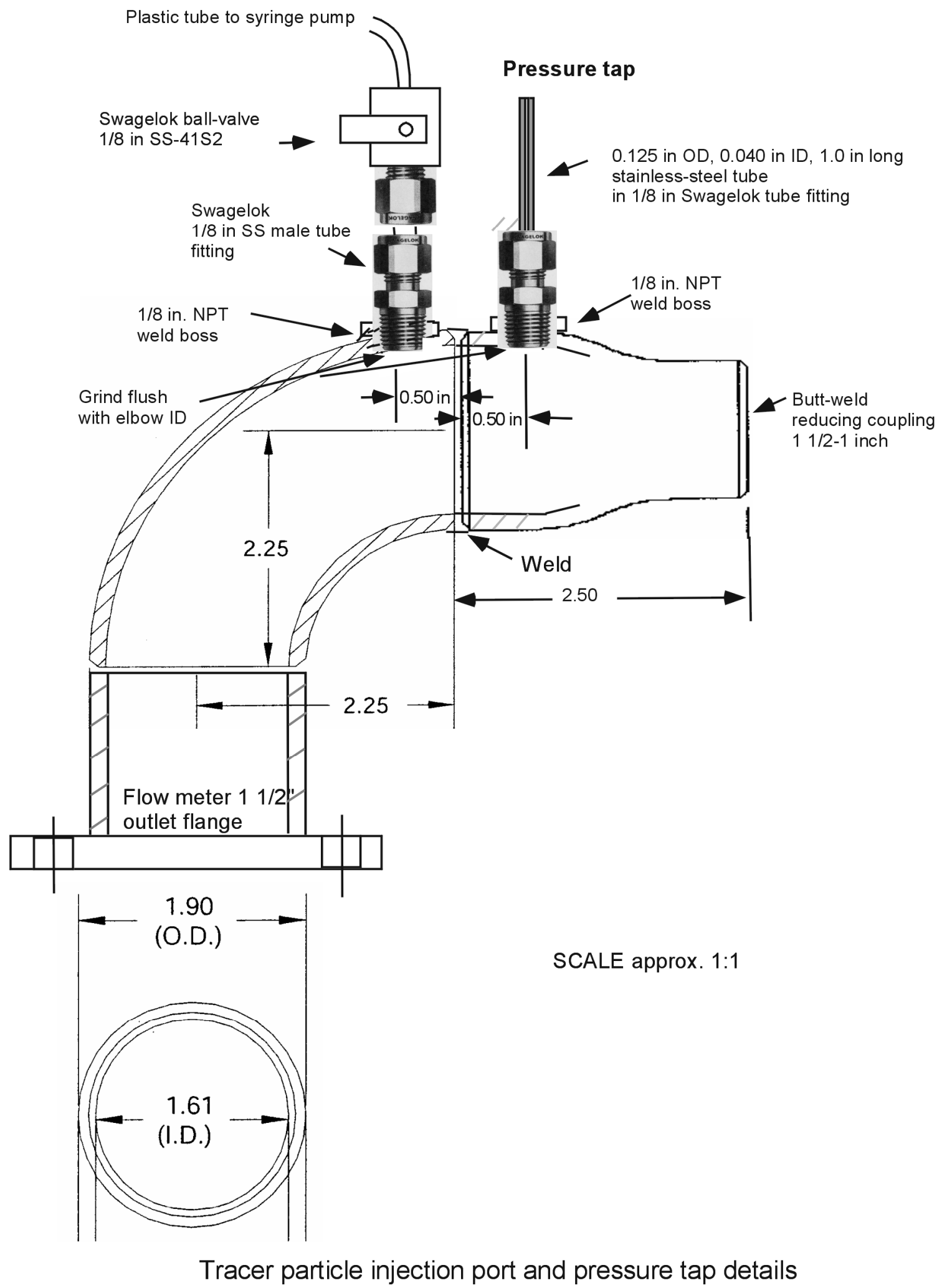

A-17. Elbow for jet inlet supply system. 


\section{References cited}

Achenbach, E., 1989. Heat transfer from a staggered tube bundle in cross-flow a high Reynolds numbers. Int. J. Heat Mass Transfer, $\underline{32}$, pp. 271-280.

Adrian, R. J., 1991. Particle-imaging techniques for experimental fluid mechanics. Ann. Rev. Fluid Mech., 23, pp. 261-304.

Amano, R. S., and H. Brandt, 1984. Numerical study of turbulent axisymmetric jets impinging on a flat plate and flowing into an axisymmetric cavity. J. Fluids Engr., 106, pp. 410-417.

Andreopoulous, J., and W. Rodi, 1984. Experimental investigation of jets in a crossflow. J. Fluid Mech., 138, pp. 93-127.

Bankston, C. A., and D. M. McEligot, 1970. Turbulent and laminar heat transfer to gases with varying properties in the entry region of circular ducts. Int. J. Heat Mass Transfer, 13, pp 319344.

Barsamian, H. R., and Y. A. Hassan, 1996. Large eddy simulation of tube bundle geometries using the dynamic subgrid scale model. Thermal Science of Advanced Steam Generators/Heat Exchangers, ASME NE-Vol. 19, pp. 49-56.

Baughn, J. W., and S. Shimizu, 1989. Heat transfer measurements from a surface with uniform heat flux and an impinging jet. J. Heat Transfer, $\underline{111}$, pp. 1096-1098.

Beale, S. B., and D. B. Spalding, 1998. Numerical study of fluid flow and heat transfer in tube banks with streamwise-periodic boundary conditions. Trans., Can. Soc. Mech. Eng., 22, pp. $397-416$.

Becker S., C. M. Stoots, K. G. Condie, F. Durst and D. M. McEligot, 2002. LDA-measurements of transitional flows induced by a square rib. J. Fluids Engr., 124, pp. 108-117.

Behnia, M., S. Parneix, Y. Shabany and P. A. Durbin, 1999. Numerical study of turbulent heat transfer in confined and unconfined impinging jets. Int. J. Heat Fluid Flow, 20, pp. 1-9.

Brundrett, E., 1973. Prediction of pressure drop for incompressible flow through screens. J. Fluids Engr., 115, pp. 239-242.

Budwig, R. S., H. M. McIlroy, W. J. Dalling, D. M. McEligot, K. G. Condie, R. J. Pink and G. E. McCreery, 2001. Near-wall behavior of a transitional boundary layer. Amer. Physical Soc. Fluid Dynamics meeting, San Diego, November. Bull. APS, 뜨, No. 10, p. 198.

Budwig, R., 1994. Refractive index matching methods for liquid flow investigations. Exp. Fluids, 17, pp. 350-355.

Campbell, J. F., and J. A. Schetz, 1973. Analysis of the injection of a heated turbulent jet into a cross flow. NASA TR R-413.

Chambers F. W., H. D. Murphy and D. M. McEligot, 1983. Laterally converging flow. II: Temporal wall shear stress. J. Fluid Mech., 127, pp. 403-428.

Chen, S. S., and J. A. Jendrzejczyk, 1987. Fluid excitation forces acting on a tube array. Tech. rpt. ANL-85-55. 
Condie, K. G., G. E. McCreery and D. M. McEligot, 2001. Measurements of fundamental fluid physics of SNF storage cannisters. Tech. rpt. INEEL/EXT-2001-1269, INEEL.

Cooper, D., D. C. Jackson, B. E. Launder and G. X. Liao, 1993. Impinging jet studies for turbulence model assessment - I. Flow-field experiments. Int. J. Heat Mass Transfer, $\underline{36}$, pp. 2675-2684.

Corino, E. R., and R. S. Brodkey, 1969. A visual observation of the wall region in turbulent flow. J. Fluid Mech., 37, pp. 1-30.

Craft, T. J., 1998. Predictions of heat transfer in turbulent stagnation flow with a new secondmoment closure. Proc., 2nd Eng. Foundation Conf. Turbulent Heat Transfer, Manchester.

Craft, T. J., L. J. W. Graham and B. E. Launder, 1993. Impinging jet studies for turbulence model assessment - II. An examination of the performance of four turbulence models. Int. J. Heat Mass Transfer, $\underline{36}$, pp. 2685-2697.

Cui, M. M., and R. J. Adrian, 1997. Refractive index matching and marking methods for highly concentrated solid-liquid flows. Exp. Fluids, 22, pp. 261-264.

Dianat, M., M. Fairweather and W. P. Jones, 1996. Prediction of axisymmetric and twodimensional impinging turbulent jets. Int. J. Heat Fluid Flow, 17, pp. 530-538.

Downs, H. T., and E. H. James, 1987. Jet impingement heat transfer - A literature survey. ASME paper 87-HT-35.

Durst, F., A. Melling and J. H. Whitelaw, 1976. Principles and practise of laser-Doppler anemometry. London: Academic Press.

Durst, F., J. Jovanovic and J. Sender, 1993. Detailed measurements of the near wall region of turbulent pipe flows. Proc., 9th Symp. Turb. Shear Flows, Kyoto, paper 2-2.

Durst, F., Keck, T., and Kleine, R., 1979. Turbulence quantities and Reynolds stress in pipe flow of polymer solutions measured by two-channel laser-Doppler anemometry. Proc., 6th Symp. on Turbulence, Rolla, Mo.

Gage, K. S., and W. H. Reid, 1968. The stability of thermally stratified plane Poiseuille flow. J. Fluid Mech., $\underline{33}$, pp. 21-32.

Gardon, R., and J. C. Akfirat, 1965. The role of turbulence in determining the heat transfer characteristics of impinging jets. Int. J. Heat Mass Transfer, $\underline{8}$, pp. 1261-1272.

Goldstein, R. J., and A. L. Behbahani, 1982. Impingement of a circular jet with and without cross flow. Int. J. Heat Mass Transfer, 25, pp. 1377-1382.

Grimison, E. D., 1937. Correlation and utilization of new data on flow resistance and heat transfer for cross flow of gases over tube banks. Trans. ASME, $\underline{59}$, pp. 583-594.

Groth, J., and A. V. Johansson,1988. Turbulence reduction by screens. J. Fluid Mech., 197, pp. 139-155.

Guezennec, Y. G., R. S. Brodkey, N. Trigui and J. C. Kent, 1994. Algorithms for fully automated three-dimensional particle tracking velocimetry. Exp. Fluids, 17, pp. 209-219. 
Guidotti, G., O. Manca, B. Morrone and S. Nardini, 2000. Experimental analysis of air natural convection between horizontal parallel plates uniformly heated from the upper plate. 3rd Euopean Thermal Sciences Conference 2000 (Ed.: E. W. P. Hahne, W. Heidemann and K. Spindler), Pisa: Edizioni ETS, vol. 1, pp. 153-158.

Heyerichs, K., and A. Pollard, 1996. Heat transfer in separated and impinging turbulent flows. Int. J. Heat Mass Transfer, 39, pp. 2385-2400.

Hrycak, P., 1981. Heat transfer from impinging jets - A literature review. Tech. rpt. AFWALTR-81-3504.

Hrycak, P., 1983. Heat transfer from round impinging jets to a flat plate. Int. J. Heat Mass Transfer, 26, pp. 1857-1865.

Huang, P. G., A. S. Majumdar and W. J. M. Douglas, 1984. Numerical prediction of fluid flow and heat transfer under a turbulent impingement jet with surface motion and crossflow. ASME paper 84-WA/HT-33.

Hunt, G. R., P. Cooper and P. F. Linden, 2001. Thermal stratfication produced by plumes and jets in enclosed spaces. Building and Environment, $\underline{36}$, pp. 871-882.

Huq, P., 1997. Observations of jets in density stratified crossflows. Atmos. Environment, $\underline{31}$, pp. 2011-2022.

Hwang, R. R., T. P. Chiang and W. C. Yang, 1995. Effect of ambient stratification on buoyant jets in cross-flow. J. Eng. Mech., 121, pp. 865-872.

Iwaki, C., K. H. Chung, H. Monji and G. Matsui, 2004. PIV measurement of the vertical crossflow structure over tube bundles. Exp. Fluids, 37, pp. 350-363.

Jirka, G. H., 2004. Integral model for turbulent buoyant jets in unbounded stratified flows. Part I: Single round jet. Environ. Fluid Mech., 4, pp. 1-56.

Katinas, V. I., R. V. Bakas, E. E. Perednis and V.A. Svedoscius, 1990. Effect of turbulence of the incident flow on flow-induced vibrations of tube bundles operating in crossflow. Fluid Mechanics-Soviet Research, 19, No. 5, pp. 9-17.

Kays, W. M., and A. L. London, 1955. Compact heat exchangers. Palo Alto: National Press.

Kim, K., and C. Camci, 1995. Fluid dynamics and convective heat transfer in impinging jets through implementation of a high resolution liquid crystal technique. Part I: Flow and heat transfer experiments. Int. J. Turbo. and Jet Engines, 12, No. 1, pp. 1-12.

King, J. B., 2004. Mixing in the VHTR lower plenum: Decomposition, data and analysis. Technical report (draft), Nuclear Engr. Dept., Oregon State Univ.

Kreith, F., 1965. Reverse transition in radial source flow between two parallel plates. Phys. Fluids, $\underline{8}$, pp.1189-1190.

Kreith, F., E. Doughman and H. Kozlowski, 1963. Mass and heat transfer from an enclosed rotating disc with and without source flow. J. Heat Transfer, $\underline{85}$, pp. 153-163.

Kugeler, K., 1996. Nuclear safety and the expectation to HTGRs deployment. Proc., 3rd JAERI Symp. HTGR Technologies. Oarai, Japan, pp. 22-35. 
Landreth, C. C., and R. J. Adrian, 1990. Impingement of a low Reynolds number turbulent circular jet onto a flat plate at normal incidence. Exp. Fluids, $\underline{9}$, pp. 74-84.

Laws, E. M., and J. L. Livesey, 1978. Flow through screens. Ann. Rev. Fluid Mech., 10, pp. 247-266.

Lee, J., and S.-J. Lee, 2000. The effect of nozzle aspect ratio on stagnation region heat transfer characteristics of elliptic impinging jet. Int. J. Heat Mass Transfer, $\underline{43}$, pp. 555-575.

Lee, X. C., C. F. Ma, Q. Zheng, Y. Zhuang and Y. Q. Tian, 1997. Numerical study of recovery effect and impingement heat transfer with submerged circular jets of large Prandtl number liquid. Int. J. Heat Mass Transfer, 40, pp. 2647-2653.

Lienhard V, J. H., R. S. Dahbura, H. F. Younis and C. H. Oh, 1996. Large area jet-array cooling modules for high heat fluxes. High Heat Flux Engineering III, SPIE Vol. 2855, pp. 66-81.

Liu, X., and J. H. Lienhard V, 1993. Extremely high heat fluxes beneath impinging liquid jets. J. Heat Transfer, 115, pp. 472-476.

Loehrke, R. I., and H. M. Nagib, 1976. Control of free-stream turbulence by means of honeycombs: A balance between suppression and generation. J. Fluids Engr., 98, pp. 342-353.

Lumley, J. L., 1964. Passage of a turbulent stream through honeycomb of large length-todiameter ratio. J. Basic Engr., 86, pp. 218-220.

Lumley, J. L., and J. F. McMahon, 1967. Reducing water tunnel turbulence by means of a honeycomb. J. Basic Engr., 9, pp. 764-770.

Ma. C. F., Q. Zheng, S. C. Lee and T. Gomi, 1997. Impingement heat transfer and recovery effect with submerged jets of large Prandtl number liquid - I. Unconfined circular jets. Int. J. Heat Mass Transfer, $\underline{40}$, pp. 1481-1490.

Ma, C. F., Q. Zheng, H. Sun, K. Wu, T. Gomi and B. W. Webb, 1997. Local characteristics of impingement heat transfer with oblique round free-surface jets of large Prandtl number fluid. Int. J. Heat Mass Transfer, $\underline{40}$, pp. 2249-2259.

MacDonald, P. E., J. W. Sterbentz, R. L. Sant, P. D. Bayless, R. R. Schultz, H. D. Gougar, R. L. Moore, A. M. Ougouag and W. K. Terry, 2003. NGNP preliminary Point Design -- Results of the initial neutronics and thermal-hydraulic assessments. Tech. report INEEL/EXT-03-00870 Rev. 1, INEEL.

Martin, H., 1977. Heat and mass transfer between impinging gas jets and solid surfaces. $A d v$. Heat Transfer, 13, pp. 1-60.

McCreery, G. E., 2005. Personal electronic communication. Idaho National Lab., 9 August.

McCreery, G. E., K. G. Condie, R. L. Clarksean and D. M. McEligot, 2002. Convective processes in spent nuclear fuel canisters. Heat Transfer 2002 (Twelfth International Heat Transfer Conference, Grenoble, August), Vol. 4, pp. 663-668.

McCreery, G. E., R. J. Pink, K. G. Condie, W. J. Dalling, D. M. McEligot, K. J. Knight and G.L. McAllister, 2001. Computational and physical modeling collaboration for DARPA Chem/Bio program application. Tech. rpt. INEEL/EXT-2001-1397, INEEL. 
McCreery, G. E., R. J. Pink, K. G. Condie and D. M. McEligot, 2003. Fluid dynamics of ribbed annuli. NuReTH-10, Seoul, Oct.

McEligot, D. M, 1986. Convective heat transfer in internal gas flows with temperaturedependent properties. Adv. Transport Processes, $\underline{4}$, pp 113-200.

McEligot, D. M., 1986. Basic thermofluiddynamic problems in high temperature heat exchangers. High Temperature Heat Exchangers, New York: Hemisphere, pp. 60-86.

McEligot, D. M., and G. E. McCreery, 2004. Scaling studies and conceptual experiment designs for NGNP CFD assessment. Tech. rpt. INEEL/EXT-04-02502.

McEligot, D. M., and M. F. Taylor, 1996. The turbulent Prandtl number in the near-wall region for low-Prandtl-number gas mixtures. Int. J. Heat Mass Transfer, $\underline{39}$, pp. 1287-1295.

McEligot, D. M., and thirteen others, 2002. Fundamental thermal fluid physics of high temperature flows in advanced reactor systems. Final. rpt. INEEL/EXT-2002-1613, INEEL.

McEligot, D. M., and twelve others, 2002. Advanced computational thermal fluid physics (CTFP) and its assessment for light water reactors and supercritical reactors. Tech. rpt. INEEL/EXT-2002-1386, INEEL.

McEligot, D. M., and twelve others, 2003. Advanced computational thermal fluid physics (CTFP) and its assessment for light water reactors and supercritical reactors. Tech. rpt. INEEL/EXT-03-01215, INEEL.

McEligot, D. M., J. Y. Yoo, J. S. Lee, L. E. Hochreiter, J. D. Jackson, S. O. Park, R. H. Pletcher, P. Vukoslavcevic and J. M. Wallace, 2004. Advanced computational thermal studies and their assessment for supercritical reactors. Presented at ANS 2004 Annual Meeting, Pittsburgh, 13-17 June. Trans., ANS, $\underline{90}$, pp. 152-153.

Mikielewicz, D. P., A. M. Shehata, J. D. Jackson and D. M. McEligot, 2002. Temperature, velocity and mean turbulence structure in strongly-heated internal gas flows. Comparison of numerical predictions with data. Int. J. Heat Mass Transfer, 45, pp. 4333-4352.

Moller, P. S., 1963. Radial flow without swirl between parallel discs. Aero. Quarterly, 14, pp. 163-186.

Morris, G. K., S. V. Garimella and J. A. Fitzgerald, 1999. Flow-field prediction in submerged and confined impinging jets using the Reynolds stress model. J. Elec. Packaging, 121, pp. 255262.

Nelson, E. S., 1987. Phase-averaged measurements of vortex interaction with a solid surface and the breakaway process. M.S. thesis, Illinois Inst. Tech.

Nicholl, C. I. H., 1970. Some dynamical effects of heat on a turbulent boundary layer. J. Fluid Mech., $\underline{40}$, pp. 361-384.

Nishino, K., M. Samada, K. Kasuya and K. Torii, 1996. Turbulence statistics in the stagnation region of an axisymmetric impinging jet flow. Int. J. Heat Fluid Flow, 17, pp. 193-201.

Olsson, M., and L. Fuchs, 1998. Large eddy simulations of a forced semiconfined circular impinging jet. Phys. Fluids, $\underline{10}$, pp. 476-486. 
Parker, J., and P. Merati, 1996. An investigation of turbulent Taylor-Couette flow using laser Doppler velocimetry in a refractive index matched facility. J. Fluids Engr., 118, pp. 810-818.

Parneix, S., M. Behnia and P. A. Durbin, 1999. Predictions of turbulent heat transfer in an axisymmetric jet impinging on a heated pedestal. J. Heat Transfer, 121, pp. 43-49.

Poskas, P. S., and V. J. Survila, 1983. Fluctuations of velocity of cross flow of air in the space between tubes in bundles. Heat Transfer-Soviet Research, 15, No. 1, pp. 75-86.

Prandtl, L., 1933. Attaining a steady air stream in wind tunnels. NACA TM 726.

Ramsey, J. W., and R. J. Goldstein, 1971. Interaction of a heated jet with a deflecting stream. $J$. Heat Transfer, 94, pp. 365-372.

Richards, A. H., R. E. Spall and D. M. McEligot, 2004. An assessment of turbulence models for strongly heated internal gas flows. International Association of Science and Technology for Development, Modelling and Simulation Conference, Marina del Ray, Cal., 1-3 March.

Rubel, A., 1980. Computations of jet impingement on a flat surface. AIAA J., 18, pp. 168-175.

San, J.-Y., C.-H. Huang and M.-H. Shu, 1997. Impingement cooling of a confined circular air jet. Int. J. Heat Mass Transfer, 40, pp. 1355-1364.

Satake, S.-I., and T. Kunugi, 1998. Direct numerical simulation of an impinging jet into parallel disks. Int. J. Num. Meth. Heat and Fluid Flow, $\underline{8}$, pp. 768-780.

Schade, K. W., and D. M. McEligot, 1971. Cartesian Graetz problems with air property variation. Int. J. Heat Mass Transfer, 14, pp. 653-666.

Schlichting, H., 1960. Boundary layer theory, 4th Ed. New York: McGraw-Hill.

Scholten, J. W., and D. B. Murray, 1998. Heat transfer and velocity fluctuations in a staggered tube array. Int. J. Heat Fluid Flow, 19, pp. 233-244.

Schultz, R. R., and D. Schowalter, 2004. CFD for advanced nuclear reactor design. In preparation for Fluent News, Fluent, Lebanon, N. H.

Shah, R. K., and A. L. London, 1978. Laminar flow forced convection in ducts. Adv. Heat Transfer, Supplement 1.

Shah, R. K., and D. P. Sekulic, 2003. Fundamentals of heat exchanger design. New York: John Wiley.

Shuster, J. M., R. J. Pink, D. M. McEligot and D. R. Smith, 2005. The interaction of a circular synthetic jet with a cross-flow boundary layer. Presented at AIAA Fluid Dynamics Conference, Toronto, June.

Siba, E. A., M. Ganesa-Pillai, K. T. Harris and A. Haji-Sheikh, 1998. Turbulent heat transfer in single phase jet impingement flow over a flat circular disk. Proc., ASME Int. Mech. Engr. Congress, HTD vol. 361-1, pp. 191-202.

Simon, T. W., S. W. Burd, C. J. Satterness, R. W. Kaszeta and R. Oke, 1999. Documenting complex flows in gas turbine gas path cooling systems. Proc., Colloquium on Turbomachinery 1999 (Ed.: S. J. Song), Turbo and Power Machinery Research Center, Seoul National University, Korea, pp. 1-16. 
Smith, B. L., 2005. Flow regimes in an idealized plenum model. Technical report, Mechanical Engr. Dept., Utah State Univ., 10 August.

Stanescu, G., A. J. Fowler and A. Bejan, 1996. The optimal spacing of cylinders in free-stream cross-flow forced convection. Int. J. Heat Mass Transfer, 39, pp. 311-317.

Stoots, C. M., S. Becker, K. G. Condie, F. Durst and D. M. McEligot, 2001. A large-scale matched-index-of-refraction flow facility for LDA studies of complex geometries. Exp. Fluids, 30, pp. 391-398.

Tan-Atichat, J., H. M. Nagib and R. I. Loehrke, 1982. Interaction of free-stream turbulence with screens and grids: a balance between turbulence scales. J. Fluid Mech., 114, pp. 501-528.

Taylor, G. I., and G. K. Batchelor, 1949. The effect of wire gauze on small disturbances in a uniform stream. Q. J. Mech. Appl. Math., ㄹ, pp. 1-29.

Thompson, B. E., O. Bouchery and K. D. Lowney, 1995. Refractive-index-matching laser velocimetry for complex nozzle entrance flow. Laser Anemometry - 1995, ASME FED-Vol. 229, pp. 365-370.

Thorpe, S. A., 1987. Transitional phenomena and the development of turbulence in straified fluids: A review. J. Geophys. Research, 92, No. C5, pp. 5231-5248.

Townsend, A. A., 1957. Turbulent flow in a stably stratified atmosphere. J. Fluid Mech., $\underline{3}$, pp. 361-372.

Turner, J. S., 1973. Buoyancy effects in fluids. Cambridge: Univ. Press.

Velichko, V. I., V. A. Pronin and N. Yassin, 1993. Heat transfer, hydrodynamics and energy efficiency in closely packed tube bundles in cross flow. Heat Transfer Research, 25, pp. 629633.

Wang, J., J. Li and J. D. Jackson, 2002. Mixed convection heat transfer to air flowing upwards through a vertical plane passage. Trans., Institution of Chemical Engineers Part A, Chemical

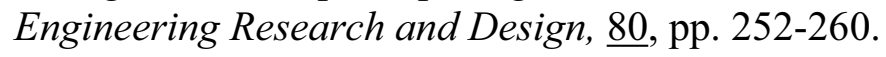

Watterson, J. K., W. N. Dawes, A. M. Savill and A. J. White, 1999. Predicting turbulent flow in a staggered tube bundle. Int. J. Heat Fluid Flow, 20, pp. 581-591.

Webb, B. W., and C.-F. Ma, 1995. Single phase liquid jet impingement heat transfer. Adv. Heat Transfer, 26, pp. 105-217.

White, F. M., 1984. Heat transfer. Reading: Addison-Wesley

Wigeland, R. A., M. Ahmed and H. M. Nagib, 1978. Management of swirling flows with application to wind tunnel design. AIAA J., $\underline{16}$, pp. 1125-1131.

Wilson, A. S., and M. K. Bassiouny, 2000. Modeling of heat transfer for flow across tube banks. Chem. Eng. Processing, 39, pp. 1-14.

Wolfshtein, M., 1970. Some solutions of the plane turbulent impinging jet. ASME paper 70-FE27. 
Womac, D. J., F. P. Incropera and S. Ramadhyani, 1994. Correlating equations for impingment cooling of small heat sources with multiple circular liquid jets. J. Heat Transfer, 116 , pp. 482486.

Wright, S. J., 1984. Buoyant jets in density-stratified crossflow. J. Hydraulic Engr., 110, pp. 643-656.

Zhang, X., and A. F. Ghoniem, 1994. A computational model for the rise and dispersion of wind-blown, buoyancy-driven plumes -- II. Linearly stratified atmosphere. Atmos. Environment, 28, pp. 3005-3018.

Zukauskas, A., 1972. Heat transfer from tubes in cross flow. Adv. Heat Transfer, $\underline{8}$, pp. 93-16. 